\title{
WestVirginiaUniversity
}

THE RESEARCH REPOSITORY @ WVU

Graduate Theses, Dissertations, and Problem Reports

2011

\section{Examining Sexual Assault Risk Factors in Female College Athletes}

Eric Limegrover

West Virginia University

Follow this and additional works at: https://researchrepository.wvu.edu/etd

\section{Recommended Citation}

Limegrover, Eric, "Examining Sexual Assault Risk Factors in Female College Athletes" (2011). Graduate Theses, Dissertations, and Problem Reports. 3366.

https://researchrepository.wvu.edu/etd/3366

This Dissertation is protected by copyright and/or related rights. It has been brought to you by the The Research Repository @ WVU with permission from the rights-holder(s). You are free to use this Dissertation in any way that is permitted by the copyright and related rights legislation that applies to your use. For other uses you must obtain permission from the rights-holder(s) directly, unless additional rights are indicated by a Creative Commons license in the record and/ or on the work itself. This Dissertation has been accepted for inclusion in WVU Graduate Theses, Dissertations, and Problem Reports collection by an authorized administrator of The Research Repository @ WVU.

For more information, please contact researchrepository@mail.wvu.edu. 


\title{
Examining Sexual Assault Risk Factors in Female College Athletes
}

\author{
Eric Limegrover
}

\author{
A Dissertation \\ Submitted to \\ The College of Human Resources and Edcuation \\ at West Virginia University \\ In Partial Fulfillment of the requirements for the Degree of \\ Doctor of Philosophy
}

\author{
Margaret Glenn, Ed.D., Chair \\ Roy Tunick, Ed.D. \\ Ed Jacobs, Ph.D. \\ Rose Marie Ward, Ph.D. \\ James W. Bartee, Ph.D.
}

Department of Counseling, Rehabilitation Counseling, and Counseling Psychology

Morgantown, West Virginia

2011

Keywords: Female Athletes, Sexual Assault, Drinking Rates 


\section{ABSTRACT \\ Examining Sexual Assault Risk Factors in Female College Athletes Eric Limegrover}

Sexual assault has been a widely studied occurrence in the United States and continues to be a major problem on college campuses. Recent surveys of college women have found that between 15\% and 20\% have experienced rape (Flack et al., 2007; McMahon, 2007). Unfortunately, little empirical research has examined specific college populations that maybe at a greater risk of sexual assault. Female college athletes comprise a special population that has been linked to many of the risk factors that are associated with an increased likelihood of experiencing sexual assault. This study examined risk factors associated with sexual assault such as alcohol use, rape myth acceptance, sexual history, and beliefs about sexual consent. Archival data that was originally gathered in 2008 was used in this study. Female athletes and non-athletes were recruited from a variety of medium-sized and small Universities and colleges in the Midwest and Northeastern United States. The sample consisted of 209 college female athletes, 417 non-athlete females, and nine participants that did not indicate their athletic status. Using a crosssectional, descriptive research design, the analyses provided an initial examination of the defined sexual assault risk factors in female college athletes and non-athletes. The results revealed no significant difference in rape myth acceptance and sexual consent across athletes and non-athletes in the sample. The results also revealed that there was no significant difference in sexual assault histories across athletic status in the sample. Finally, the results revealed that athletic status did not have a significant main effect on 
drinking rates, but sexual victimization did have a main effect on participants' drinking rates. Specifically, rape victims drank more frequently than those who experienced lower levels of sexual assault. The findings of this study show the specific areas that can be targeted to decrease the likelihood of sexual assault not only to female college athletes but also to non-athletes. 


\section{DEDICATION}

For my parents, Mark and Heather, who taught me to never give up. I miss and love you. 


\section{ACKNOWLDGEMENTS}

It would have been impossible to complete this project, with all of the seemingly endless obstacles, without the support of the following people. I want to express my gratitude to the chair of my committee, Dr. Margaret Glenn. She supported me to the finish with encouragement and guidance. Likewise, I greatly appreciate the support and assistance I received from my remaining committee members, Dr. Roy Tunick, Dr. Ed Jacobs, Dr. Rose Marie Ward, and Dr. James W. Bartee who contributed to the successful completion of this dissertation in many ways.

I also want to offer a sincere thank you to my family and friends for their encouragement and patience throughout the years. In particular, my children Ava and Blake, who sacrificed without knowing it and motivated me in ways impossible to describe.

With all of the support I received, one person truly stood out. My appreciation for my wife, Angie, is paramount. Her presence in my life is a blessing and this experience has made us stronger and closer through and through. I love you. 


\section{TABLE OF CONTENTS}

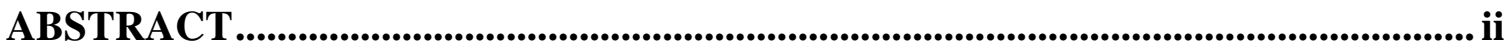

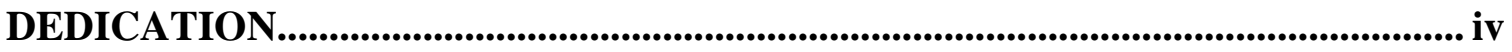

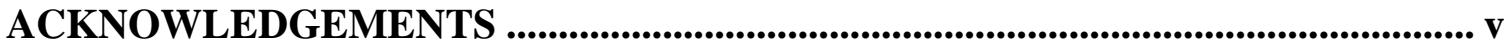

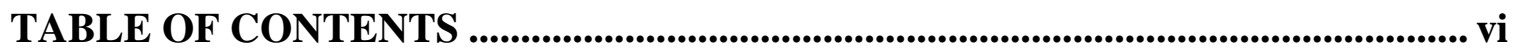

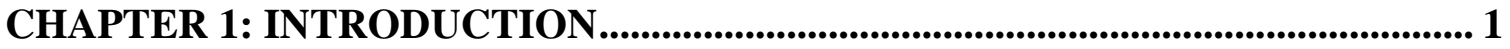

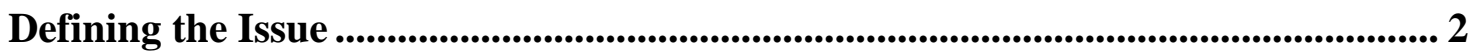

Theoretical Framework ......................................................................................................... 3

Prevalence of Sexual Assault ........................................................................... 5

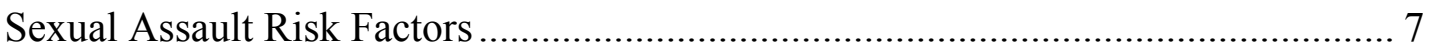

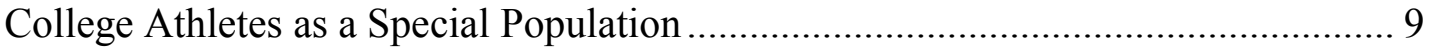

Statement of the Problem .................................................................................................. 11

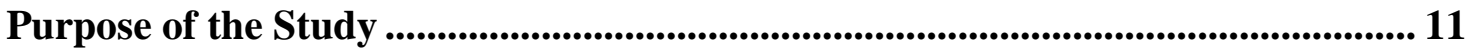

Definition of Key Concepts................................................................................................ 12

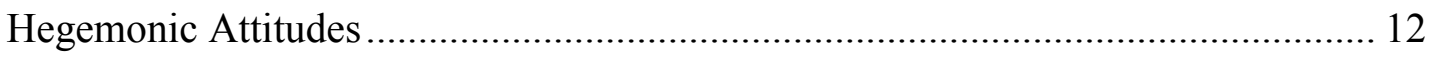

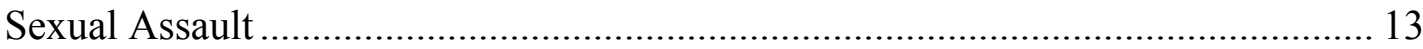

CHAPTER 2: REVIEW OF THE LITERATURE............................................... 14

Sexual Assault Trends, Consequences, and Associated Psychological Factors ..... 14

Prevalence Rates of Sexual Assault ................................................................ 14

Sexual Assault Victim Demographics .......................................................... 16

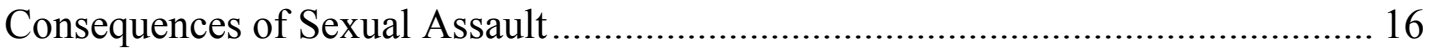

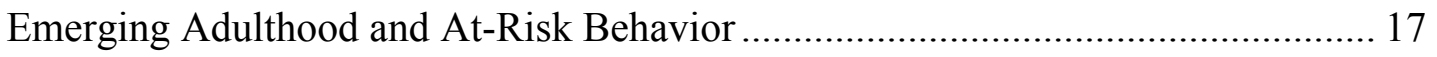

College Athletes as a Special Population ....................................................................... 22 
Sexual Assault Risk Factors ................................................................................................. 26

Sexual Assault Risk Factors for the Female College Athlete ................................. 26

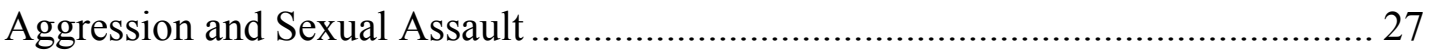

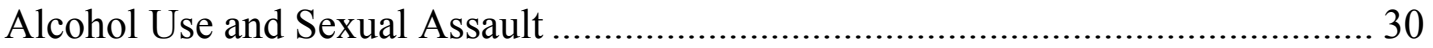

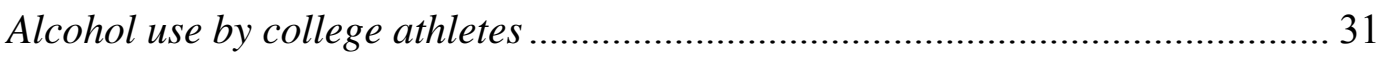

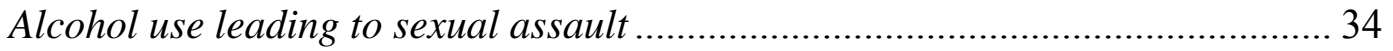

Other drug use leading to sexual assault ........................................................ 35

Rape Myth Acceptance and Sexual Assault..................................................... 36

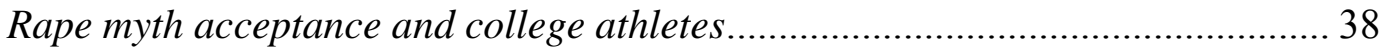

Sexual History and Sexual Assault ................................................................ 40

Characteristics predicitive of sexual assault .................................................... 40

Sexual history of female college athletes ....................................................... 41

Beliefs About Sexual Consent and Sexual Assault ............................................... 42

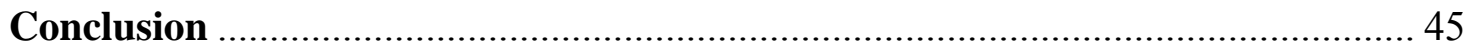

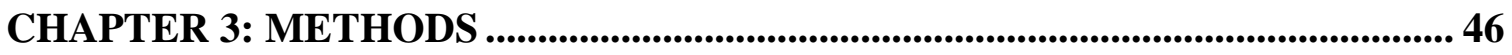

Archival Data Collection ..................................................................................... 46

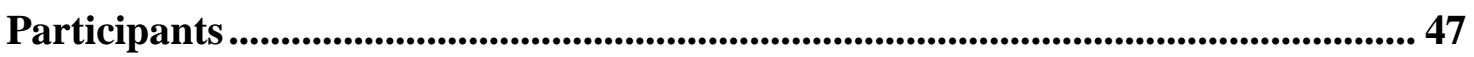

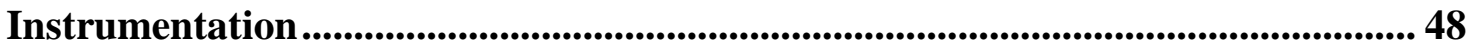

Illinois Rape Myth Acceptance Scale ............................................................ 49

Table 1: Published Means and Standard Deviations for the IRMAS ..................... 50

Sexual Assault Questionnaire....................................................................... 50

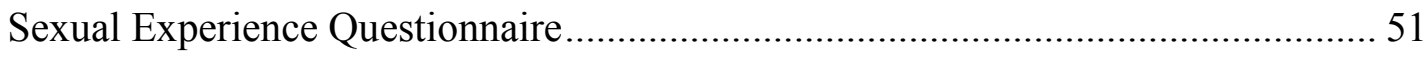

Modified Sexual Experiences Survey -- Female ................................................. 51 


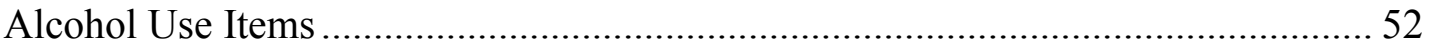

Alcohol and Sexual Consent Scale ..................................................................... 53

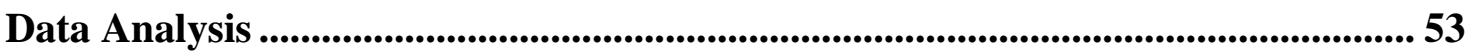

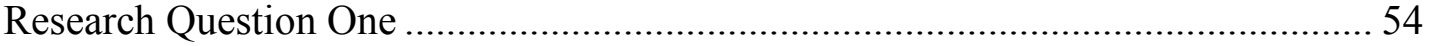

Research Question Two................................................................................. 54

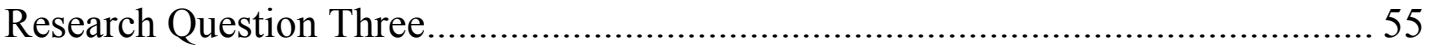

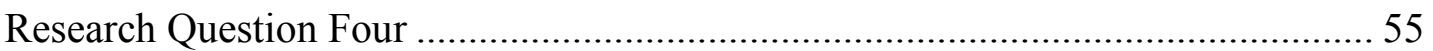

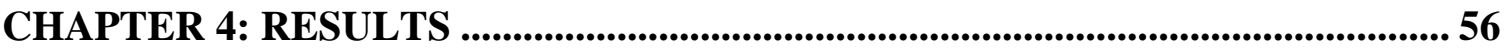

Table 2: Demographic- Ethnicity, Age, Family Income, Year in School, GPA,

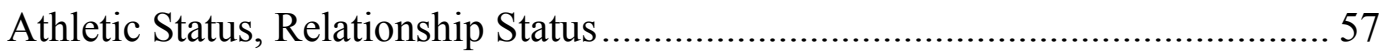

Descriptive Statistics of Study Variables ................................................................ 58

Table 3: Descriptive Statistics of Athletes' Status and Rape Myth Acceptance ....... 59

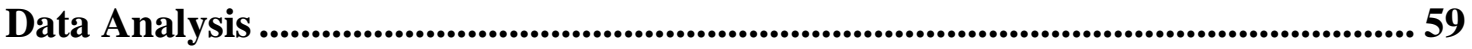

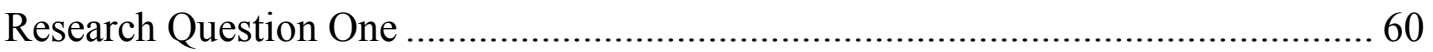

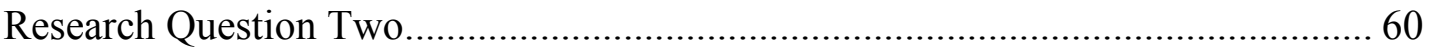

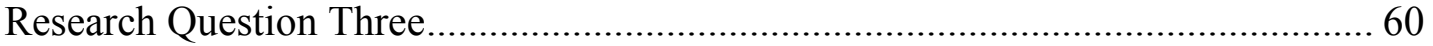

Table 4: Crosstabulation Between Athletic Status and Sexual Victimization

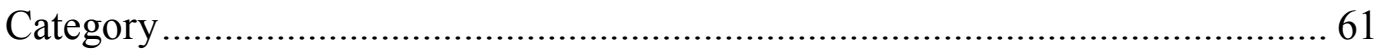

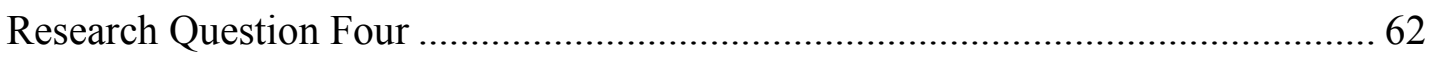

Table 5: Means and Standard Deviations for Athletes and Non-Athletes by Victimization Status

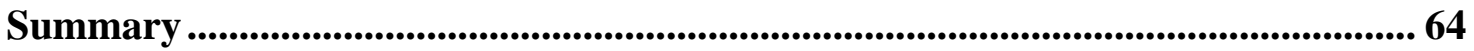


College Athletes as a Special Population ......................................................................... 66

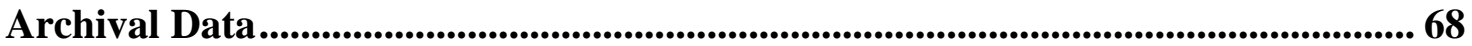

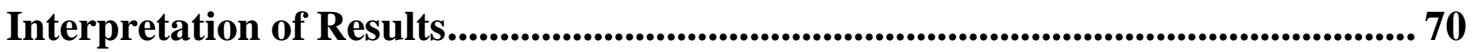

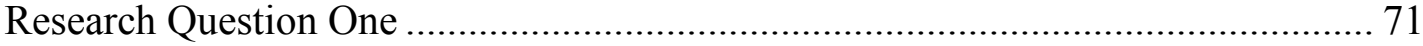

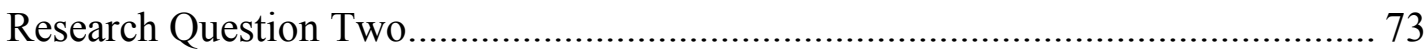

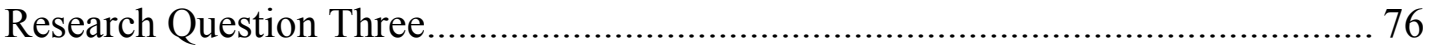

Research Question Four ................................................................................. 79

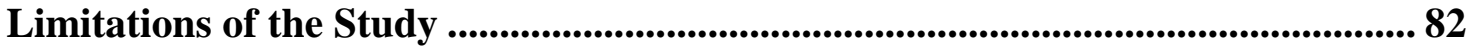

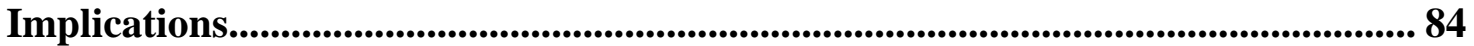

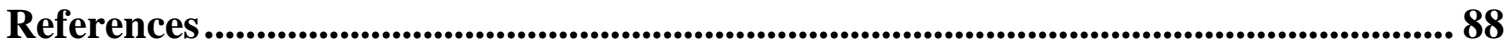

Appendix A: IRB Protocol Approval for Dr. Ward's Data Collection..................... 108

Appendix B: West Virginia University (IRB) Protocol Approval ........................... 109

Appendix C: Informed Consent for Archival Data ......................................................... 110

Appendix D: Illinois Rape Myth Acceptance Scale .................................................. 112

Appendix E: Sexual Assault Questionnaire.......................................................................... 114

Appendix F: Sexual Experience Questionnaire ......................................................... 115

Appendix G: Modified Sexual Experiences Survey -- Female..................................... 117

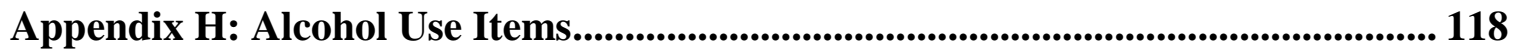

Appendix I: Alcohol and Sexual Consent Scale ............................................................... 120

Appendix J: Table of Research Questions and Analyses ........................................... 121 


\section{CHAPTER 1: INTRODUCTION}

Sexual assault has been widely studied in the United States and continues to be a major problem on U.S. college campuses. The National Crime Victimization Survey reported that at least 248,300 individuals were raped or sexually assaulted in 2007 , a $25 \%$ increase from 190,600 in 2005 (Bureau of Justice Statistics, 2008). The estimates of rape prevalence taken from largescale community samples of women have been remarkably consistent with those obtained from samples of college students (Brecklin \& Ullman, 2002; Tjaden \& Thoennes, 2000). Recent surveys of college women have found that between $15 \%$ and $20 \%$ have experienced rape (Kahn, Jackson, Kully Badger, \& Halvorsen, 2003; Littleton, Radecki, \& Breitkopf, 2006; Schwartz \& Leggett, 1999). To understand the high percentage of college females that have experienced rape, researchers have increasingly focused their attention on factors that place people at risk for sexual victimization (Rich, Combs-Lane, Resnick, \& Kilpatrick, 2004). Yet, little empirical research has examined specific college populations at greater risk of experiencing sexual assault, such as female college athletes, this focus on specific college populations is needed to fully understand the problem of rape on college campuses (Wetherill \& Fromme, 2007).

Koss, Gidycz, \& Wisniewski (1987) were the first of many researchers to formally document sexual assault as a common problem on college campuses. Research since this early study has shown prevalence rates, while difficult to calculate precisely, of one in five college women raped during their college years (Brener, McMahon, Warren, \& Douglas, 1999; Fisher, Cullen, \& Turner, 2000; Koss et al., 1987; Littleton, Radecki, Breitkopf, \& Berenson, 2007; McMahon, 2007). These statistics are alarming and the negative impact of sexual assault is severe and far-reaching. Those who experience sexual assault are likely to experience high levels of psychological distress, including the development of posttraumatic stress disorder 
(PTSD), depression, substance abuse, and anxiety (Boudreaux, Kilpatrick, Resnick, Best, \& Saunders, 1998; Breslau et al., 1998; Kilpatrick et al., 2003). Therefore, rape has continued to be a major concern on college campuses and the scope of the problem needs further definition.

\section{Defining the Issue}

The scholarly literature has used multiple research terms to examine the construct of sexual assault. The two terms that have been used synonymous with nonconsensual sexual activity are rape and sexual assault. The legally grounded definition of rape has been used to describe behaviors that involve some type of sexual penetration achieved under force or threat of force, a lack of consent, or an inability to give consent due to age, intoxication, or mental status (Bureau of Justice Statistics, 2008). The term sexual assault has been used by researchers to describe the full range of forced sexual acts including forced touching and kissing, verbally coerced intercourse, and physically forced vaginal, oral, and anal penetration (NIH/National Institute on Alcohol Abuse and Alcoholism [NIAAA], 2007). The terms differ in that sexual assault has included a range of experiences that encompass rape, sexual abuse in childhood, nonforcible sexual contact, and verbally coerced sex.

Considerable overlap exists among these definitions because both were derived from legal statutes. This overlap has not caused any confusion from the legal/jurisprudence perspective because the United States Legal Code has included the crime of rape under the more comprehensive term "sexual abuse" (US Code, 1994). Sexual abuse and aggravated sexual abuse are the two types of sexual assault defined in the United States Legal Code (Koss, Woodruff, \& Koss, 1991). Sexual abuse includes acts in which an individual has been forced to engage in sexual activity by use of threats or other fear tactics, or instances in which an individual has been physically unable to decline. Aggravated sexual abuse occurs when an individual has been 
forced to submit to sexual acts by use of physical force, threats of death, injury, or kidnapping, or substances that render that individual unconscious or impaired. The scholarly literature has found that rape and sexual assault have comparable prevalence rates (Kahn et al., 2003; Littleton et al., 2006; Littleton et al., 2007; McMahon, 2007; Schwartz \& Leggett, 1999).

Given the various definitions of rape and sexual assault, the appropriate labeling of nonconsensual sexual activity has been complicated. The different terms used to define nonconsensual sexual activity and the associated behaviors have also made determining prevalence rates of sexual assault more difficult. In this study, the term sexual assault was used as it includes a range of experiences that encompass rape.

\section{Theoretical Framework}

The sexual assault experiences of college women have been examined in a variety of studies (Abbey, 2002; Brener et al., 1999; Fisher et al., 2000; Koss et al., 1987; Littleton et al., 2007; McMahon, 2007). Historically, the social psychology literature has often characterized college women as being at high risk for sexual victimization (Aizenman \& Kelley, 1988;

Brecklin \& Ullman, 2002; DeKeseredy \& Kelly, 1995; Douglas, Collins, \& Warren, 1997; Koss, Gidycz, \& Wisniewski, 1989; Koss, 1992; Koss et al., 1987; Littleton et al., 2006; Muehlenhard \& Linten, 1987; Parrot, Cummings, Marchell, \& Hofher, 1994; Rennison, 1999; Tjaden \& Thoennes, 2000). Researchers have consistently reported that about $20 \%$ of women are sexually assaulted during their college years (Abbey, 2002; Fisher et al., 2000; Flack et al., 2007; Testa \& Parks, 1996). Major interdisciplinary conceptual models utilized in studying risk have contained commonalities in their methods, including the incorporation of risk factors, risk behavior, and health outcomes as three major components in the likelihood of sexual assault (Ahern, 2006; Blum, McNeely, \& Nonnemaker, 2002; Jessor, 1991; Rew \& Horner, 2003). These studies have 
outlined variables responsible for risk behavior that may result in sexual assault. The theoretical and statistical models utilized by researchers studying sexual assault have identified some common risk factors that increase the likelihood of sexual assault, including alcohol use behaviors (Abbey, 2002; Brenner \& Swanik, 2007; Sampson, 2006; Tjaden \& Thoennes, 2000), endorsement of rape myths (Gage, 2009; McMahon, 2007; Sawyer, Thompson, \& Chicorelli, 2002), prior sexual assault experiences (Faurie, Pontier, \& Raymond, 2004; Gidycz, Orchowski, King, \& Rich, 2008; Wetherill \& Fromme, 2007), and beliefs about sexual consent (Hickman \& Muehlenhard, 1997; Humphreys, 2007; Lim \& Roloff, 1999; O’Byrne, Hansen, \& Rapley, 2008). Although variation among studies in definitions and methodologies have rendered comparisons across studies difficult, it has been suggested that college women are at a high risk of sexual assault in large part because of alcohol consumption by the perpetrator, victim, or both (Abbey, 2002; Adams-Curtis \& Forbes, 2004; Fisher et al., 2000; Koss et al., 1987; Testa \& Parks, 1996). However, no studies have evaluated if risk factors are consistent across different populations of college females (i.e., non-athletes and athletes). This study drew from existing theoretical and statistical findings to examine risk factors of a specific population of college females (Leichliter, Meilman, Presley, \& Cashin, 1998; Nelson \& Wechsler, 2001; Wechsler et al., 1997). Samples of college women athletes and college women non-athletes were used to assess the prevalence, differential impact of, and risk factors for sexual assault.

It may be valuable to review the conceptualization of risk that forms the basis of this study. Traditionally, risk has been used as a term that connotes a possibility of loss or gain (Stalker, 2003). The decision on whether to take a risk depends on the balance of what can be gained or lost by the action (Prochaska et al., 1994). In the context of health, risk has been viewed as engagement in activity or behavior that may result in negative health consequences 
(Jacobs, 2000). In other words, the view of risk from a health context does not allow for the possibility of gain by engagement in health risk behavior.

The social psychology literature has acknowledged that the outcomes of engaging in health risk behavior can be positive and part of normative development (Arnett, 2007; Jessor, 1991; Michaud, 2006). Health risk behavior may play a critical role in development as long as the behavior is not associated with detrimental health outcomes (Arnett, 2007). Engagement in health risk behavior (i.e., alcohol use, sexual activity) may provide an individual the opportunity to master situations that are potentially detrimental to their health (Michaud, 2006). According to the research, little to no psychological or social adjustment problems have been associated with occasional risk taking behaviors. On the other hand, frequent risk takers have been shown to be more motivated by sensation seeking than occasional risk takers and more likely to develop detrimental risky behavioral patterns (Desrichard \& Denarie, 2005). Therefore, future research must focus on identifying factors that increase the likelihood of detrimental health outcomes by examining populations with higher levels of sensation seeking motivation (i.e., female college athletes).

Prevalence of Sexual Assault. Sexual assault prevalence refers to the percentage of people in a population who have been victimized during their entire lifetimes (McMahon, 2007). The sexual assault prevalence rate is about $20 \%$ for adult women in the United States (Flack et al., 2007). The observed victimization rate for women peaks in the 16-19 year-old age group, with the 20-24 year-old age group having the second highest victimization rate (Turchik, Probst, Irvin, Chau, \& Gidycz, 2009). Even though methodological concerns have made precise quantification difficult, it is clear that within the United States, rape has not been and is not currently a rare event (Kilpatrick, Veronen, \& Best, 1984). 
In the last twenty years, studies examining the prevalence rate of rape and sexual assault have involved college students (Aizenman \& Kelley, 1988; Brecklin \& Ullman, 2002; DeKeseredy \& Kelly, 1995; Douglas et al., 1997; Koss, Gidycz, \&Wisniewski, 1989; Koss, 1992; Koss et al., 1987; Littleton et al., 2006; Muehlenhard \& Linten, 1987; Parrot et al., 1994; Rennison, 1999; Tjaden \& Thoennes, 2000). These studies have consistently demonstrated that there is an increased prevalence of acquaintance rape and other coerced sexual activity in college. It has been estimated that as many as $35 \%$ of female students have been victims of sexual offenses during their college years (McMahon, 2007; Mohler-Kou, Dowdall, Koss, \& Wechsler, 2004). Annually, almost 100,000 female college students report being victims of sexual assault, and this figure does not include the estimated 100,00 students who have reported having been too intoxicated to know if they consented to having sex (Hingson, Heeren, Winter, $\&$ Wechsler, 2005). In sum, research has indicated that women in college are at a greater risk of sexual victimization. In order to understand and combat the problem of sexual assault on college campuses, the factors that place female college victims at risk of sexual violence warrant special attention (Kimble, Neacsiu, Flack, \& Horner, 2008; Cass, 2007).

Despite research efforts to ascertain the scope of rape, a large number of victims do not report their sexual victimization to police or authorities (Tjaden \& Thoennes, 2000). In 2007, the National Crime Victimization Survey (NCVS) results revealed that only $41 \%$ of rapes/sexual assaults were reported to the police (Bureau of Justice Statistics, 2008). Of the violent crimes reported in 2007, rape and sexual assault have had the lowest report rates, whereas robbery $(61 \%)$ and aggravated assault (62\%) were the most reported (BJS, 2008). However, at least six identified problems with studies on sexual assault could result in a failure to properly identify incidences, including a lack of confidentiality, negative characteristics of the interviewers, 
inappropriate context of questioning, inconsistent rape screening items, variable definitions of rape, and variable treatment of repeated assaults (Koss, 1992).

Compounding the problems with sexual assault studies, individuals fail to disclose sexual assault experiences if they are not able to control the outcome of the disclosure. Much of the variance in the prevalence rates has been linked to whether or not the responses have been treated as confidential (Winfield, George, Swartz, \& Blazer, 1990). Nondisclosure, either by purposive non-reporting (e.g., withholding relevant experience) or unintentional non-reporting (e.g., lack of recall), has been a serious obstacle to understanding the prevalence of sexual assault (Koss, 1993; Littleton et al., 2007; Skogan, 1981). Recently, researchers have begun to examine the relationship between disclosure and the victim's acknowledgement status of their own sexual assault. Victim's who have acknowledged their assault have demonstrated differences in coping, disclosure, and disclosure reactions versus sexual assault victims who did not acknowledge their assault (Littleton et al., 2007). Victims who acknowledged their assault have been shown to engage in more disclosure behavior, reported greater feelings of stigma about being a sexual assault victim, and have been less likely to access therapeutic services after the assault than unacknowledged victims (Littleton et al., 2007).

Sexual Assault Risk Factors. Sexual assault continues to be an all too common experience among college students (Flack et al., 2007; McMahon, 2007). Identification of populations at risk of sexual assault first involves a summarization of the risk factors that may influence the likelihood of sexual assault. Studies have consistently shown a positive correlation between sexual assault and increased alcohol intake (Brenner \& Swanik, 2007; Flack et al., 2007; Hummer, LaBrie, \& Lac, 2009; Yusko, Buckman, White, \& Pandina, 2008). Alcohol consumption has been shown to impair a woman's ability to recognize and avoid sexual assault 
and her ability to respond assertively to unwanted sexual advances. Furthermore, both male and female college athletes abuse alcohol at higher rates than non-athletes (Gutgesell, Moreau, \& Thompson, 2003; Hildebrand, Johnson, \& Bogle, 2001; Weschler \& Davenport, 1997). Between 82 and $85 \%$ of all college students use alcohol, but alcohol use among athletes is estimated to be $6 \%$ higher than that of non-athletes (Hildebrand et al., 2001; Leichliter et al., 1998). Increased alcohol abuse among college athletes has been positively correlated with risky behaviors that are associated with sexual assault (Gruenewald, Johnson, \& Treno, 2002).

In addition to the positive association between alcohol consumption and incidence of risky behaviors, studies have also documented a link between rape supportive ideology and sexually aggressive behavior (Anderson, 2007; Gage, 2009; Humphrey, 2007; McMahon, 2007; O’Byrne et al., 2008). Rape-tolerant attitudes and behaviors, including adherence to traditional sex-role attitudes, adversarial attitudes toward women, and acceptance of violence toward women, are widely accepted by rapists and potential rapists and contribute to sexual violence (Burt, 1991; Gage, 2009). Additionally, college athletes have often been exposed to rapetolerant attitudes and behaviors that are conducive to sexual assault as part of their experience (McMahon, 2007). Therefore, female athletes may be more accepting of rape myths, less likely to recognize and/or report incidents of sexual violence, and may ultimately be more tolerant of abuse and aggression directed at them (O'Byrne et al., 2008).

An individual's sexual history is another risk factor that may increase vulnerability to sexual assault. College athletes report more frequent sexual intercourse, a greater number of sexual partners, and a higher prevalence rate of sexually transmitted diseases compared to nonathletes (Faurie et al., 2004; Gidycz et al., 2008; Littleton et al., 2007; Nattiv \& Puffer, 1991; Nattiv et al., 1997). In particular, female athletes have been shown to be less likely to take 
precautions and are more likely to engage in risky situations that increase the possibility of a sexual assault (McMahon, 2007). It is known that individuals who underestimate or overestimate their capacity to control outcomes of interactions with others have been less likely to engage in precautions against risky situations (Nurius, 2000).

Beliefs about sexual consent have been shown to affect an individual's ability to recognize and react to sexual advance appropriately and may also increase an individual's vulnerability to sexual assault. Obtaining consent has been shown to be an ongoing process of mutual communication as sexual behaviors progress, regardless of who initiates it. Sexual consent means that at the time of the act, there have been actual words or physical conduct indicating freely given agreement to have sexual intercourse or sexual contact (Hickman \& Muehlenhard, 1997; Humphreys, 2007; O’Byrne et al., 2008). The research to date has examined the outward manifestation of sexual consent - the way in which couples communicate their consent (Hall, 1995; Hickman \& Muehlenhard, 1997; Humphreys, 2007). Sexual activity has been shown to progress without overt consent being communicated and, if consent were given, it was usually granted nonverbally (Hall, 1995). Contextual variables influence female and male expectations of the anticipated sequence of sexual events, and thus, have direct implications to sexual consent (Humphreys, 2007). Using the current literature surrounding sexual assault, the following sections examined the risk factors related to sexual assault of female college athletes and the challenges that female college athletes face with respect to sexual assault.

College Athletes as a Special Population. Individuals who participate in athletics are often thought to partake in an athletic lifestyle involving benefits that have been provided to the athlete from supporting structures (Wetherill \& Fromme, 2007). Unfortunately, the supporting 
structures at some universities and the culture at large have resulted in elite treatment that conflicts with normative social beliefs (Wetherill \& Fromme, 2007). The elite treatment of college athletes has been shown to promote feelings of entitlement and insulation from consequences. Both male and female college athletes have experienced elite treatment or privileges because of their athletic status, such as scholarships, one-on-one tutoring, gifts from alumni, and leniency from professors (Murnen \& Kohlman, 2007). The special treatment afforded to male and female athletes has been linked to athletes possessing lower perceived risk, particularly in regard to unacceptable behavior (Wetherill \& Fromme, 2007). The elite treatment of some college athletes may therefore lead to an increase in at-risk health behaviors, such as alcohol use and engaging in high rates of sexual activity.

In addition to the promotion of risky behaviors in athletes due to elite treatment, athletic participation has also been shown to contribute to the development of hegemonic attitudes and behaviors in males and females (Fallon \& Jome, 2007; Gage, 2009; Letendre, 2007; Miller et al., 2007). Hegemonic attitudes (i.e., culturally normative ideal of male dominance) have been associated with the creation and perhaps the reinforcement of perspectives that are associated with sexual aggression (Miller et al., 2007; Murnen \& Kohlman, 2007). Female athletes who have adopted more hegemonic masculine views and behaviors are less likely to take precautions against victimization and are more likely to engage in risky situations that increase the possibility of sexual assault. It is plausible that the time spent in athletics could increase a female athlete's sense of invincibility, which would serve as a risk factor for the development of unhealthy behaviors. Therefore, female athletes that have adopted hegemonic views (i.e., physical dominance) and behaviors (i.e., risk taking) may be at greater risk for experiencing negative health outcomes such as sexual assault. 
This study examined the rates of victimization in female college athletes using Koss's definition of sexual assault that describes the full range of forced sexual acts including forced touching and kissing, verbally coerced intercourse, and physically forced vaginal, oral, and anal penetration (Koss, 1992). By focusing on the characteristics of the victims and non-victims of sexual assault, this study helped to illustrate the challenges that female college athletes face with respect to sexual assault.

\section{Statement of the Problem}

Women face a higher risk of sexual assault while they are in college (Flack et al., 2007; McMahon, 2007; O’Byrne et al., 2008). As the rates of sexual assault on college campuses continue to rise, the need to identify populations at greater risk for sexual assault has become more urgent. Women ages 16 to 24 have experienced rape at rates four times higher than the assault rate of all women (Turchik et al., 2009). By identifying populations at greater risk for sexual assault, educational and prevention services may be targeted to these populations. Female college athletes are an understudied population that may experience sexual assault risk factors that place them at higher risk for sexual assault than their non-athlete peers. The understanding of the challenges that female college athletes face with respect to sexual assault was enhanced by comparing female athlete and non-athlete sexual assault risk factors. The findings of this research have helped to improve prevention efforts targeting female college athletes.

\section{Purpose of the Study}

Female college athletes constitute a population that experiences a particularly high risk for sexual assault, yet there remains a lack of information about how their risk factors differ from those of female college non-athletes. This study investigated the rates of substance-facilitated sexual assaults among both female college athletes and non-athletes. This research also explored 
different sexual assault risk factor variables that influence rates of sexual assault in female college athletes and non-athletes, such as rape myth acceptance, issues involving sexual consent, sexual assault histories and frequency of alcohol use. The correlations among the measured variables were examined to predict potential for sexual assault in female college athlete and nonathlete populations.

This study explored sexual assault risk factors among female college athletes and addressed four research questions:

1. Does rape myth acceptance differ between female college athletes and non-athletes?

2. Do attitudes towards sexual consent in the context of alcohol differ between female college athletes and non-athletes?

3. Do sexual assault histories differ between female college athletes and non-athletes?

4. Does athletic status and victimization status relate to the participants' drinking rates?

\section{Definition of Key Concepts}

Hegemonic Attitudes. Hegemonic attitudes place traditional masculine qualities at the top of the gender hierarchy and exist in relation to subordinated gender constructs. Traditional constructions of hegemonic attitudes include risk-taking, self-discipline, physical toughness and/or muscular development, aggression, violence, emotional control, and overt heterosexual desire. Athletic identity has placed emphasis on conformity to an ethic that combines elements of hegemonic masculinity (i.e., culturally normative ideal of male dominance), risk taking, and personal exception from ordinary rules. The end result is that hegemonic attitudes create hierarchies that subordinate others while simultaneously placing their own perceived characteristics in positions of symbolic dominance (Hinojosa, 2010). 
Sexual Assault. The term sexual assault has been used by researchers to describe the full range of forced sexual acts including forced touching and kissing, verbally coerced intercourse, and physically forced vaginal, oral, and anal penetration (Koss, 1992; NIAAA, 2007). The term sexual assault includes a range of experiences that encompasses rape, sexual abuse in childhood, non-forcible sex contact, and verbally coerced sex. Sexual abuse and aggravated sexual abuse are the two types of sexual assault defined in the United States Legal Code (Koss, Woodruff, \& Koss, 1991). Sexual abuse includes acts in which an individual has been forced to engage in sexual activity by use of threats or other fear tactics, or instances in which an individual has been physically unable to decline. Aggravated sexual abuse occurs when an individual has been forced to submit to sexual acts by use of physical force, threats of death, injury, or kidnapping, or substances that render that individual unconscious or impaired. 


\section{CHAPTER 2: REVIEW OF THE LITERATURE}

The study of sexual assault has traditionally involved extensive survey research as well as descriptive reports of the devastating effects of sexual assault. The results have produced a general understanding of the subject, generated from descriptive statistics, demographic data, and early ideas about factors associated with sexual assault risk. The efforts have also encouraged opportunities to raise awareness in communities where sexual assault has been more prevalent, such as the case for college females. Although the survey research and descriptive reports have been valuable in identifying the general scope of the problem, the literature to date has not focused on specific populations with higher risk for experiencing sexual assault. Female college athletes comprise a special population that has been linked to many of the risk factors that are associated with an increased likelihood of sexual assault.

\section{Sexual Assault Trends, Consequences, and Associated Psychological Factors}

Prevalence Rates of Sexual Assault. As early as 1980, the prevalence of completed rape among adult women was estimated to be approximately $20 \%$, a figure that has remained consistent over the last three decades (Burt, 1980). Comprehensive national studies have yielded lifetime prevalence estimates of sexual assault among adult women ranging from $12 \%$ to $25 \%$ (Flack et al., 2007; Kilpatrick, Edmunds, \& Seymour, 1992; Koss, 1993; McMahon, 2007; Tjaden $\&$ Thoennes, 2000). In addition, women aged 16 to 24 have been reported to experience rape at rates four times higher than women in other age brackets, while the second highest rate occurs in the 20-24 year-old age group (Parrot et al., 1994; Rennison, 1999; Turchik et al., 2009). Therefore, based solely on age, women who are likely transitioning from high school to college and/or work have been identified to be at the greatest risk of experiencing sexual assault. 
A growing body of research has examined rape and sexual assault prevalence among college students (Aizenman \& Kelley, 1988; Brecklin \& Ullman, 2002; DeKeseredy \& Kelly, 1995; Douglas et al., 1997; Koss, Gidycz, \&Wisniewski, 1989; Koss, 1992; Koss et al., 1987; Littleton et al., 2006; Muehlenhard \& Linten, 1987; Parrot et al., 1994; Rennison, 1999; Tjaden \& Thoennes, 2000). Early estimates of the scope of sexual assault among college women have varied between 14\% and 27.5\% (Koss, 1992; Koss et al., 1989; Muehlenhard \& Linten, 1987). More recent surveys of college women have found that between $15 \%$ and $20 \%$ have experienced rape during college (Kahn et al., 2003; Littleton et al., 2006; Schartz \& Leggett, 1999). Thus, research has consistently demonstrated the alarming prevalence of sexual assault on college campuses.

In one of the most cited and comprehensive studies on sexual assault in college examined the extent of sexual assault among 6,159 students at 32 colleges in the United States (Koss et al., 1987). In this study, $54 \%$ of the students surveyed had experienced some form of sexual assault. Fifteen percent of the women surveyed had experienced an act that met the legal definition of completed rape, $12 \%$ had experienced an attempted rape, and 17\% had experienced rape or attempted rape in the past year. Only 5\% of the rape victims had reported the incident to police and $42 \%$ did not tell anyone about the sexual assault. Koss et al. (1987) highlights the fact that rape victimization may be highly underreported which has prevented a consensus on the prevalence rates of rape and sexual assault of college women. In fact, many other studies have found that similar or even lower percentages of victims report the sexual assault incident to local police, county sheriffs, campus police, campus security, and/or other authorities (Bachman, 1998; Kilpatrick et al., 1992; Kilpatrick, Saunders, Veronen, Best, \& Von, 1987; Sloan, Fisher, 
\& Cullen, 1997; Tjaden \& Thoennes, 2000), but that older women are more likely to report their sexual victimization to the police than younger victims (Gartner \& Macmillian, 1995).

Sexual Assault Victim Demographics. In the last 20 years, only a handful of studies have highlighted the racial and cultural differences associated with sexual assault victims, even though sexual assault prevalence data varies based on the socio-demographic characteristics of the victim, such as age, sex, and race (Avegno, Mills, \& Mills, 2009; Bachman, 1998; Gartner \& Macmillan, 1995; George, Winfield, \& Blazer, 1992; Sorenson \& Siegel, 1992). The studies that have been conducted have had very little diversity in their samples (i.e., young Caucasian female college students) and thus, the findings cannot be generalized to the greater population. In a recent study, Avengo et al., (2009) reported that victims of sexual assault were generally young (ages 20-27) and female (92.6\%). Over half (54\%) of the 1172 surveyed victims reported involvement of drugs or alcohol during the assault. In terms of racial and cultural differences, blacks (59.1\%) suffered higher rates of sexual assault than whites (38.6\%). Avengo et al. (2009) builds upon the findings of George et al. (1992), who reported that Caucasian, AfricanAmerican, and Latinas had higher rates of rape associated with a prior history of child sexual abuse when compared with Asian-American women, and Sorenson and Siegel (1992), who found that the prevalence of sexual assault is lower among Hispanic women compared with nonHispanic women. Further research is needed to understand the demographic differences among sexual assault victims and to identify populations at greater risk of experiencing sexual assault.

Consequences of Sexual Assault. It is clear that the occurrence of sexual assault, though consistently underreported and influenced by socio-demographic characteristics, has negative and far-reaching effects on the survivor (Kilpatrick et al., 2003). Those who have experienced sexual assault are likely to experience high levels of psychological distress, 
including the development of posttraumatic stress disorder (PTSD), depression, and anxiety (Boudreaux et al., 1998; Breslau et al., 1998; Kilpatrick et al., 2003; Petrak \& Hedge, 2002). Compared to other crime victims, rape survivors appear to suffer more negative outcomes and develop problems more quickly (Petrak \& Hedge, 2002). Petrak and Hedge (2002) noted that $94 \%$ of survivors of sexual assault met the diagnostic criteria for PTSD within the first few weeks following their assault. Other lifelong consequences such as pregnancy, sexually transmitted diseases, and difficulty with interpersonal relationships have also been noted.

Though the most sexual assault survivors suffer one or more negative consequences of their assault, the majority of survivors do not seek treatment from mental health professionals, crisis centers, or physicians (Kimmerling \& Calhoun, 1994; New \& Berliner, 2000). Nearly half of survivors seek counseling only after their symptoms have become too prolonged or intense to manage (Campbell, Ahrens, Sefl, Wasco, \& Barnes, 2001). Given the vulnerability of the survivors and the failure to receive adequate support, professionals need to be better equipped to provide educational and prevention services to these populations. With such high prevalence of sexual assault and serious potential consequences, it is essential professionals in the field of counseling psychology work to identify populations at greater risk for sexual assault.

Emerging Adulthood and At-Risk Behavior. Despite the devastating effects associated with experiencing a sexual assault, some researchers have argued that exposure to factors associated with sexual assault is a necessary developmental process for young adults. The transition from adolescence to adulthood, occurring most often in college-aged individuals, has been shown to involve an increased exposure to and the subsequent navigation through certain at-risk behaviors (Arnett, 2000). This period of development has been called emerging adulthood and it is the most volatile phase of life because of the wide range of opportunities and 
diversity of decisions (Arnett, 2000). Emerging adulthood has been characterized as a period of self-exploration and experimentation in multiple, health related domains (e.g. sexual behavior, alcohol use) that will proceed until an individual no longer needs to evaluate various possibilities and has established a stable identity at home, work, and in the community (Arnett, 2006). Emerging adulthood has been noted as a time where freedom intersects with the lack of strict norms and a decrease in social control (Arnett, 2006). The heterogeneity of interests and desires allow for the expression of personal preferences that have been deemed necessary for identity development. Correspondingly, the experimentation in multiple domains associated with emerging adulthood has the potential for outcomes that are both desired and disadvantageous. Social institutions of education, employment, family, and civil society structure the transition to adulthood, which provide emerging adults with opportunities to develop competency and discover purpose (Hamilton \& Hamilton, 2009).

The theory of emerging adulthood has provided a new theoretical perspective to describe the age period from the late teens through the $20 \mathrm{~s}$. This period has been described as a preparatory state that precedes young adulthood in which emerging adults feel neither adolescent nor adult (Tanner, 2006). Emerging adulthood has been shown to constitute a separate development period of life because the previous stage models do not attend to the demographic changes that have occurred in industrialized countries over the last 50 years (Arnett, 2000). This protracted development has resulted in a postponing of activities associated with adulthood, such as marriage, parenthood, and the attainment of stable work (Arnett, 2000). For many people, the activities associated with adulthood are not realized until they reach their mid-twenties or beyond. Emerging adults have been shown to engage in heightened identity exploration and greater experimentation in the areas of love, work, and worldviews (Arnett, 2000). The process 
of attaining adulthood has been deemed as essential to the development of an individual's cultural and social identity.

The five identifiable features of emerging adulthood found in the United States and other economically developed societies are the age of identity explorations, instability, self-focused, feeling in-between, and possibilities (Arnett, 2004, 2006). The coherence of the five features has been confirmed via exploratory and confirmatory factor analyses (Reifman, Arnett, \& Colwell, 2007). During the self-focused age, social and institutional control dissipates and the emerging adult is free to explore opportunities before having to commit to marriage, parenthood, and longterm employment (Arnett, 2004). The challenges associated with emerging adulthood (e.g., heightened identity exploration and experimentation in the areas of love, work and worldviews) have been often accompanied by subsequent increases in risk-taking behavior. Research has shown that emerging adults are more likely than younger or older individuals to engage in risky and reckless behaviors, such as drug use and unplanned sexual activities (Arnett, 2007; Duangpatra, Bradley, \& Glendon, 2009). Increased alcohol intake and unplanned, erratic sexual encounters by emerging adults elevates their potential for experiencing negative outcomes associated with risky behavior. Future research should examine the development of at-risk behavior among emergent adults.

Emerging adulthood has been designated as a period of sexual exploration outside the context of marriage (Lefkowitz \& Gillen, 2006). Sexual activity and premarital sex has increased in Western societies over the last 50 years, with the increase most likely related to the introduction of the birth control pill and changes in gender role expectations (Lefkowitz \& Gillen, 2006). Emerging adults have highly diverse sexual behaviors and are more likely to have multiple sexual partners during the transition from adolescence to adulthood (Arnett, 2006). The 
freedom associated with emerging adulthood, in addition to the lack of social expectations, combines to create a period of sexual exploration. Emerging adulthood marks the first time during development that sexuality is incorporated into an individual's overall identity (Lefkowitz \& Gillen, 2006). Individuals may create a sexual self-schema that allows them to have a wide range of sexual experiences including same-sex attraction. In fact, lesbian, gay, bisexual, and/or transgendered individuals have been more likely to come out during emerging adulthood (Arnett, 2006). Sexual exploration and multiple sex partners likely place emerging adults at an increased risk for sexual assault.

It is likely that the lack of social constraints during emerging adulthood has led to an increase in at-risk behavior. A documented increase in alcohol and other drug use during emerging adulthood corroborates the transition catalyst model of emerging adulthood (Arnett, 2007). According to this model, the lifestyle choices of emerging adults include many decisions that undermine mental and physical health, such as poor nutrition, high stress, and lack of sleep (Steptoe \& Wardle, 2001). In addition, automobile accidents, sexually transmitted diseases, and homicide have been noted to increase in likelihood during emerging adulthood (Heuveline, 2002). Unfortunately, emerging adults in industrialized countries have been shown to be more susceptible to a variety of injuries, diseases, and death due to high-risk behaviors than at any other point in their development (Arnett, 2007). Substance abuse has also been shown to peak during emerging adulthood (Arnett, 2006). Conversely, as social roles, obligations, and expectations increase throughout emerging adulthood, at-risk behavior has been shown to decrease (Tanner, 2006). Similarly, antisocial behavior becomes less developmentally normative during emerging adulthood as the psychosocial and legal consequences tend to increase (Schulenberg \& Zarrett, 2006). 
College students are a special population of emerging adults. In college, emerging adults have been shown to drink excessively and have multiple sexual partners, hence elevating their risk for sexual assault (Duangpatra et al., 2009). The increase in risky behavior has been precipitated by the transition to college and a host of related transitions inherent to the college transition (Sher \& Rutledge, 2007). Emerging adults typically have transitioned to college from living with their parents and abiding by the rules of their family. They have also transitioned from structured educational environments with rules and routines to the autonomous collegiate environment. Early college drinking has been embedded in the context of ongoing adolescent development during emerging adulthood (Sher \& Rutledge, 2007). Therefore, it is likely that emerging adults in college will engage in social networks that provide facilitative norms and increased access to alcohol, thus increasing the risks associated with excessive alcohol usage.

There are certain subgroups of emerging adults in the college population (e.g., athletes) that have been identified to be more at risk of developing negative health behaviors (e.g., alcohol consumption and multiple sex partners) than other student populations (Pritchard, Milligan, Elgin, Rush, \& Shea, 2007). Athletes have been shown to experience greater amounts of stress than non-athletes due to the combined demands of athletics and academics (Pritchard et al., 2007). To cope with the added demands of the collegiate experience, athletes may develop behaviors that place them at greater risk of developing negative health behaviors. During emerging adulthood, athletes engage in social comparisons related to behaviors perceived as normative to the collegiate athletic experience (Grossbard et al., 2007). It is plausible that the athletic experience has been associated with alcohol consumption and drinking related consequences due to normative perceptions of athlete-specific alcohol use. Therefore, certain 
subgroups of emerging adults (e.g., college athletes) have been identified as more vulnerable to the development of health risk behaviors due to their experiences and their peer group.

Female college athletes comprise a special population of emerging adults that may be at risk for experiencing negative consequences associated with self-exploration and experimentation in multiple domains. Research examining sexual behaviors of female college athletes has found that they have more frequent sexual intercourse, a greater number of sexual partners, and a higher prevalence of sexually transmitted diseases (Grossbard et al., 2007). Studies that have examined athletic involvement and drinking suggest that female college athletes report as much or greater alcohol use than female college non-athletes (Martens, DamsO’Connor, \& Kilmer, 2007). Similarly, female college student athletes have been shown to be at a greater risk for problematic drinking patterns such as greater weekly alcohol consumption, more frequent episodic drinking and higher rates of negative alcohol related consequences (Grossbard et al., 2007). Given the documented association between alcohol use and sexual risk behavior, female college athletes may be more likely to suffer the negative consequences of sexual risk taking, such as sexual assault.

\section{College Athletes as a Special Population}

Individuals who participate in athletics are often thought to partake in an athletic lifestyle involving benefits that have been provided to the athlete from supporting structures (Wetherill \& Fromme, 2007). Athletic behavior has traditionally taken place within a conventional social context, generally involving adult supervision, structured guidance, and immersion in a social network that may promote prosocial values (Miller, Melnick, Barnes, Sabo, \& Farrell, 2007). Athletic identity has placed emphasis on conformity to an ethic that combines elements of hegemonic masculinity (i.e., culturally normative ideal of male dominance), risk taking, and 
personal exception from ordinary rules (Miller et al., 2007). Athletic status at some universities and the culture at large has resulted in elite treatment that conflicts with normative social beliefs (Wetherill \& Fromme, 2007). Due to the nature of the elite treatment of some college athletes, it is likely that some athletes will engage in risk taking behavior.

The elite treatment of college athletes has been shown to promote feelings of entitlement and insulation from consequences. Both male and female college athletes have experienced elite treatment or privileges because of their athletic status, such as scholarships, one-on-one tutoring, gifts from alumni, and leniency from professors (Murnen \& Kohlman, 2007). Some athletes have received special residences that resulted in the creation of strong group bonds or have reportedly received minimal punishment for offenses such as alcohol and drug use, unwanted sexual activity, and fighting (Murnen \& Kohlman, 2007). The special treatment afforded to male and female athletes has been linked to athletes possessing lower perceived risk, particularly in regard to unacceptable behavior (Wetherill \& Fromme, 2007). Male athletes have generally reported lower perceived risks than female athletes, due to social factors (Wetherill \& Fromme, 2007). Even though female athletes have been reported to perceive more social consequences than male athletes for their actions, they still have lower perceived risks than their non-athletic peers (Wetherill \& Fromme, 2007). The elite treatment of some college athletes may therefore lead to an increase in at-risk health behaviors, such as alcohol use and engaging in high rates of sexual activity.

In addition to the promotion of risky behaviors in athletes due to elite treatment, athletic participation has also been shown to contribute to the development of hegemonic attitudes and behaviors in males and females (Fallon \& Jome, 2007; Gage, 2009; Letendre, 2007; Miller et al., 2007). Hegemonic attitudes (i.e., culturally normative ideal of male dominance) have been 
associated with the creation and perhaps the reinforcement of perspectives that are associated with sexual aggression (Miller et al., 2007; Murnen \& Kohlman, 2007). Typically, sports with relatively high status in society and the capacity to attract economic resources have endorsed views associated with hegemonic masculinity (i.e., domination, intimidation, and aggressiveness). A team's stature may be expressed in several ways, such as the amount of commercial attention and pressures placed on the team, the traditional masculine notions associated with such pressures, or the opportunities individual athletes have to exploit their relative athletic identity (Gage, 2009). Being that female athletes have been socialized to be competitive and participate in activities with high status (e.g., football, basketball) athletes, there is an increased likelihood that they will take on certain masculine hegemonic perspectives such as intimidation and domination, which may normalize sexual aggression (Fallon \& Jome, 2007). Hegemonic attitudes and behaviors have also been reinforced through the living situations and social milieu associated with collegiate athletics. Male or female college athletes typically have lived together in residence halls or other campus housing, which may lead to the development of strong group bonds (Murnen \& Kohlman, 2007). During the bonding process, male and female athletes will connect to others with similar values that are reinforced within a social milieu (Murnen \& Kohlman, 2007). A social milieu of athletes has primarily included their team members, other athletes at their college or university, and others who have demonstrated comparable values (Cass, 2007). As a result, loyalty within the social milieu has meant that any aggressive group values and behaviors are likely to be perpetuated among all of the group members. Thus, female athletes in the athletic social milieu may be influenced to adopt the hegemonic attitudes expressed by their male peers (Fallon \& Jome, 2007). 
Female athletes who have adopted more hegemonic masculine views and behaviors are less likely to take precautions against victimization and are more likely to engage in risky situations that increase the possibility of sexual assault. Female college athletes have been shown to express the belief that sexual assault happens to weaker, nonathletic women who put themselves in bad situations (McMahon, 2007). This myth not only overestimates their physical superiority, but also suggests that they may have a false sense of security in risky situations. Thus, female athletes may be more likely than non-athletes to remain within the physical proximity of an offender, thereby increasing their risk of victimization (Cass, 2007). The proximity construct holds that the underlying factor for sexual assault risk may be the ability to appropriately assess risk in an environment (Cass, 2007). It is plausible that the time spent in athletics could increase a female athlete's sense of invincibility, which would serve as a risk factor for the development of unhealthy behaviors. Therefore, female athletes that have adopted hegemonic views (i.e., physical dominance) and behaviors (i.e., risk taking) may be at greater risk for experiencing negative health outcomes such as sexual assault.

Additional social and/or contextual factors have accounted for the increase in risk taking behaviors among college athletes (Grossbard et al., 2007). Factors such as higher levels of stress, sensation seeking traits, coping motivations, and overestimation of peer normative behaviors have been identified as factors that increase the likelihood of risky health behaviors in athletes (Yusko et al., 2008). Due to the nature of athletic competition, athletic activities have often involved taking risks that result in physical injury (Zamboanga \& Ham, 2008). Athletic competition tends to attract risk takers who extend their risk taking into the areas of sexual activity and substance use. For instance, female athletes have more frequent sexual intercourse, a greater number of sexual partners, and a higher prevalence rate of sexually transmitted diseases 
than non-athletes (Grossbard et al., 2007). Female athletes have also been shown to place themselves in more risky situations due to the fact that they are higher in sensation seeking than their non-athletic peers (Grossbard et al., 2007). In addition, those female athletes who have been high in sensation seeking may look to enhance sexual experience via alcohol use. Athletes have been noted to be more likely than their non-athlete peers to engage in risky activities related to alcohol consumption (Brenner \& Swanik, 2007). Correspondingly, male and female collegiate athletes have been shown to expect enhanced sexual performance or experiences associated with risky behaviors (e.g., unprotected sex) due to drinking (Zamboanga \& Ham, 2008). Many social and contextual factors influence female athletes and place them at greater risk for developing risky behaviors that increase their likelihood of experiencing sexual assault.

\section{Sexual Assault Risk Factors}

Sexual Assault Risk Factors for the Female College Athlete. Sexual assault remains an all too common experience among college students. The National Crime Victimization Survey reported that, in the United States, at least 248,300 individuals were raped or sexually assaulted in 2007 , a $25 \%$ increase from a reported 190,600 individuals in 2005 , the previous year the survey was conducted (Bureau of Justice Statistics, 2008). The United States national data consistently reports $20 \%$ of collegiate women have experienced sexual assault while in college (Flack et al., 2007). Research has consistently demonstrated the prevalence of acquaintance rape and other coerced sexual activity on college campuses (Flack et al., 2007; McMahon, 2007). However, little empirical research has examined specific college populations that may be at greater risk of sexual assault.

Research has consistently shown an association between sexual assault and alcohol use (Brenner \& Swanik, 2007; Flack et al., 2007; Hummer et al., 2009; Yusko et al., 2008) and a link 
between rape supportive ideology and sexually aggressive behavior (for a review, see Gage, 2009). An individual's sexual history has been identified as a risk factor that may increase one's vulnerability to sexual assault (Gidycz et al., 2008; Littleton et al., 2007). Finally, an individual's beliefs about sexual consent have been shown to reduce a woman's ability to recognize and react to sexual advances appropriately and have increased vulnerability to sexual assault (Humphreys, 2007; O’Byrne et al., 2008). Female college athletes possess many of the risk factors that increase the likelihood of sexual assault, but remain an understudied population. Using the current literature surrounding sexual assault, the following sections examined the risk factors related to sexual assault of female college athletes and the challenges that female college athletes face with respect to sexual assault.

Aggression and Sexual Assault. The developmental process thought to underlie aggressive behavior in women is the socialization of aggression in women. This process, as applied to women, has gained increased attention in the recent literature. There are contextual factors associated with how a female asserts herself that have been shown to affect the development of aggression in females (Letendre, 2007). Traditionally, females have been socialized to place a high value on relationships and the needs of others (Letendre, 2007). A female's self-image is strongly connected to her relationships and thus a female may feel threatened when faced with interpersonal situations involving conflict (Basow, Cahill, Phelan, Longshore, \& McGillicuddy-DeLisi, 2007). Recent research has focused on the use of aggression by females to solve interpersonal problems (Basow et al., 2007; Letendre, 2007). Females have been shown to manage anger, hurt, and disappointment by asserting power through indirect aggression that produces psychological or social harm (Letendre, 2007). In contrast, females were less likely to exhibit direct aggression that involves pain or physical injury (Basow 
et al., 2007). This research supports the cultural stereotypes that depict men as more physically aggressive and women as more relationally aggressive. However, no recent empirical research has examined the socialization of aggression in female athletes.

The literature on the socialization of aggression in females has provided some insight into the development of certain behaviors that increase the risk of experiencing sexual assault. Aggressive behavior in females has been associated with the development of serious social and emotional problems (Letendre, 2007). Aggressive females have higher rates of loneliness, depression, and social isolation than their less aggressive peers (Letendre, 2007). In addition, aggressive behavior in females has been associated with an increased likelihood of school failure and dropout, violent romantic relationships, increased sexual activity, pregnancy, substance use, and increased criminal behavior (Letendre, 2007). Aggressive females tend to have lower confidence and they perceive themselves more negatively because aggression is viewed as a more masculine trait (Basow et al., 2007). Finally, secondary school and college peers typically reject female perpetrators of physical and relational aggression (Basow et al., 2007). Therefore, females who manage conflict and anger by resorting to aggression were more likely to develop behaviors that increase the likelihood of experiencing sexual assault, such as increased sexual activity and substance use.

The research on gender-role adherence has focused on the risk factors for perpetration of violence, but not sexual assault (Gage, 2009; Parrot \& Gallagher, 2008; Reidy, Shirk, Sloan, \& Zeichner, 2009; Richardson \& Hammock, 2007). Research on gender-roles has suggested that men and women who strongly adhere to traditional gender-roles are more aggressive (Parrot \& Gallagher, 2008; Richardson \& Hammock, 2007). Traditionally, hypermasculine males have utilized violence against females to maintain dominance, control, and ultimately their perceived 
masculinity (Reidy et al., 2009; Richardson \& Hammock, 2007). Hypermasculine males have also utilized violence against intimate partners, gay males, and other women when their traditional masculine ideals have been challenged (Reidy et al., 2009; Richardson \& Hammock, 2007). Additionally, research has demonstrated that hypermasculine male athletes who endorse traditional gender-role beliefs are more likely to condone and perpetuate rape-tolerant attitudes (Gage, 2009). Similarly, hyperfeminine women have demonstrated anger and aggressiveness toward women who do not adhere to traditional female gender-roles (Reidy et al., 2009). For example, hyperfeminine women became angry while viewing videos of sexual acts of female same sex dyads (Parrot \& Gallagher, 2008). Although gender-role adherence studies have provided important insight into risk factors for anger and perpetration of aggression, the research on gender-role conflict theory has more clearly pertained to female college athletes.

Gender-role conflict theory has been debated as a pivotal obstacle for women in sports because participation in sports has customarily been perceived to be a masculine activity. Gender-role conflict theory suggests that female athletes will experience role conflict because they are attempting to enact both masculine (i.e., athlete) and feminine (i.e., gender-role) behaviors (Fallon \& Jome, 2007; Gage, 2009; Letendre, 2007). As a result, female athletes, who have been socialized to adopt masculine behaviors (i.e., aggressiveness and competitiveness), are more likely to experience gender-role conflict than their non-athletic peers (Letendre, 2007). In addition, there is an increased likelihood that female athletes will have their sexual orientation questioned because they exhibit both masculine and feminine behaviors (Fallon \& Jome, 2007). The process by which they cope with gender-role conflict influences how female athletes assert themselves, express their feelings, and protect themselves from harm (Letendre, 2007). As a method of coping with the gender-role conflict, female athletes may develop gender-congruent 
behaviors dependant on the situational context (Fallon \& Jome, 2007; Gage, 2009; Letendre, 2007). For example, as a way of bolstering their feminine appearance, female athletes have worn ribbons in their hair during competition. Contrastingly, female athletes who were viewed as too feminine have been shown to adopt more masculine behaviors (i.e., intimidation) or drop out of sports. These coping behaviors have allowed female athletes to influence how society views their athletic participation from a gendered perspective. Therefore, female athletes face a myriad of unique social and contextual factors that influence their identity development which helps to differentiate them from female college non-athletes.

Alcohol Use and Sexual Assault. The main drug abused on college campuses is alcohol (Wechsler et al., 2002). Heavy alcohol consumption among college students in the United States has a long and well-documented history. Much of the early research on alcohol consumption assumed that men drank at higher rates than women (Berkowitz \& Perkins, 1987; Brennan, Walfish, \& AuBuchon, 1986; Saltz \& Elandt, 1986; Straus \& Bacon, 1953), but more recent literature has found that alcohol consumption and the frequency of binge drinking among women has grown considerably (Wechsler et al., 2002), and gender differences in alcohol consumption continues to be an active area of research (Brenner \& Swanik, 2007; Flack et al., 2007; Yusko et al., 2008). Even though men continue to drink at a higher rate than women, the predictors of binge drinking are becoming more similar than different between men and women (NolenHoeksema, 2004). Thus, alcohol consumption by female college student has been an issue of increasing concern (Brenner \& Swanik, 2007; Flack et al., 2007; Yusko et al., 2008).

Alcohol consumption alters physical ability and psychological perceptions (Flack et al., 2007). The amount of alcohol consumed is associated with the experience of negative alcoholrelated consequences, particularly in the case of heavy episodic or high-risk drinking (Brenner \& 
Swanik, 2007; Nelson \& Wechsler, 2001; Wechsler, Lee, Kuo, \& Lee, 2000; Yusko, Buckman, White, \& Padina, 2008). Because women require smaller amounts of alcohol to achieve intoxication, women are at greater risk for negative health consequences (Hummer et al, 2009). For instance, college women who consume alcohol are nine times more likely to have experienced sexual assault than those who do not drink (Hummer et al., 2009). In addition, recent evidence has suggested that college women binge drink at levels that are comparable to men (Hummer et al., 2009).

Peer influence, commonly associated with heavy episodic or high risk drinking, has been a consistently strong predictor of alcohol use in college (Brenner \& Swanik, 2007; Hummer et al., 2009). Social norms theory has proposed that the normative beliefs about student drinking, regardless of accuracy, influence individual drinking decisions (Grossbard et al., 2007; Hummer et al., 2009). Normative beliefs about student drinking are usually erroneous and yet influence personal drinking quantity, drinking frequency, binge drinking, and drinking to intoxication (Hummer et al., 2009). Women have noted that they perceive pressure from others to drink heavily (Flack et al., 2007). For example, college women have reported that they perceive social pressures to drink heavily in order to receive positive attention from male peers (Hummer et al, 2009).

Alcohol use by college athletes. Participation in athletics has been associated with a social milieu consisting of a peer network, greater access to alcohol, and more frequent episodic drinking (Grossbard et al., 2007). In addition, heavy alcohol use by male and female athletes has served as a bonding activity for an interathletic community (Brenner \& Swanik, 2007). The degree to which one identifies with the interathletic community has been significantly associated with alcohol consumption and drinking related consequences. Within the interathletic 
community, female athletes have reportedly felt safe in the presence of their drinking male peers, even though those drinking peers may pose a significant risk to them. Thus, the alcohol related attitudes of the social milieu have been shown to influence personal decisions about alcohol use while exposing an individual to drinking related consequences.

Participation in college athletics is associated with a higher risk for alcohol use and abuse, possibly as a result of a social milieu that supports alcohol consumption (Brenner \& Swanik, 2007; Grossbard, Lee, Neighbors, Hendershot, \& Larimer, 2007; Gutgesell et al., 2003; Hummer et al., 2009; Leichliter et al., 1998; Martens, Dams-O’Connor, \& Beck, 2006; Nelson \& Wechsler, 2001; Zamboanga \& Ham, 2008). Both male and female athletes have been noted to abuse alcohol at higher rates than non-athletes (Brenner \& Swanik, 2007). National studies have found that intercollegiate athletes consumed more alcohol, engaged in more frequent episodic drinking (defined as having four or five drinks in a span of 4 hours), and experienced more negative alcohol-related consequences as compared with non-athletes (Brenner \& Swanik, 2007; Grossbard, Lee, Neighbors, Hendershot, \& Larimer, 2007; Gutgesell et al., 2003; Hummer et al., 2009; Leichliter et al., 1998; Martens, Dams-O’Connor, \& Beck, 2006; Nelson \& Wechsler, 2001; Zamboanga \& Ham, 2008). Female athletes are believed to be at a higher risk for alcoholuse related problems because of heightened physical and psychological stress, their unique social environment, and greater time constraints experienced by female athletes as a result of their dual status as an athlete and a student (Brenner \& Swanik, 2007). A large body of evidence links women, especially female athletes, to heavy alcohol consumption, possibly due to psychosocial stressors and peer influence.

The most accurate and comprehensive data on the prevalence rates of alcohol use among intercollegiate athletes and how they compare among non-athletes has been provided by three 
independent large scale and well-designed nationwide studies (Martens et al., 2006). The studies all made comparisons between sampled populations of intercollegiate athletes and non-athletes (Leichliter et al., 1998; Nelson \& Wechsler, 2001; Wechsler et al., 1997). Wechsler et al. (1997) and Nelson and Wechsler (2001) compared frequency of heavy episodic drinking (having five or more drinks in a span of 4 hours for males and four or more drinks for females) between intercollegiate athletes and non-athletes. Wechsler et al. (1997) found that a greater percentage of both male and female athletes than non-athletes reported heavy episodic drinking (61\% vs. $43 \%$ for males and $50 \%$ vs. $36 \%$ for females; $p<.01)$ and frequent heavy episodic drinking (defined as three or more heavy drinking episodes; $29 \%$ vs. $18 \%$ for males and $24 \%$ vs. $15 \%$ for females; $p<.01$ ) in the past 2 weeks. A similar pattern emerged 4 years later when Nelson and Wechsler (2001) found that a greater percentage of athletes than non-athletes reported heavy episodic drinking $(57 \%$ for athletes and $48.8 \%$ for non-athletes; $p<.01)$ in the past 2 weeks.

Similar to Wechsler et al. (1997) and Nelson and Wechsler (2001), Leichliter et al. (1998) sampled 51,483 college students from 125 U.S. universities and colleges, of whom 8,749 were involved in intercollegiate athletics. The results indicated that the intercollegiate athletes consumed more drinks per week as compared with non-athletes, with athletes averaging 7.57 drinks per week and non-athletes averaging $4.12(p<.05)$. Results also indicated that a greater percentage of athletes than non-athletes reported heavy episodic drinking (defined as having five or more drinks in one sitting for both males and females $)$ in the past 2 weeks $(55.3 \%$ of athletes vs. $36.3 \%$ of non-athletes; $p<.0001)$. Based on the results of these studies, heavy episodic drinking appears to be far more common among athletes. Correspondingly, it has been reported that female athletes binge drink at higher rates than their non-athlete female peers (Grossbard et al., 2007; Gutgesell et al., 2003; Hummer et al., 2009). In the past, it has been noted that nearly 
$60 \%$ of NCAA Division I female college athletes binge drink out of season and $35 \%$ binge drink in season (Martin, 1998). The increased rate at which female college athletes binge drink may have increase the likelihood of unwanted sexual activity and risky sexual behavior.

Alcohol use leading to sexual assault. Alcohol use has been among the most frequently cited contributors to sexual assault risk behavior among adolescents and young adults (Abbey, 2002; Cooper, 2002; Donovan \& MacEwan, 1995; Weinhardt \& Carey, 2000). Research has consistently indicated that alcohol is a major factor that places people, especially women, at increased risk for sexual assault (Abbey, 2002; Abbey, McAuslan, \& Ross, 1998; Brenner \& Swanik, 2007; Koss et al., 1987; Norris, Nurius, \& Graham, 1999; Sampson, 2006; Sochting, Fairbrother, \& Koch, 2004; Tjaden \& Thoennes, 2000; Yusko et al., 2008; Ullman, 2003). In fact, an estimated $50 \%$ of sexual assaults among young adult populations have involved alcohol use (Abbey, 2002; Abbey, Zawacki, Buck, \& Clinton, 2004; Testa \& Parks, 1996; Testa, 2002).

There are many differing ways that alcohol may increase the likelihood of a sexual assault. Women who drink alcohol are perceived as more sexually available and promiscuous compared with women who do not drink alcohol (Abbey et al., 1996). Alcohol has often been used to justify sexual assault, as men tend to believe that women who drink alcohol are more interested in having sex than women who do not drink alcohol (Abbey, 2002). Sexual assaults against intoxicated women were more likely to be completed, compared to those committed against sober women (Ullman, 2003). In addition, women have been more likely to suffer physical harm during the assault when they have been using alcohol (Nolen-Hoeksema, 2004). Alcohol has also been shown to distort a woman's perception of risk in potentially dangerous interpersonal situations, which increases a woman's likelihood of assault (Abbey, 2002). For example, women who have been drinking alcohol may rate a potential aggressor more positively 
and perceive less risk in engaging in other behaviors that are likely to increase their vulnerability to sexual aggression than women who have not been drinking (Testa, 2002).

Alcohol may also place women at risk for potential sexual assault because its use may render the potential victim less capable of resisting sexual advances. There is a strong negative linear relationship between quantity of alcohol consumed and rape resistance, such that women who have consumed more alcohol are less capable of resisting unwanted sex than women who drank less (Abbey, McAuslan, Zawacki, Clinton, \& Buck, 2001).

Other drug use leading to sexual assault. Other substances that have been associated with drug-facilitated sexual assault include flunitrazepam (Rohypnol), gamma- hydroxybutyrate (GHB) and ketamine (Ketanest) (Negrusz \& Gaensslen, 2003; Pope \& Shouldice, 2001; Schwartz, Milteer, \& LeBeau, 2000). These drugs have been used to incapacitate potential victims, which increases their vulnerability to sexual assault. The symptoms of these drugs often mimic the symptoms of alcohol intoxication, such as dizziness, loss of motor coordination, visual disturbances, and nausea. In addition, these substances typically have been easy to administer, impair consciousness, and have caused anterograde amnesia (Payne-James \& Rogers, 2002). Substance-induced blackouts, a type of anterograde neurological amnesia, render an individual unable to convert new sensory information into long-term memories (Payne-James \& Rogers, 2002). People who have experienced anterograde neurological amnesia may talk and interact normally during the evening, but the next morning they are not be able to remember the events or interactions that occurred during the amnesiac period.

Alcohol remains the drug most commonly associated with sexual assaults (Hindmarch, ElSohly, Gambles, \& Salamone, 2001), with over one-half of all sexual assault victims reporting alcohol use at the time of the assault (Howard, Griffen, \& Boekeloo, 2008). Alcohol 
consumption has been shown to impair a woman's ability to recognize risky situations and compromise her ability to respond assertively to unwanted sexual advances (Flack et al., 2007). In addition, intoxicated women have been more likely to consent to sexual intercourse (Howard et al., 2007). Therefore, the use and abuse of alcohol increases the likelihood of sexual assault, especially among college female athletes who consume alcohol at a greater rate than their nonathlete peers (Howard, Griffen, \& Boekeloo, 2008).

Rape Myth Acceptance and Sexual Assault. Rape-tolerant attitudes and behaviors, including adherence to traditional sex-role attitudes, adversarial attitudes toward women, and acceptance of violence toward women, play an important role in contributing to sexual violence (Burt, 1991). Rape supportive attitudes and beliefs may define situations in which sexually aggressive behavior is considered justifiable (Gage, 2009). These deeply ingrained rape supportive beliefs have been manifested through societal norms dictating appropriate behavior for women, providing occasions of so-called "justifiable rape" (Burt, 1980). Rape supportive ideology involves the endorsement of rape myths that include the belief that the way a woman dresses or acts indicates that "she wanted it" and that the clothing or acts justify the sexual assault. Women who wear sexy clothing have been seen by both men and women as being more vulnerable to victimization and are thought to be more responsible for sexual crimes committed against them, compared to women who dress more conservatively (Edmonds \& Cahoon, 1986; McMahon, 2007).

Feminist researchers have argued that we are living in a "rape culture" in which our fundamental attitudes and values are supportive of gender stereotypes and violence against women (McMahon, 2007). Rape tolerant attitudes include the adherence to traditional genderrole attitudes, adversarial attitudes toward women, and an acceptance of violence toward women. 
Rape myths have been expressed through the acceptance of dating violence and the idea that sexual relationships are basically exploitive (McMahon, 2007). Within a social structural framework, rape-supportive myths have reflected a societal attitude that blames victims and enables perpetrators of sexual assault (Anderson, 2007). An example of rape supportive ideology is the view that the way a woman dresses or acts indicates consent and justifies sexual intercourse.

Research has demonstrated that the acceptance of rape myths promoted by the "rape culture" not only indicates problematic attitudes, but has also been an explanatory predictor of the actual perpetration of sexual violence (Lonsway \& Fitzgerald, 1994; McMahon, 2007). The literature has clearly indicated that college males are more likely than females to harbor rape myth acceptance and beliefs correlated with perpetrating sexual assault (Burt, 1980; Boeringer, 1999; Gage, 2009; Lonsway \& Fitzgerald, 1994; McMahon, 2007; Syzmanski, Devlin, Chisler, \& Vyse, 1993). Previous studies have also documented the link between rape supportive ideology and sexually aggressive behavior (Gage, 2009; Koss, Leonard, Beezley, \& Oros, 1985; McMahon, 2007; Muehlenhard \& Linton, 1987; Reilly, Lott, Caldwell, \& Deluca, 1992). A person's acceptance of rape myths has been correlated with an increased acceptance of dating violence, and attitudes that reflect adherence to rape myth beliefs have included sex role stereotyping, acceptance of violence as part of relationships, and the idea that sexual relationships are basically exploitive (Gage, 2009). Therefore, rape myth acceptance and beliefs in attitudes about sexuality has been widely considered to be a product of a general cultural context that objectifies women and condones the use of force by men to obtain goals, including sexual conquest (Berkowitz, 1992; Burt, 1980; Gage, 2009; McMahon, 2007). 
Rape myth acceptance and college athletes. Male and female college athletes endorse rape supportive ideology and behaviors at a higher rate than non-athletes (McMahon, 2007). As part of the college athlete experience, female college athletes are exposed to hegemonic beliefs and behaviors that are conducive to sexual assault (McMahon, 2007). The normative environment of sport has reinforced the development of competitiveness and dominance through positively sanctioned aggression (McMahon, 2007). Accordingly, male and female athletes who display hegemonic behaviors such as aggressiveness and anger have shown higher levels of rape acceptance (McMahon, 2007; O’Byrne et al., 2008). If female college athletes have been socialized to accept rape myths, they may be less likely to recognize and/or report incidents of sexual violence and may ultimately be more tolerant of abuse and aggression directed at them (O’Byrne et al., 2008). It may be more difficult for female athletes, who have adhered to hegemonic views, to a seek assistance due to self-blame and stigma. Therefore, the hegemonic values common in athletics (e.g., the use of force to obtain goals) may contribute to an increased acceptance of rape supportive ideology by female athletes.

The United States society, which has for years socialized men to be competitive, has created a cultural norm that has transcended the varying levels of athletics, including female sports (Sawyer et al., 2002). Sawyer et al. (2002) examined institutions from two separate athletic divisions and reported higher rape myth acceptance among female athletes from Division I versus Division II schools. The authors hypothesized that female athletes, whose foray into the world of athletics has been much more recent, are less likely than male athletes to have been influenced to subscribe to traditionally male rape myth attitudes, except, perhaps, those extremely competitive female athletes (i.e., Division I female athletes) who have participated at the highest levels of their sport. 
The literature to date has suggested that men subscribe to higher rape myth acceptance than women, but there exists a need for further research focusing on the female athlete. Furthermore, there are no studies that have examined to what extent rape myth acceptance and beliefs are correlated with sexual assault perpetration in female college athletes versus female college non-athletes. The hegemonic values have been shown to be especially salient for those extremely competitive female athletes (i.e., Division I female athletes) who participate at the highest levels of their sport. For instance, female athletes have been shown to consistently endorse victim-blaming perspectives, including the belief that women are responsible for sexual crimes committed against them (McMahon, 2007). Similarly, female college athletes have reported that sexual assault happens to weaker, nonathletic women who put themselves in bad situations (McMahon, 2007). Victim blaming among female athletes has served as a sort of selfprotection (McMahon, 2007). In group settings, such as team interviews, female athletes have openly verbalized the belief that they are less likely of rape than their non-athlete peers (Wetherill \& Fromme, 2007). Individuals who have underestimated or overestimated their capacity to control outcomes are less likely to take precautions against risky situations (Wetherill \& Fromme, 2007). Faulty beliefs foster a false sense of security, thus inadvertently placing an individual at risk.

Peer influence creates and reinforces rape supportive ideology (Anderson, 2007; Wetherill \& Fromme, 2007). A number of subtle, yet powerful, beliefs espousing rape supportive ideology have been observed in both male and female athletes. Male and female athletes who were interviewed in group settings were more likely to justify sexually aggressive behavior and unintentional sexual assault, and were more likely to fault the victim of a sexual assault (Anderson, 2007). When surrounded by their peers, both male and female athletes were 
less likely to assign accountability to the perpetrator for the sexual assault (Anderson, 2007;

Wetherill \& Fromme, 2007). For example, it has been commonly expressed in group interviews that women put themselves in bad situations by dressing in a provocative manner, drinking alcohol, and behaving in other ways such as flirting. Conversely, when surveyed individually, male and female athletes have expressed the beliefs that the sexual violence was wrong and the victim was not to blame. These beliefs were consistent among male and female athletes when interviewed in a group, thus highlighting the effects of peer influence among athletes (Anderson, 2007).

Sexual History and Sexual Assault. Particular characteristics of an individual's sexual history may increase one's vulnerability to sexual assault. The research has indicated that women with a history of multiple male sex partners, greater rates of unprotected vaginal intercourse, lower rates of condom protected anal intercourse, more sexual contacts involving blood, more sexually transmitted diseases, and genital ulcers are at a greater risk for sexual assault (Gidycz et al., 2008; Kalichman \& Cain, 2004; Littleton et al., 2007). Women with a history of forced sexual intercourse, or non-voluntary sexual experiences due to verbal or physical pressure, have also been shown to be at a greater risk for sexual assault (Gidycz et al., 2008; Littleton et al., 2007). Researchers have also suggested that a subset of sexual assault victims tend to engage in risky behaviors such as sexual risk taking and drinking excessively, thus increasing their susceptibility to subsequent sexual assaults (Davis, Combs-Lane, \& Jackson, 2002; Wetherill \& Fromme, 2007).

Characteristics predictive of sexual assault. The personality characteristics, attitudes, and life experiences of women who were sexually assaulted were recently examined and compared with those of other women who had not been sexually assaulted (Gidycz et al., 2008). 
The results of this research suggested that women with a history of sexual victimization are less able to accurately judge risky situations or people (Gidycz et al., 2008; Littleton et al., 2007). Women with sexual assault histories have also indicated that they would leave an interpersonally risky situation much later than a woman who had never experienced a sexual assault (Gidycz et al., 2008; Meadows, Jaycox, Webb, \& Foa, 1996). Women that have experienced any type of sexual assault report more sexual partners and earlier initiation of sexual activity than women who have not experienced any type of sexual assault (Gidycz et al., 2008).

Additionally, a subset of sexual assault victims have been more likely to engage in risky behaviors such as sexual risk taking and drinking excessively, thus increasing their susceptibility to subsequent sexual assaults (Gidycz et al., 2008; Littleton et al., 2007). Women who have been sexually assaulted are more likely than other women to have experienced childhood sexual abuse, to have frequent sexual relationships, and to be heavy drinkers (Abbey, 2002; Abbey et al., 2004; Koss \& Dinero, 1989). In addition, women who engaged in sexual intercourse at an earlier age and reported a greater number of sexual partners have been more likely to be sexually victimized (Gidycz et al., 2005; Himelein et al., 1994; Koss \& Gidycz, 1985; Koss \& Dinero, 1989). Similarly, another study found that women reporting any type of sexual assault also reported more sexual partners and earlier initiation of sexual activity than did women who had not been sexually assaulted (Gidycz et al., 2008). Therefore, the literature clearly illustrates that women with a history of multiple male sexual partners have a greater risk for sexual assault, and women who have been sexually assaulted are at risk for the development of negative health behaviors such as subsequent sexual assaults.

Sexual history of female college athletes. Research examining the sexual history of female college athletes has indicated more frequent sexual intercourse, a greater number of 
sexual partners, and a higher prevalence rate of sexually transmitted diseases when compared with female non-athletes (Faurie et al., 2004; Gidycz et al., 2008; Nattiv \& Puffer, 1991; Nattiv, Puffer, \& Green, 1997; Wetherill \& Fromme, 2007). Wetherill and Fromme (2007) have hypothesized that female athletes are less likely to take precautions and are more likely to engage in risky situations that may increase the possibility of a sexual assault. Athletes in general are more likely to engage in sex with multiple partners due to social and contextual factors. Grossbard et al. (2007) reviewed the sex motive factors associated with subsequent sexual behavior in athletes. These motivational factors have included having sex to obtain personal enhancement or intimacy/emotional closeness with a partner, to cope with negative emotions, to obtain approval from peers and partners, and to obtain self-affirmation. Specifically, the enhancement motives (e.g., have sex to satisfy personal needs), as well as coping motives (e.g., have sex to cope with negative affect), have been associated with higher levels of sexual risktaking in athletes, such as multiple partners and unprotected sex. Therefore, given our knowledge of the physical and mental demands associated with athletic participation, sex motives provide a useful construct for understanding the elevated sexual risk taking behavior of athletes (Wetherill \& Fromme, 2007).

Beliefs About Sexual Consent and Sexual Assault. An individual's beliefs about sexual consent have been shown to reduce their ability to recognize and appropriately react to sexual advances and may increase vulnerability to sexual assault (Humphreys, 2007). Situational variables (e.g., relationship experiences) and participant factors (e.g., gender) have been shown to influence how, when, and why an individual may consent to sexual contact (Humphreys, 2007; O’Byrne et al., 2008). Obtaining sexual consent is an ongoing process of mutual communication as sex progresses, regardless of who initiates it (Humphreys, 2007). Much of the 
current literature on sexual coercion and rape has focused on the lack of consent (Humphreys, 2007). Sexual consent is defined as the exchange of actual words or physical conduct indicating agreement to have sexual intercourse or sexual contact at the time of the act (Hickman \& Muehlenhard, 1997; Humphreys, 2007; O’Byrne et al., 2008). The research to date has examined the outward manifestation of sexual consent, specifically the way in which couples communicate their consent (Hall, 1995; Hickman \& Muehlenhard, 1997; Humphreys, 2007). Hickman and Muehlenhard (1997) have found that men, more than women, use their way of understanding consent to rationalize whether others have consented. Men have been more likely than women to interpret "no conversation" as consent to sexual activity (Borges, Banyard, \& Moynihan, 2008; Sawyer, Pinciaro, \& Jessell, 1998).

Sexual activity tends to progress even if overt consent is not communicated and, if consent is given, it usually is granted nonverbally (Hall, 1995; Humphreys, 2007). Consent to sexual activities up to and including intercourse often is communicated nonverbally (Byers \& Heinlein, 1989; Humphreys, 2004; LaPlante, McCormick, \& Brannigan, 1980). However, because nonverbal cues are subtle and sometimes vague, miscommunication often occurs, particularly when communication skills have been impaired by alcohol use (Abbey, 2002). Verbal cues have been deemed a clearer indication of sexual consent than nonverbal cues across a number of social contexts (Lim \& Roloff, 1999). It is clear that even though verbal consent might improve sexual communications significantly, it traditionally has not been the normative behavior among college aged individuals.

Contextual variables influence female and male expectations of the anticipated sequence of sexual events, and thus, have direct implications to sexual consent (Humphreys, 2007; O’Byrne et al., 2008). Certain contextual variables have been identified that influence 
expectations in both men and women with regard to sexual activity and sexual consent. The history of the relationship is an important factor in determining the level and type of consent given, with individuals in stable dating relationships more likely to have established consent, especially after sexual activity has taken place (O’Byrne et al., 2008). Once consent in steady relationships has been established, it is expected to continue unless one or both of the partners change the parameters (O’Byrne et al., 2008). In a casual relationship, communication that is subtle and sometimes vague may lead to miscommunication, particularly if communication skills have been impaired by alcohol use (Humphreys, 2007). When one or both of the participants have been impaired (e.g., intoxicated) sexual activity tends to progress without overt consent being communicated and, if consent has been given, it has usually been granted nonverbally (Humphries, 2007). Humphreys (2007) has emphasized that verbal cues are clearer indications of sexual consent than nonverbal cues across a number of contexts that have involved alcohol and marijuana usage. Females may therefore have an increased risk of sexual assault because their increased alcohol consumption may reduce their ability to recognize and properly control the progression of sexual activity

Social scripting theory has proposed that males and females have differing internalized scripts that guide sexual behavior and may therefore account for differences between men and women in perceived sexual consent (Humphreys, 2007; O’Byrne et al., 2008). Traditionally, men in heterosexual relationships have been socialized to initiate sexual encounters and, due to hypermasculine values they may possess, dominate the women they sexually desire sexually (Humphreys, 2007; O’Byrne et al., 2008). Conversely, women in heterosexual relationships have been socialized to be the limit setters in sexual encounters (Humphreys, 2007; O'Byrne et al., 2008). Traditionally, women have been socialized to play a defensive role in sexual 
situations in order to avoid the far-reaching effects of sexual victimization. It is plausible that female athletes who have been socialized to be athletically aggressive and competitive are less likely to assume a defensive role in sexual situations. Therefore, ambiguous sexual situations may place female athletes at a greater risk for sexual assault than women who have been socialized to be the limit setters in sexual encounters. The differences in sexual scripts between genders and the gender-role conflict in female athletes may contribute to an increase in the likelihood of experiencing sexual assault.

\section{Conclusion}

Female college athletes comprise a special population of emerging adults that has been linked to many of the risk factors associated with an increased likelihood of sexual assault. The social environment associated with athletics places female athletes at risk of developing certain at-risk behaviors. In addition, the conflict associated with their gender-role and identity development has also been shown to place female athletes at risk of negative health behaviors. This review has examined the social psychology literature pertaining female college athletes and their risk factors for experiencing sexual victimization. It is clear that more research that is focused specifically on female athletes and their sexual assault risk is warranted. By further examining the female college athlete population, it is likely that prevention efforts targeting female college athletes will be enhanced and their subsequent risk of sexual assault may be reduced. The purpose of this study was to build upon the existing literature by looking at the risk factors for experiencing sexual assault as they pertained to college female athletes and nonathletes. 


\section{CHAPTER 3: METHODS}

This study explored specific areas of concern that place female college athletes at risk for sexual assault by asking if female athletes and non-athletes differ in sexual assault victimization risk factors. The study was guided by four research questions: (1) does rape myth acceptance differ between female college athletes and non-athletes? (2) do attitudes towards sexual consent in the context of alcohol differ between female college athletes and non-athletes? (3) do sexual assault histories differ between female college athletes and non-athletes? (4) does athletic status and victimization status relate to the participants' drinking rates?

This study used archival data collected in the spring of 2008 by Rose Marie Ward, Ph.D., of Miami University, Oxford, Ohio. The data collection was approved by Miami University’s Institutional Review Board (IRB\# 07-128; see Appendix A) as part of a study of sexual health, emotions, and leadership of college students. One of the aims of the original study was to develop a measure of the Alpha Female Personality and to examine whether this personality trait was related to sexual assault risk. Neither the Alpha Female measure nor any of its items were used in the current project. There are no publications in press or in print using these data. The archival data are currently housed on the nebula server at Miami University in Rose Marie Ward's account. In addition, approval was granted from West Virginia University's Institutional Review Board (IRB\# H-22643; see Appendix B) to use these data for secondary analysis in this study.

\section{Archival Data Collection}

Participants were undergraduate female students from a variety of medium-sized and small Universities and colleges in the Midwest and Northeastern United States. Participants were recruited via email invitations, announcements in class, announcements on course and sport 
team websites, and via online recruitment tools (i.e., Experimetrix.com) during the spring of 2008. Some students who chose to participate were given "research" credit in an introduction to psychology course. Participants who received email invitations were randomly selected from the female population at each respective college or university. Lists of 500 emails were generated from each school's registrar or by utilizing the school's online directory. The participants were sent an email invitation requesting their participation in a study on relationships, sexual health, and alcohol. Participants received an informed consent form prior to any data collection session (see Appendix C). Students were reminded that their participation was voluntary and they could skip any questions without penalty. If students agreed to participate in the study, they were given a weblink to the study and the contact information for the principal investigator. The weblink directed the participants to the consent form and a question requesting their consent to participate in the study. Prezza Checkbox software, housed at Dr. Ward's host institution, hosted the online survey. All data collected were protected behind the institution's firewall. IP addresses of the participants were not pursued. When the participant finished the survey or chose to exit the survey, a debriefing screen was shown, providing more information about the study and contact information for local counseling services. Participants were instructed to print this information for their records. The Institutional Review Board of Miami University approved the study (Appendix A). The documentation covering approval by the participating colleges and universities is available upon request from the principal investigator, Dr. Rose Marie Ward, 513529-9355 or wardrm1@muohio.edu.

\section{Participants}

Female athletes and non-athletes were recruited from 15 medium-sized and small Universities and 3 colleges in the Midwest and Northeastern United States. A total of 635 
female students completed the survey. The complete demographic frequencies and percentages are provided in Table 1. The sample consisted of 209 college female athletes, 417 non-athlete females and 9 who did not indicate their athletic status. The females that did not indicate their athletic status were not used in the current investigation. A vast majority of the survey respondents were Caucasian/White $(n=561 ; 88.3 \%)$ and indicated that they were currently in a romantic/dating relationship $(n=346,54.5 \%)$. Participants between the ages of 18 and 20 constituted $64.4 \%$ of the sample $(n=409)$; participants between the ages of 21 and 23 constituted $27.7 \%$ of the sample $(n=176)$; and participants age 24 and older constituted $6.1 \%$ of the sample $(n=39)$. There were no participants under the age of 18 . Freshman $(n=225 ; 35.4 \%)$ had the highest number of participants with sophomore $(n=136 ; 21.4 \%)$, senior $(n=118$; $18.6 \%)$ and junior $(n=99 ; 15.6 \%)$ having similar levels of representation. There were 29 seniors beyond their fourth year (4.6\%) and 7 non-matriculated students $(1.1 \%)$ included in the sample.

\section{Instrumentation}

A number of instruments were used in this study, each instrument was assessed for internal consistency using Cronbach's alpha. According to Cronbach (1951), coefficient alphas should be obtained before other types of reliability estimates, because the major source of measurement error is likely to be content sampling; the internal consistency of a measure considers the sampling of situational factors associated with the administration of items. The most common way to estimate the reliability of these types of scales is with coefficient alpha (Nunnally, 1978). Coefficient alpha can range from 0 (no reliability) to 1 (perfect reliability). Measures that can affect an individual's future, such as IQ tests or college entrance exams should 
have a minimum reliability of .90 , and preferably a reliability of .95 . For this research project, measurement reliability should be .70 to .80 (Nunnally, 1978).

Illinois Rape Myth Acceptance Scale. The Illinois Rape Myth Acceptance Scale (IRMAS; Appendix D; Payne, Lonsway, \& Fitzgerald, 1999) is a 45-item scale measuring the endorsement of several sexual situation myths. Acceptance of rape myths is perceived as a risk for sexual assault (Fallon \& Jome, 2007; Gage, 2009; Letendre, 2007; Miller et al., 2007). Respondents indicate their level of agreement with the statements on a 7-point Likert scale (from not at all agree to very much agree). Higher scores indicate attitudes supportive of sexual assault. The IRMAS possesses high item test-retest reliability, $r(495)=.90, p<.01$, (Payne et al., 1999). Payne et al. (1999) developed the seven subscales of the IRMAS (i.e., "She Asked for It," "It Really Wasn’t Rape," "He Didn’t Mean To," "She Wanted It," "She Lied," "Rape is a Trivial Event," and "Rape is a Deviant Event.") through six studies including a factor analysis for construct definition and item pool selection, a complete-link cluster analysis to determine the structure and dimensions of the scale, item pool selection based on fit to a hierarchical model, and a construct validity study correlating the IRMAS to seven similar measures (with correlations between .50 and $.74, p<.001$ in each case). The researchers also conducted a study which found that groups known to differ in rape myth acceptance scored differently as predicted on the IRMAS $(p<.001)$ and a validity study correlating IRMAS scores with a content analysis of open-ended scenarios written by participants that were analyzed for rape myth content $(r=$ $.32, p<.05)$. In the current study, Cronbach's alphas (Cronbach, 1951), a measure of internal consistency, for each sub-scale were as follows: "She Asked For It" $\alpha=0.87$, "It Wasn't Really Rape" $\alpha=0.84$, "He Didn't Mean To" $\alpha=0.77$, "She Wanted It" $\alpha=0.80$, "She Lied" $\alpha=0.84$, 
"Rape Is A Trivial Event" $\alpha=0.82$, "Rape Is A Deviant Event" $\alpha=0.84$. See Table 1 for a comparison between published means and the means in the current sample.

Table 1.

Published Means and Standard Deviations for the IRMAS

\begin{tabular}{|c|c|c|c|}
\hline Scale & $\begin{array}{l}\text { Published } \\
\text { M (SD) }\end{array}$ & $\begin{array}{l}\text { Sample } \\
\text { Overall }\end{array}$ & One sample $\mathrm{t}$ test \\
\hline IRMAS -she asked for it (8 items) & $\begin{array}{l}2.4 \\
(1.0)\end{array}$ & $\begin{array}{l}2.52 \\
(1.13)\end{array}$ & $t(609)=2.59, p=.01$ \\
\hline IRMAS -It Wasn’t Really Rape (5 items) & $\begin{array}{c}1.3 \\
(0.5)\end{array}$ & $\begin{array}{l}1.44 \\
(.73)\end{array}$ & $t(610)=4.72, p<.001$ \\
\hline IRMAS -He Didn't Mean To (5 items) & $\begin{array}{l}3.4 \\
(1.3)\end{array}$ & $\begin{array}{l}2.88 \\
(1.18)\end{array}$ & $t(610)=10.78, p<.001$ \\
\hline IRMAS -She Wanted It ( 5 items) & $\begin{array}{c}2.2 \\
(1.1)\end{array}$ & $\begin{array}{l}1.93 \\
(1.09)\end{array}$ & $t(609)=6.23, p<.001$ \\
\hline IRMAS -She Lied (5 items) & $\begin{array}{l}2.8 \\
(1.2)\end{array}$ & $\begin{array}{c}2.79 \\
(1.13)\end{array}$ & $t(607)=.25, \quad p=.80$ \\
\hline IRMAS -Rape Is A Trivial Event (5 items) & $\begin{array}{c}1.3 \\
(0.5)\end{array}$ & $\begin{array}{l}1.43 \\
(.69)\end{array}$ & $t(610)=4.73, p<.001$ \\
\hline IRMAS -Rape Is A Deviant Event (7 items) & $\begin{array}{r}1.6 \\
(0.6)\end{array}$ & $\begin{array}{l}1.79 \\
(.82)\end{array}$ & $t(609)=5.81, p<.001$ \\
\hline
\end{tabular}

Sexual Assault Questionnaire. The Sexual Assault Questionnaire (SAQ; Appendix E; Frazier \& Borgida, 1988) is a questionnaire designed to measure knowledge of rape. The scale is 
comprised of 18 items using true, false, and don't know response options. Example items include "stranger rape is much more common than acquaintance rape" and "the percentage of false rape reports is about equal to that of the false reports of other crimes." More than half of the questions are false (56\%). Participants are instructed to respond to the best of their ability. In the current study, the internal consistency, calculated using Cronbach's (1951) alpha, was 0.81 .

Sexual Experience Questionnaire. The Sexual Experience Questionnaire (Appendix F) is a demographic questionnaire designed to ask participants about their marital status, whether or not they had sexual intercourse (vaginal or anal), if they were in a current romantic relationship, how old they were at the time of first intercourse, number of sexual intercourse partners, and their sexual orientation.

Modified Sexual Experiences Survey - Female. The SES (Koss \& Oros, 1982) is a self-report measure designed to reflect hidden cases of rape and document the many aspects of sexual victimization. The original SES instrument consisted of 10 items in yes/no format. Koss and Oros (1982) reported a Cronbach's alpha of 0.63 for women taking the original 10-item SES.

The Modified Sexual Experiences Survey (SES; Appendix G; Koss \& Gidycz, 1985) was modified from the original 10-item SES to include additional items assessing specific sexual behaviors in greater detail, as well as information about alcohol-facilitated sexual victimization (see Appendix G). The additional questions regarding alcohol-facilitated victimization were added and patterned after modifications made by Muehlenhard, Powch, Phelps, and Giusti (1992). Based on their responses to the 13-item Modified SES, participants were categorized according to the most severe level of sexual victimization that they reported. These four levels of victimization, in order from least to most severe, include the following: sexual contact 
(unwanted fondling, kissing, or petting subsequent to verbal pressure and/or the misuse of authority, force, or threat of force), sexual coercion (unwanted intercourse subsequent to verbal pressure or the misuse of authority), attempted rape (unwanted attempted intercourse subsequent to force, threat of force, or inability to consent when impaired by intoxicants), and rape (unwanted intercourse subsequent to force, threat of force, or inability to consent when impaired by intoxicants). Test-retest reliability was assessed among 71 females who took the Modified SES 1 week apart; correlation coefficient between the assessments was 0.93 (Koss \& Gidycz, 1985). In a validity study of the Modified SES, Koss and Gidycz (1985) administered the Modified SES to 242 female students who were also interviewed by a psychologist assessing the same behaviors. For females, the Modified SES and the behaviors they reported in the interview were consistent with a correlation coefficient of 0.73 . In the aforementioned study, Cronbach's alpha score was not computed to determine the internal consistency estimate of reliability of test scores of the Modified SES. Test-retest reliability is an alternative to internal consistency reliability. This type of reliability computation involves having the same set of participants complete the same version of the scale on different occasions. The test-retest reliability of the Modified SES at 1 week was 0.93 , and this correlation is considered to be acceptable.

Alcohol Use Items. Alcohol use items (See Appendix H) were similar to those used in the Center on Addiction and Substance Abuse (2007) report on the status of alcohol use in college. Participants were asked if they ever had an alcoholic drink, the number of days in a typical week that they drink, the number of drinks on a typical drinking occasion, the highest number of drinks on one occasion in the last 30 days, and the number of drinks consumed on average for each day of the week. Participants were provided with the definition of the standard drink to facilitate their responses. 
Alcohol and Sexual Consent Scale. The Alcohol and Sexual Consent Scale (ASCS; Appendix I; Ward, 2008) is a 12-item scale designed to assess situations that involve alcohol, sexual communication, and consent for sexual activity. Participants were asked how much they agree with the statements on a 7-point Likert scale (from not at all agree to very much agree). Example items include "consensual drunk sex is a normal and harmless part of college life" and "as a general rule, alcohol makes sexual situations easier and more enjoyable for both men and women." Higher scores reflect endorsement of risky attitudes towards alcohol and sexual communication. The internal consistency, calculated using Cronbach's (1951) alpha, was 0.76.

\section{Data Analysis}

Using a cross-sectional, descriptive research design, the analyses provided an initial examination of the sexual assault risk factors (rape myth acceptance, sexual assault experiences, sexual consent, and alcohol use) in female athletes and non-athletes. When appropriate, multivariate analyses were used to avoid an inflated Type I Error rate.

A power analysis was used to determine the sensitivity of the research design for a variety of effect sizes. Cohen (1988) suggests that 0.80 is the level of statistical power that is sufficient for the social science literature. Assuming a two-tailed test with an alpha level of 0.05 and two groups (athletes versus non-athletes), the project had the statistical power of 0.69, 0.99 , and 0.99 for small, medium, and large effect sizes. When the power analysis was run assuming unequal sample sizes in the groups, the design still had ample $(>0.80)$ statistical power to detect a medium effect size or greater.

An effect size is a measure of the strength of the relationship between two variables in a statistical population (Cohen, 1988). According to Cohen (1988), it is popular to use words such as "small," "medium," and "large" to describe the size of the effect in social science literature. In 
other words, these "T-shirt" effect sizes are based on surveys of the social science literature, and using them simply gives you the sample size as is commonly used in large, medium, and small published studies in the social sciences.

The power of a statistical test is the probability of rejecting the null hypothesis when it is false (i.e. that it will not make a Type II error) (Cohen, 1988). As power increases, the chances of a Type II error decrease. The probability of a Type II error is referred to as the false negative rate $(\beta)$. Therefore power is equal to $1-\beta$. Power analysis can be used to calculate the minimum sample size required to accept the outcome of a statistical test with a particular level of confidence.

Research Question One: Does rape myth acceptance differ between female college athletes and non-athletes? The responses of female athletes and non-athletes to the seven Illinois Rape Myth Acceptance scales were compared (Payne et al., 1999). The scales measure the endorsement of several sexual situation myths. Acceptance of rape myths is perceived as a risk for sexual assault (Payne et al., 1999). A one-way MANOVA (IV=athlete vs. non-athlete; DV= the seven IRMA scales) assessed the interactions between athletic status and responses to questions surrounding rape myth acceptance. A MANOVA is appropriate to limit an inflation of the Type I Error rate. When the overall MANOVAs were significant, post hoc analysis were conducted to identify the significant differences. When the MANOVAs were non-significant, one-way ANOVAs assessed the individual interactions to evaluate their individual contributions.

Research Question Two: Do attitudes towards sexual consent in the context of alcohol differ between female college athletes and non-athletes? An independent t-test on the total score of the ASCS was used to assess if differences in the definition of sexual consent between female college athletes and non-athletes were significant. 
Research Question Three: Do sexual assault histories differ between female college athletes and non-athletes? Female athletes and non-athletes were compared with respect to their responses on the Modified Sexual Experiences Survey (Koss \& Gidycz, 1985). To examine this research question, a chi square test of independence was run on the 5 levels of victimization status.

Research Question Four: Does athletic status and victimization status relate to the participants' drinking rates? Three separate fixed effect ANOVAs were computed to test the hypothesis that athletic status and level of victimization were associated with drinking rates. In the calculation of all three ANOVAs the independent variables were: (1) athlete/non-athlete status treated as a dichotomous variable, and (2) victimization status that has 5 categorical levels based on their responses on the Modified Sexual Experiences Survey (Koss \& Gidycz, 1985) ranging from "non-victim" through "rape". The dependent variables linked to each ANOVA were: (1) number of days per week spent drinking, (2) number of drinks on a typical drinking occasion, and (3) highest number of drinks on one occasion in the last 30 days. The design for testing research question four was comprised of three separate 2 X 5 analyses of variance each associated with nine degrees of freedom.

To test the hypothesis that the day of the week was associated with drinking rates, a MANOVA was computed. The independent variables for this question were again (1) athlete/non-athlete status and (2) victimization status with the same five levels described above that yielded a 2 X 5 MANOVA design having nine degrees of freedom. Each day of the week, Monday through Sunday was treated as a separate dependent variable using average number of drinks on that day as the measured outcome.

To review the full research design in tabular form, please reference Appendix J. 


\section{CHAPTER 4: RESULTS}

This study examined risk factors for sexual assault among female college athletes and non-athletes. Data was gathered on a sample of 635 undergraduate female students enrolled in 15 small and medium sized universities and 3 colleges, all of which were located in the Midwest and Northeastern areas of the United States. The sample consisted of 209 college female athletes, 417 non-athlete females and 9 did not indicate their athletic status. The complete demographic frequencies and percentages are provided in Table 2. In terms of the differences in demographic variables, the racial/ethnic demographics of the sample included a vast majority of Caucasian/White participants $(n=561 ; 88.3 \%)$, followed by African-American participants $(n=$ $16,2.5 \%)$

The age distribution of the participants was as follows: (a) there were no participants under the age of $18,(\mathrm{~b})$ participants between the ages of 18 and 20 constituted $64.4 \%$ of the sample $(n=409)$, (c) participants between the ages of 21 and 23 constituted $27.7 \%$ of the sample $(n=176)$ and participants 24 and older constituted $6.1 \%$ of the sample $(n=29)$. Most of the sample consisted of freshmen $(n=225 ; 35.4 \%)$. The sophomores $(n=136 ; 21.4 \%)$, seniors $(n=$ $118 ; 18.6 \%)$ and juniors $(n=99 ; 15.6 \%)$ had similar levels of representation. There were 29 seniors beyond their fourth year $(4.6 \%)$ and 7 non-matriculated students $(1.1 \%)$ included in the sample. There were 346 participants currently in a romantic/dating relationship or marriage (54.5\%), 275 not currently in a romantic/dating relationship or marriage (43.4\%), and 14 did not indicate their romantic/dating relationship status (2.2\%). 
Table 2

Demographic- Ethnicity, Age, Family Income, Year in School, Athletic Status, Relationship Status

\begin{tabular}{|c|c|c|c|c|c|}
\hline Demographic & $n$ & $\%$ & Demographic & $n$ & $\%$ \\
\hline Year in School & & & Athletic Status & & \\
\hline Freshman & 225 & 35.4 & Athlete & 209 & 32.9 \\
\hline Sophomore & 136 & 21.4 & Non-Athlete & 417 & 65.7 \\
\hline Junior & 99 & 15.6 & Not Indicated & 9 & 1.4 \\
\hline Senior & 118 & 18.6 & Relationship Status & & \\
\hline $5^{\text {th }}$ year Senior & 29 & 4.6 & Romantic Relationship & 346 & 54.5 \\
\hline Non-Matriculated & 7 & 1.1 & No Romantic Relationship & 275 & 43.4 \\
\hline Not Indicated & 21 & 3.3 & Not Indicated & 14 & 2.2 \\
\hline Family Income & & & Ethnicity & & \\
\hline below- $\$ 25,000$ & 21 & 3.3 & African American & 16 & 2.5 \\
\hline$\$ 25,001-\$ 50,000$ & 46 & 7.2 & Asian American & 15 & 2.4 \\
\hline$\$ 50,001-\$ 65,000$ & 53 & 8.3 & Hispanic & 8 & 1.3 \\
\hline$\$ 65,001-\$ 80,000$ & 74 & 11.7 & Caucasian & 561 & 88.3 \\
\hline$\$ 80,001-\$ 100,000$ & 84 & 13.2 & Other & 35 & 5.5 \\
\hline$\$ 100,001-\$ 150,000$ & 82 & 12.9 & Age & & \\
\hline$\$ 150,001$-above & 89 & 14 & $<18$ years old & 0 & 0 \\
\hline Don't know & 168 & 26.5 & $18-20$ & 409 & 64.4 \\
\hline \multirow[t]{2}{*}{ Not Indicated } & 18 & 2.8 & $21-23$ & 176 & 27.7 \\
\hline & & & $24<$ & 50 & 7.9 \\
\hline
\end{tabular}


The family income of the participants was predominately between " $\$ 80,001-\$ 100,000$ " $(n=84 ; 13.2 \%), “ \$ 100,001-\$ 150,000 "(n=82 ; 12.9 \%)$, and“\$65,001 - $\$ 80,000 ”(n=74 ;$ $11.7 \%$ ); the percentages of participants in each of the other five income categories fell between $3.3 \%$ and $8.7 \%$. It should be noted that 168 participants $(26.5 \%)$ did not know the answer to this item. As a result, participants' family income was not used in any further statistical analyses because of missing data concerns.

\section{Descriptive Statistics of Study Variables}

For this study, the endorsement of rape myths was measured by the Illinois Rape Myth Acceptance Scale (IRMA). Results of the IRMA were subdivided into seven scales; these are the "she asked for it," "it wasn't really rape," "he didn't mean to," "she wanted it," "she lied," "rape is a trivial event," and "rape is a deviant event." The descriptive statistics for these variables are shown in Table 3 . Table 3 indicates the mean scores of the considered variables in the study: "she asked for it" $($ athlete $=21.02$; non-athlete $=19.70)$, "it wasn’t really rape" $($ athlete $=7.33 ;$ non-athlete $=7.15)$, "he didn't mean to" $($ athlete $=15.13 ;$ non-athlete $=14.05)$, "she wanted it" (athlete $=10.22$; non-athlete $=9.35)$, "she lied" $($ athlete $=14.88$; non-athlete $=$ 13.53), "rape is a trivial event" (athlete $=7.15$; non-athlete $=7.18)$ and "rape is a deviant event" $($ athlete $=12.52 ;$ non-athlete $=12.47)$. 
Table 3

Descriptive Statistics of Athletes' Status and Rape Myth Acceptance

\begin{tabular}{|c|c|c|c|c|}
\hline Scale & Athletic Status & Mean & $\begin{array}{l}\text { Standard } \\
\text { Deviation }\end{array}$ & $n$ \\
\hline \multirow[t]{2}{*}{ IRMAS -she asked for it } & Non-athlete & 19.70 & 9.01 & 391 \\
\hline & Athlete & 21.02 & 9.01 & 192 \\
\hline \multirow[t]{2}{*}{ IRMAS -It Wasn't Really Rape } & Non-athlete & 7.15 & 3.78 & 391 \\
\hline & Athlete & 7.33 & 3.58 & 192 \\
\hline \multirow[t]{2}{*}{ IRMAS -He Didn’t Mean To } & Non-athlete & 7.15 & 3.78 & 391 \\
\hline & Athlete & 7.33 & 3.58 & 192 \\
\hline \multirow[t]{2}{*}{ IRMAS -She Wanted It } & Non-athlete & 9.35 & 5.32 & 391 \\
\hline & Athlete & 10.22 & 5.66 & 192 \\
\hline \multirow[t]{2}{*}{ IRMAS -She Lied } & Non-athlete & 13.53 & 5.38 & 391 \\
\hline & Athlete & 14.88 & 6.15 & 192 \\
\hline \multirow[t]{2}{*}{ IRMAS -Rape Is A Trivial Event } & Non-athlete & 7.18 & 3.45 & 391 \\
\hline & Athlete & 7.15 & 3.58 & 192 \\
\hline \multirow[t]{2}{*}{ IRMAS -Rape Is A Deviant Event } & Non-athlete & 12.47 & 5.75 & 391 \\
\hline & Athlete & 12.52 & 5.71 & 192 \\
\hline
\end{tabular}

\section{Data Analysis}

The data in the present study were analyzed using one way MANOVA, independent sample t-test and chi-square test to determine whether or not there was a significant difference in the rape myth acceptance, definition of sexual consent, and sexual assault histories across 
athletic status. In addition, a series of ANOVA were conducted to resolve whether athletic status and victimization status related to the participants' drinking rates.

Research Question One: Does rape myth acceptance differ between female college athletes and non-athletes? This research question concerned group differences in rape myth acceptance between athletes and non-athletes in the sample. This research question was addressed with a one-way MANOVA. This multivariate test was conducted to determine if the seven types of rape myth acceptance shown in Table 3 significantly varied across athletic status. The overall MANOVA was not significant, Wilk's $\Lambda=.98, F(7,575)=1.85, p=.08$, partial $\eta^{2}$ $=.02$. Wilks' lamda is a multivariate measure of group differences over several variables (Bartlett, 1954). There were no significant differences in rape myth acceptance between athletes and non-athletes in the sample, which means the null hypothesis could not be rejected. Hence, athletes were no more likely than non-athletes to endorse rape myths.

Research Question Two: Do attitudes towards sexual consent in the context of alcohol differ between female college athletes and non-athletes? This research question concerned differences in the definition of alcohol-involved sexual consent between athletes and nonathletes. This research question was addressed using an independent samples t-test to test whether there was a significant difference in total scores of Alcohol and Sexual Consent Scale (ASCS) across athletic status. There was no significant difference in perceived sexual consent between female athletes $(M=28.88, S D=8.77)$ and non-athletes $(M=27.65, S D=9.14)$ in the sample, $t(597)=1.56, p=.12$, hence the null hypothesis was not rejected. This means that sexual consent does not vary significantly across athletic status.

Research Question Three: Do sexual assault histories differ between female college athletes and non-athletes? This research question concerned differences in sexual assault history 
across athletic status. This research question was addressed using chi-square test of independence to test for differences in the 5 levels of victimization status tested in the sexual victimization category: non-victim, unwanted sexual contact, coercion, attempted rape, and rape. There was no significant difference in sexual victimization across athletic status, $\chi^{2}(n=611,4)=$ $9.05, p=.06$. Female athletes and non-athletes did not significantly differ in levels of sexual victimization. Table 4 displays the results of crosstabulation with the percentages of each athletic status between the sexual victimization categories in the study. It is notable that the $20.95 \%$ of the sample reporting rape is consistent with the percentages reported in the research literature (Abbey, 2002; Fisher et al., 2000; Flack et al., 2007; Testa \& Parks, 1996).

Table 4

Crosstabulation Between Athletic Status and Sexual Victimization Category

\begin{tabular}{lccc}
\hline Victimization Status & \multicolumn{2}{c}{ Athletic Status } & Total \\
& Non-Athlete & Athlete & \\
& & & \\
\hline Non-victim & $106(25.92 \%)$ & $68(33.66 \%)$ & $174(28.48 \%)$ \\
Unwanted Sexual Contact & $149(36.43 \%)$ & $77(38.12 \%)$ & $226(36.99 \%)$ \\
Sexual Coercion & $42(10.27 \%)$ & $14(6.93 \%)$ & $56(9.17 \%)$ \\
Attempted Rape & $23(5.62 \%)$ & $4(1.98 \%)$ & $27(4.42 \%)$ \\
Rape & $89(21.76 \%)$ & $39(19.31 \%)$ & $128(20.95 \%)$ \\
\hline
\end{tabular}

To further examine the proportions of athletes and non-athletes in each category of victimization, two proportion z-tests were conducted (two-tailed). The z-test examining the proportion of athletes versus non-athletes who were non-victims was significant, $\mathrm{z}=2.00, p<$ .05. The z-test examining athletes versus non-athletes on unwanted sexual contact was not 
significant, $\mathrm{z}=.41, p=.68$. The $\mathrm{z}$-test examining sexual coercion was also non-significant, $\mathrm{z}=$ $1.35, p=.18$. The $\mathrm{z}$-test examining attempted rape was non-significant, $\mathrm{z}=1.75, p=.08$.

Finally, the z-test examining rape was non-significant, $\mathrm{z}=.70, p=.48$.

Research Question Four: Does athletic status and victimization status relate to the participants' drinking rates? The fourth research question concerned the group differences in participant drinking rates across sexual victimization and athletic status. This research question was addressed through 2-way between-groups ANOVAs. The first ANOVA concerned the number of days in a typical week that they drink (i.e., Monday, Tuesday, Wednesday, Thursday, Friday, Saturday, Sunday). The means and standard deviations are displayed in Table 5. The main effect for athletic status was not significant, $F(1,601)=.71, p=.40$, partial $\eta^{2}=.001$. The main effect for victimization status was significant, $F(4,601)=11.70, p<.001$, partial $\eta^{2}=.07$. The interaction between athletic status and victimization status was not significant, $F(4,601)=$ $.58, p=.68$, partial $\eta^{2}=.004$

Tukey's Post Hoc tests were conducted to examine the differences in number of days drinking between groups of sexual victimization categories. Non-victims drank for fewer days than participants who experienced unwanted sexual contact or rape. Similarly, participants who experienced rape drank more days than those who experienced unwanted sexual contact and participants who experienced coercion. 
Table 5

Means and Standard Deviations for Athletes and Non-Athletes by Victimization Status

\begin{tabular}{|c|c|c|c|c|c|c|c|c|c|c|}
\hline & \multicolumn{4}{|c|}{ Non-Athlete } & \multicolumn{6}{|c|}{ Athlete } \\
\hline & $\begin{array}{l}\text { Non- } \\
\text { Victim }\end{array}$ & $\begin{array}{c}\text { Unwanted } \\
\text { Sexual } \\
\text { Contact }\end{array}$ & $\begin{array}{c}\text { Sexual } \\
\text { Coercion }\end{array}$ & $\begin{array}{l}\text { Attempted } \\
\text { Rape }\end{array}$ & Rape & $\begin{array}{c}\text { Non- } \\
\text { Victim }\end{array}$ & $\begin{array}{c}\text { Unwanted } \\
\text { Sexual } \\
\text { Contact }\end{array}$ & $\begin{array}{c}\text { Sexual } \\
\text { Coercion }\end{array}$ & $\begin{array}{l}\text { Attempted } \\
\text { Rape }\end{array}$ & Rape \\
\hline $\begin{array}{l}\text { Number of } \\
\text { Days } \\
\text { Drinking }\end{array}$ & $\begin{array}{l}.64 \\
(.96)\end{array}$ & $\begin{array}{c}1.07 \\
(1.11)\end{array}$ & $\begin{array}{c}1.19 \\
(1.25)\end{array}$ & $\begin{array}{c}1.20 \\
(1.17)\end{array}$ & $\begin{array}{c}1.60 \\
(1.68)\end{array}$ & $\begin{array}{l}.61 \\
(.78)\end{array}$ & $\begin{array}{c}1.11 \\
(1.24)\end{array}$ & $\begin{array}{l}.64 \\
(.84)\end{array}$ & $\begin{array}{c}1.00 \\
(1.15)\end{array}$ & $\begin{array}{c}1.64 \\
(1.27)\end{array}$ \\
\hline $\begin{array}{l}\text { Typical } \\
\text { Number of } \\
\text { Drinks }\end{array}$ & $\begin{array}{c}1.87 \\
(1.92)\end{array}$ & $\begin{array}{c}2.76 \\
(2.22)\end{array}$ & $\begin{array}{c}2.82 \\
(2.27)\end{array}$ & $\begin{array}{c}2.67 \\
(2.37)\end{array}$ & $\begin{array}{c}3.67 \\
(2.66)\end{array}$ & $\begin{array}{c}2.31 \\
(2.80)\end{array}$ & $\begin{array}{c}3.21 \\
(2.39)\end{array}$ & $\begin{array}{c}3.00 \\
(2.74)\end{array}$ & $\begin{array}{c}4.00 \\
(3.37)\end{array}$ & $\begin{array}{c}4.18 \\
(2.14)\end{array}$ \\
\hline $\begin{array}{l}\text { Highest } \\
\text { drinking } \\
\text { Occasion }\end{array}$ & $\begin{array}{l}2.66 \\
(2.62)\end{array}$ & $\begin{array}{c}4.40 \\
(4.17)\end{array}$ & $\begin{array}{c}4.55 \\
(3.30)\end{array}$ & $\begin{array}{c}4.04 \\
(3.77)\end{array}$ & $\begin{array}{c}5.55 \\
(4.46)\end{array}$ & $\begin{array}{c}3.26 \\
(3.62)\end{array}$ & $\begin{array}{c}4.60 \\
(3.68)\end{array}$ & $\begin{array}{c}4.36 \\
(5.09)\end{array}$ & $\begin{array}{c}5.00 \\
(6.00)\end{array}$ & $\begin{array}{c}7.28 \\
(5.09)\end{array}$ \\
\hline Monday & $\begin{array}{l}.03 \\
(.22)\end{array}$ & $\begin{array}{l}.07 \\
(.53)\end{array}$ & $\begin{array}{l}.10 \\
(.62)\end{array}$ & $\begin{array}{c}.04 \\
(.21)\end{array}$ & $\begin{array}{c}.37 \\
(1.56)\end{array}$ & $\begin{array}{l}.01 \\
(.12)\end{array}$ & $\begin{array}{l}.09 \\
(.69)\end{array}$ & $\begin{array}{l}.00 \\
(.00)\end{array}$ & $\begin{array}{l}.00 \\
(.00)\end{array}$ & $\begin{array}{l}.21 \\
(.92)\end{array}$ \\
\hline Tuesday & $\begin{array}{l}.05 \\
(.29)\end{array}$ & $\begin{array}{l}.05 \\
(.36)\end{array}$ & $\begin{array}{l}.12 \\
(.55)\end{array}$ & $\begin{array}{c}.39 \\
(1.08)\end{array}$ & $\begin{array}{l}.24 \\
(.89)\end{array}$ & $\begin{array}{l}.00 \\
(.00)\end{array}$ & $\begin{array}{l}.12 \\
(.92)\end{array}$ & $\begin{array}{l}.14 \\
(.54)\end{array}$ & $\begin{array}{l}.00 \\
(.00)\end{array}$ & $\begin{array}{l}.44 \\
(1.54)\end{array}$ \\
\hline Wednesday & $\begin{array}{l}.05 \\
(.25)\end{array}$ & $\begin{array}{c}.25 \\
(1.05)\end{array}$ & $\begin{array}{l}.13 \\
(.53)\end{array}$ & $\begin{array}{c}.70 \\
(1.72)\end{array}$ & $\begin{array}{c}.62 \\
(1.98)\end{array}$ & $\begin{array}{l}.06 \\
(.34)\end{array}$ & $\begin{array}{l}.25 \\
(.95)\end{array}$ & $\begin{array}{c}.00 \\
(.00)\end{array}$ & $\begin{array}{c}.00 \\
(.00)\end{array}$ & $\begin{array}{l}.49 \\
(1.28)\end{array}$ \\
\hline Thursday & $\begin{array}{l}.18 \\
(.81)\end{array}$ & $\begin{array}{c}.54 \\
(1.44)\end{array}$ & $\begin{array}{c}.71 \\
(1.50)\end{array}$ & $\begin{array}{l}.17 \\
(.65)\end{array}$ & $\begin{array}{c}.69 \\
(1.89)\end{array}$ & $\begin{array}{l}.19 \\
(.89)\end{array}$ & $\begin{array}{c}.53 \\
(1.70)\end{array}$ & $\begin{array}{c}.57 \\
(2.14)\end{array}$ & $\begin{array}{l}.00 \\
(.00)\end{array}$ & $\begin{array}{l}1.13 \\
(2.58)\end{array}$ \\
\hline Friday & $\begin{array}{c}1.02 \\
(1.60)\end{array}$ & $\begin{array}{c}1.98 \\
(2.67)\end{array}$ & $\begin{array}{c}1.69 \\
(2.44)\end{array}$ & $\begin{array}{c}1.49 \\
(2.29)\end{array}$ & $\begin{array}{c}2.59 \\
(3.04)\end{array}$ & $\begin{array}{c}.93 \\
(1.94)\end{array}$ & $\begin{array}{c}1.75 \\
(2.52)\end{array}$ & $\begin{array}{c}1.29 \\
(2.81)\end{array}$ & $\begin{array}{c}.50 \\
(1.00)\end{array}$ & $\begin{array}{l}2.46 \\
(2.79)\end{array}$ \\
\hline Saturday & $\begin{array}{c}1.30 \\
(1.82)\end{array}$ & $\begin{array}{c}2.00 \\
(2.65)\end{array}$ & $\begin{array}{c}2.31 \\
(2.68)\end{array}$ & $\begin{array}{c}2.10 \\
(2.60)\end{array}$ & $\begin{array}{c}3.01 \\
(3.20)\end{array}$ & $\begin{array}{c}1.81 \\
(2.41)\end{array}$ & $\begin{array}{c}2.71 \\
(2.63)\end{array}$ & $\begin{array}{c}2.71 \\
(2.92)\end{array}$ & $\begin{array}{c}3.00 \\
(3.83)\end{array}$ & $\begin{array}{l}4.10 \\
(3.32)\end{array}$ \\
\hline Sunday & $\begin{array}{l}.08 \\
(.53)\end{array}$ & $\begin{array}{l}.04 \\
(.42)\end{array}$ & $\begin{array}{c}.26 \\
(1.06)\end{array}$ & $\begin{array}{l}.04 \\
(.21)\end{array}$ & $\begin{array}{c}.17 \\
(1.01)\end{array}$ & $\begin{array}{l}.10 \\
(.63)\end{array}$ & $\begin{array}{l}.08 \\
(.48)\end{array}$ & $\begin{array}{l}.00 \\
(.00)\end{array}$ & $\begin{array}{c}.75 \\
(1.50)\end{array}$ & $\begin{array}{l}.10 \\
(.64)\end{array}$ \\
\hline
\end{tabular}

Note: $M(S D)$

The second ANOVA concerned the typical number of drinks per drinking day across sexual victimization and athletic status. The means and standard deviations are displayed in Table 5. The main effect for athletic status was not significant, $F(1,601)=3.24, p=.07$, partial $\eta^{2}=.005$. The main effect for victimization status was significant, $F(4,601)=10.25, p<.001$, partial $\eta^{2}=.06$. The interaction between athletic status and victimization status was not significant, $F(4,601)=.16, p=.96$, partial $\eta^{2}=.001$. Tukey's HSD revealed that non-victims drink significantly fewer drinks than those who have experienced unwanted sexual contact and those who have been raped.

The third ANOVA concerned the highest drinking occasion in the last 30 days across sexual victimization and athletic status. The means and standard deviations are displayed in Table 4. The main effect for athletic status was not significant, $F(1,601)=1.53, p=.22$, partial 
$\eta^{2}=.003$. The main effect for victimization status was significant, $F(4,601)=12.91, p<.001$, partial $\eta^{2}=.08$. The interaction between athletic status and victimization status was not significant, $F(4,601)=.82, p=.52$, partial $\eta^{2}=.005$. According to the Tukey's HSD, the nonvictims had significantly lower number of drinks on their highest drinking occasion in the last 30 days when compared to those who experienced unwanted sexual contact and those who have been raped. Those who were raped also drank significantly more than those who experienced unwanted sexual contact.

The next analysis, a twoway MANOVA, concerns drinking rates per day across sexual victimization levels and athletic status. The means and standard deviations are located in Table 4. The main effect for athletic status was significant, Wilk's $\Lambda=.97, p=.008$, partial $\eta^{2}=.03$. The main effect for victimization status was significant, Wilk's $\Lambda=.90, p<.001$, partial $\eta^{2}=$ .03. The interaction between athletic status and victimization status was not significant Wilk's $\Lambda=.97, p=.92$, partial $\eta^{2}=.01$.

The follow up ANOVAs revealed that athletes reported drinking significantly more on Saturdays. In addition, follow up tests revealed the rape victims drank more than non-victims and victims on Mondays, Tuesday, Wednesday, Thursday, Friday, and Saturdays. Victims of unwanted sexual contact also reported drinking more than non-victims on every day of the week except Sunday. Rape victims drank more than victims of unwanted sexual contact on Mondays, Tuesdays, and Saturdays.

\section{Summary}

This study concerned sexual risk factors among female athletes and non-athletes on college campuses. Archival data on 635 participants in colleges and universities in the Midwestern and Northeastern areas of the U.S was utilized in this study. The first research 
question concerned whether the acceptance of rape myth differed between female college athletes and non-athletes. MANOVA results revealed no significant difference in rape myth acceptance across athletes and non-athletes in the sample. The second research question addressed whether the definition of sexual consent differs between female college athletes and non-athletes. The results of independent samples t-tests revealed that sexual consent did not differ significantly across athletes and non-athletes in the sample.

The third research question concerned whether sexual assault histories differ between female college athletes and non-athletes. Chi-square test of independence results revealed that there was no significant difference in sexual assault histories across athletic status in the sample. The fourth research question concerns whether the athletic status and victimization status related to the participants' drinking rates. In general, the results of the ANOVAs and a MANOVA revealed that athletic status did not have a significant main effect on drinking rates, but sexual victimization did have a main effect on participants' drinking rates. The exception was the twoway MANOVA examining drinking patterns for each day of the week. Athletes reported drinking more than non-athletes on Saturdays. Post hoc tests were also conducted to show that rape victims drank more frequently than those who experienced lower levels of sexual assault. These results were analyzed and synthesized in the following section. 


\section{CHAPTER 5: DISCUSSIONS, CONCLUSIONS AND RECOMMENDATIONS}

This study investigated the rates of substance-facilitated sexual assaults among both female college athletes and female college non-athletes. Archival data was used to assess the prevalence, differential impact of, and risk factors for sexual assault in samples of college women athletes and college women non-athletes. The female college athletes surveyed in this study did not have a greater prevalence of sexual victimization than the control population of college female non-athletes. Specific types of sexual assault risk factors were examined to determine if they influenced rates of sexual assault in female college athletes and non-athletes, such as rape myth acceptance, issues involving sexual consent, sexual assault histories and frequency of alcohol use. The results yielded support for the findings of prior studies related to alcohol consumption and victimization status, in addition to providing new directions for research.

\section{College Athletes as a Special Population}

Some research studies have argued that sport is a male dominated institution and a sexist culture (Fallon \& Jome, 2007; Gage, 2009; Letendre, 2007; Miller et al., 2007, Murnen \& Kohlman, 2007). The special treatment afforded to male and female athletes has been linked to athletes possessing lower perceived risk, particularly in regard to unacceptable behavior (Wetherill \& Fromme, 2007). Athletic participation has also been shown to contribute to the development of hegemonic attitudes and behaviors in females from coaches and male athletes (Fallon \& Jome, 2007; Gage, 2009; Letendre, 2007; Miller et al., 2007). Hegemonic attitudes (i.e., culturally normative ideal of male dominance) have been associated with the creation and perhaps the reinforcement of perspectives that are associated with sexual aggression (Miller et al., 2007; Murnen \& Kohlman, 2007). Female athletes who have adopted more hegemonic 
masculine views and behaviors are less likely to take precautions against victimization and are more likely to engage in risky situations that increase the possibility of sexual assault. Therefore, female athletes that have been exposed to hegemonic views (i.e., physical dominance) and behaviors (i.e., risk taking) may be at greater risk for experiencing negative health outcomes such as sexual victimization.

Conversely, researchers have argued that athletic participation can protect female athletes from sexual victimization through a variety of social-psychological mechanisms (Fasting, Brackenridge, Miller, \& Sabo, 2008; Wetherill \& Fromme, 2007). These studies suggest that sport is a source of empowerment in lives of many women, helping them to develop a positive body image and identity and to make less risky choices about sexual relationships. To this extent, sport might be said to protect females from some forms of sexual victimization. Fasting et al. (2008) have suggested that sport offers some protection to female athletes because it develops their strength, self-confidence and sense of physical adeptness, characteristics which have previously been associated with resistance and rape avoidance. In other words, being physically strong and having high self esteem - all outcomes associated with female athletics - may thereby protect women from experiencing sexual victimization. According to Fasting et al. (2008) being a collegiate female athlete may offer some protection from the sexual assault risk variables examined in this study.

The development of positive social-psychological mechanisms may reflect the presence of professionals such as athletic trainers at these schools devoted to educating and counseling female athletes about sexual assault risk. At all of the schools surveyed in this study, a support system was present to help female athletes avoid and identify risky drinking behaviors that increase the risk of experiencing sexual assault. The support system included education by the 
National Collegiate Athletic Association CHAMPS/Life Skills program for coaches, athletic trainers, and athletes on the signs and risk for sexual assault and alcohol abuse. The support system also provided referral for student athletes when counseling was warranted. This suggests that female college athletes are better educated on the factors associated with experiencing sexual assault and less likely to experience sexual victimization than their non-athletic counterparts. These findings point to the need for further investigation on the protective processes associate with athletic participation which is beyond the scope of the archival data utilized for this study.

\section{Archival Data}

This research study utilized a quantitative research methodological approach to address the objectives of the study, making use of archival data collected in the spring of 2008 by Rose Marie Ward, Ph.D., of Miami University in Oxford, Ohio. Data on rape myth acceptance, conception of sexual consent, level of sexual victimization, and rate of alcohol consumption was gathered on 635 female college participants (209 athletes and 416 non-athletes). It has been noted that evaluations using archival data risk severe limitations (Jones, 2010). The primary concern about archival data is whether the data serves the purpose of the current evaluation.

The appropriateness and accuracy of the archival data tends to be a problem because the original purpose for collecting the data is different than the rationale for the current study. Historically, evaluators typically avoid using archival data due to its' inherent limitations and opt to collect their own data to insure control over the content and process (Jones, 2010). The hypotheses for this study were based on the the relevant research literature associated with sexual victimization and the prevalence of specific types of sexual assault risk factors. Based on this literature, it was hypothesized that female college athletes constitute a population that are at 
particularly high risk for experiencing sexual assault. The appropriateness of the archival data was not expected to be a problem because the goals of this research evaluation were congruent with the purposes for which the data were originally collected.

The accuracy of the archival data refers to the quality of the data, specifically, the reliability and validity of the results. When working with archival data it is important to consider the possible inaccuracies that the data may contain (Jones, 2010). Based on the methods used to collect the data and the reliability of the instruments administered, any inaccuracies associated with the data would have been limited, so, it was expected that the archival data was externally valid. Unfortunately, since the data was collected by another researcher, it was possible that questions asked for this research study may be beyond the scope of the archival data because previous research was collected to address different research hypotheses.

In addition, the longer the time period between the evaluation and the use of the data, the greater the concerns with the reliability and validity of the archival data (Jones, 2010). Three years have lapsed since Dr. Ward had collected the data in the Spring of 2008, which raises reliability and validity concerns about the results of this study. Discontinuities in the data are caused by changes in the research as well as changes in the population (Jones, 2010). Despite the passage of time, the current study will expand the research literature associated with female college athletes. There continues to be no research examining sexual assault risk factors between female college athletes and female college non-athletes.

However, there are some advantages to using archival data, as it represents a rich, plentiful source of information for psychological studies (Jones, 2010). Research on female college athletes continues to be sparse and no previous studies have compared female college athletes and non-athletes on the variables that were examined for this study. The data collected 
by Dr. Ward was used for identifying the prevalence of sexual victimization among college female athletes and non-athletes, assessing the impact of specific types of sexual assault risk factors and further understanding female college athletes. This data has led to valuable insights about college female athletes and will guide future research projects.

\section{Interpretation of Results}

This study examined the rates of substance-facilitated sexual assaults among both female college athletes and female college non-athletes. Past research has suggested that female athletes choose to participate in high-risk health behaviors (McMahon, 2007). The results of the study under discussion provided greater awareness of the complexity associated with examining factors existing for a specific population that places them at risk for sexual assault. The results did not consistently yield support for the findings of prior studies related to female college athletes (Anderson, 2007; Gage, 2009; Humphrey, 2007; McMahon, 2007; O’Byrne et al., 2008; Wetherill \& Fromme, 2007; Zamboanga \& Ham, 2008). The findings of this study and their corresponding implications are discussed in this chapter with attention to significance, limitations and recommendations for future research.

Previous studies have documented a link between rape supportive ideology and sexually aggressive behavior (Anderson, 2007; Gage, 2009; Humphrey, 2007; McMahon, 2007; O’Byrne et al., 2008). Rape-tolerant attitudes and behaviors, including adherence to traditional sex-role attitudes, adversarial attitudes toward women, and acceptance of violence toward women, are widely accepted by rapists and potential rapists and have been shown to contribute to sexual violence (Burt, 1991; Gage, 2009). Rape myth acceptance has also been shown to be a strong potential predictor of sexual victimization and a factor that exists for experiencing sexual assault (Burt, 1991; Gage, 2009). Both male and female college athletes have been shown to endorse 
rape supportive ideology and behaviors at a higher rate than non-athletes (McMahon, 2007). It is believed that as part of the college athlete experience, female college athletes are exposed to hegemonic beliefs and behaviors that are conducive to sexual assault (Burt, 1991; Gage, 2009; McMahon, 2007; Sawyer et al., 2002). Therefore, female athletes may be more accepting of rape myths and less likely to recognize and/or report incidents of sexual violence.

Research Question One: Does rape myth acceptance differ between female college athletes and non-athletes? In order to address research question 1, the statistical analyses performed on the data gathered from the Illinois Rape Myth Acceptance Scale (IRMA) revealed there were no significant differences in rape myth acceptance between athletes and non-athletes. The results of the IRMA were subdivided into seven scales; these are the "she asked for it," "it wasn't really rape," "he didn't mean to," "she wanted it," "she lied," "rape is a trivial event," and "rape is a deviant event." This research question was answered by processing the data through one way MANOVA. The results of the MANOVA performed indicated that, for the entire study sample, female college athletes did not endorse rape myths at a higher level than non-athletes. In other words, the female college athletes did not differ on the seven scales which were part of the administered instrument IRMA. Thus, female college athletes and female college non-athletes did not differ significantly on the endorsements of several situational rape myths.

This finding builds upon the existing literature of rape supportive ideology and behaviors by McMahon (2007) and Sawyer et al. (2002). Both of the previous studies theorized that female college athletes are exposed to hegemonic beliefs by coaches and male athletes, which are a normative environment for sports, and can reinforce the development of competitiveness and dominance by positively sanctioning aggression conducive to sexual assault. McMahon's (2007) study utilized survey, focus groups, and individual interviews to explore the meaning and 
role of rape myths. Interestingly, she found low acceptance of rape myths utilizing survey instruments alone. Her survey finding was contradicted by the results of the focus groups and individual interviews. The survey results from the present study also found no significant differences between female college athletes and female college non-athletes. Using archival survey data may have been a flawed approach to assessing this research hypothesis. The previous researchers that gathered the archival data utilized a survey instrument to assess rape myth acceptance. In future studies, focus groups and individual interviews of the sample may result in differences between female college athletes and non-athletes on rape myth acceptance.

Sawyer et al. (2002) examined male and female collegiate athletes attending institutions from two separate athletic divisions. Sawyer et al. (2002) reported higher rape myth acceptance among female athletes from Division I versus Division II schools. This finding seems contrary to the results of the current study but the methodological difference between the two studies make comparison difficult. Future studies are needed to expand the understanding rape myth acceptance among female college athletes. For instance, researchers could examine male and female college athletes versus male and female college non-athletes on rape myth acceptance. In addition, researchers could examine female college athletes from Division I and Division II schools versus female college non-athletes from Division I and Division II schools.

Beliefs about sexual consent have also been shown to affect an individual's ability to recognize and react to sexual advances appropriately (Humphreys, 2007). The previous literature on sexual consent is extremely sparse. The research to date has examined the outward manifestation of sexual consent, specifically the way in which couples communicate their consent (Hall, 1995; Hickman \& Muehlenhard, 1997; Humphreys, 2007). These studies examined the differences between men and women on their definitions about sexual consent. 
The current study was the first to examine a population comprised solely of women and their views on alcohol and sexual consent. This was also the only study to examine beliefs about sexual consent in female college athletes. In terms of sexual consent, the results revealed no significant difference in definitions of sexual consent across athletes and non-athletes in the sample. According to Humphreys (2007) discrepancies between the conceptual understanding of sexual consent between the two parties involved may lead to feelings of victimization and rape.

Research Question Two: Do attitudes towards sexual consent in the context of alcohol differ between female college athletes and non-athletes? In order to address Research Question 2, potential differences in definitions of sexual consent were measured by The Alcohol and Sexual Consent Scale (ASCS). The ASCS is a 12-item scale designed to assess situations that involve alcohol, sexual communication, and consent for sexual activity. Participants were asked how much they agree with the statements on a 7-point Likert scale (from not at all agree to very much agree). Example items include "consensual drunk sex is a normal and harmless part of college life" and "as a general rule, alcohol makes sexual situations easier and more enjoyable for both men and women." Higher scores reflect endorsement of risky attitudes towards alcohol and sexual communication. The statistical analyses performed on the data gathered from the ASCS revealed no significant differences between female college athletes and female college non-athletes. In other words, the conceptions of sexual consent did not vary across athletic status in the sample.

This study marks the beginning of the findings related to understanding female college athletes' attitudes towards sexual consent. Based on the existing theoretical models and the previous research involving female college athletes (i.e., sensation seeking and social scripting), it was theorized that female college athletes' attitudes toward sexual consent in the context of 
alcohol would be different than female college non-athletes. Based on the sensation seeking literature, I presumed that female athletes would be less likely to recognize and appropriately react to sexual advances than female college non-athletes (Wetherill \& Fromme, 2007). Previous research had indicated that female college athletes consumed more alcohol and were more likely to take health risks than their non-athlete peers (Zamboanga \& Ham, 2008). For that reason, it seemed plausible that female college athletes who had been socialized to be athletically aggressive and competitive would be more likely than non-athletes to endorse risky attitudes towards sexual communication and alcohol use.

Based on the social scripting research done by O'Byrne et al. (2008), it was also theorized that female athletes may not be able to appropriately recognize and react to ambiguous sexual situations. This study reported that males and females have different internalized scripts that guide sexual behavior and may therefore account for differences between men and women in perceived sexual consent. Different sexual scripts may increase miscommunication and contribute to an increase in the likelihood of experiencing sexual assault. In addition, the research has demonstrated that alcohol use may lead to miscommunication, which increases the likelihood of experiencing sexual assault (Humphries, 2007). Based on this work, it was hypothesized that ambiguous sexual situations may place female athletes at a greater risk for experiencing sexual assault than women who have been socialized to be the limit setters in sexual encounters.

Similar to the previous hypothesis, assumptions were made based on previous research involving female athletes and using archival survey data may have been a flawed approach to assessing this research hypothesis. According to the archival data, female college athletes have the same risk of experiencing sexual assault as non-college athletes based on their ability to 
recognize and properly control sexual advances. A survey instrument, like the one used by the previous researchers to gather the archival data, may not be sensitive enough on its' own to detect difference in the populations sampled in this study. The Alcohol and Sexual Consent Scale (ASCS) may not have been used enough to reach scale maturity. In the context of the development of prototypic assessment instruments the issues of standardization, norming procedures, and the important psychometrics of test reliability and validity are evaluated critically (Cicchetti, 1994). Criteria, guidelines, and cronbach's alpha scores are provided to assist the clinician faced with the challenge of choosing an appropriate test instrument for a given psychological assessment. Future studies utilizing the ASCS may identify differences between female college athletes and non-athletes on their attitudes toward sexual consent in the context of alcohol, as the scale reaches maturity. For this study, it seems according to the findings that female college athletes were just as likely as female college non-athletes to recognize and play a defensive role in ambiguous sexual situations.

Certain aspects of an individual's sexual history have been shown to be a factor that may increase vulnerability to sexual assault. For example, college athletes have reported more frequent sexual intercourse, a greater number of sexual partners, and a higher prevalence rate of sexually transmitted diseases compared to non-athletes (Faurie et al., 2004; Gidycz et al., 2008; Littleton et al., 2007; Nattiv \& Puffer, 1991; Nattiv et al., 1997). Both male and female athletes have been shown to be less likely to take precautions and are more likely to engage in risky situations that increase the possibility of experiencing a sexual assault (Wetherill \& Fromme, 2007). It is known that individuals who underestimate or overestimate their capacity to control outcomes of interactions with others have been less likely to engage in precautions against risky 
situations (Nurius, 2000). Thus, it was hypothesized that the sexual histories of female college athletes would be different than the sexual histories of female college non-athletes.

Research Question Three: Do sexual assault histories differ between female college athletes and non-athletes? In order to address Research Question 3, the statistical analyses performed on the data gathered from the Modified Sexual Experiences Survey (SES) revealed no significant differences between female college athletes and non-athletes on the 5 levels of victimization status. These five levels of victimization, in order from least to most severe, include the following: non-victim, sexual contact (unwanted fondling, kissing, or petting subsequent to verbal pressure and/or the misuse of authority, force, or threat of force), sexual coercion (unwanted intercourse subsequent to verbal pressure or the misuse of authority), attempted rape (unwanted attempted intercourse subsequent to force, threat of force, or inability to consent when impaired by intoxicants), and rape (unwanted intercourse subsequent to force, threat of force, or inability to consent when impaired by intoxicants). The archival data were analyzed by a chi-square test of independence analysis

The results suggested that female college athletes can not be distinguished from female non-college athletes on the basis of the five levels of sexual victimization. The level of victimization (i.e., non-victim, unwanted sexual contract, coercion, attempted rape and rape) did not seem to relate to athletic status. This implies that sexual assault histories do not vary between female college athletes and non-athletes. Using crossatbulations for further examination, it appears that athletes had lower levels of some forms of sexual victimization, particularly unwanted sexual contact, coercion, and attempted rape, but not for rape itself. These crosstabulations appear in Table 3 with the percentages of each athletic status between the sexual 
victimization categories in the study. It appears that female college athletes were less likely to have experienced relatively mild forms of sexual assault, but no less likely to have been raped.

This finding supports the interconnected relationship between sexual history and alcohol use among athletes and non-athletes identified by Wetherill \& Fromme (2007). Their results suggested that when one variable (i.e., average quantity and frequency of alcohol use, number of sexual partners, frequency of unprotected sex, and perceived risk) is regressed the other variables regress. In the current study, there were no differences in alcohol use or type of sexual history between female college athletes and non-athletes, thus supporting Wetherill \& Fromme's (2007) interconnected relationship theory. The athletes in the current study were at most only as likely as their non-athlete counterparts to have experienced sexual assault.

Recent research has also indicated interconnectedness between alcohol consumption and sexual risk-taking (Huang, Jacobs, \& Derevensky, 2010; Mays, Thompson, Kushner, Mays, Farmer, \& Windle, 2010; Simons, Maisto, \& Wray, 2010). Simons et al. (2010) found significant associations between risky sexual behavior and the amount of alcohol consumed per drinking day. Both Mays et al. (2010) and Huang et al. (2010) found that heavy episodic drinking elevated sexual risk taking in athletes and non-athletes. Huang et al. (2010) also found that heavy episodic drinking plays a relatively more important role in sexual risk taking among female athletes than among their male peers. The findings of these previous studies are consistent with the findings of the current study. Moreover, both studies seem to indicate that alcohol mediates the differences in sexual experiences regardless of athletic status.

The female college athletes in the sample reportedly were less likely to have experienced non-rape sexual assault, even though, they were just as likely to endorse rape myths and express sexual consent as their non-athlete counterparts. Unfortunately, no research exists on the stages 
of assault, from harassment to rape, that fleshes out this finding. Since different sexual activities involve different levels of risk, the lack of definition of stages of assault makes this variable difficult to study (Huang et al., 2010). This raises some interesting questions: What protective factors existed for these female college athletes that reduced their exposure to these forms of sexual assault? Were there protective factor that protected these college female athletes from exposure to consummate rape, but did protect them from attempted rape, coercion, and unwanted sexual encounters. Could education and prevention services geared toward female college athlete have played a protective moderating role here? For instance, an educational game show called "Sex Signals" has been commonly utilized by collegiate athletic departments to discuss a range of topics including: rape attitudes, rape-related attitudes, rape knowledge, behavioral intent, and incidence of sexual assault. Future research on the effectiveness of college sexual assault education programs such as "Sex Signals" will be necessary to understand what protective factors influence female college athletes.

Studies have also consistently shown a positive correlation between increased alcohol intake and sexual assault (Brenner \& Swanik, 2007; Flack et al., 2007; Hummer, LaBrie, \& Lac, 2009; Yusko, Buckman, White, \& Pandina, 2008). Alcohol consumption has been shown to impair a woman's ability to recognize and avoid sexual assault and her ability to respond assertively to unwanted sexual advances. Furthermore, both male and female college athletes abuse alcohol at higher rates than non-athletes (Gutgesell, Moreau, \& Thompson, 2003; Hildebrand, Johnson, \& Bogle, 2001; Huang, DeJong, Schneider \& Towvim, 2006; Huang et al., 2010; Weschler \& Davenport, 1997). Between 82 and 85\% of all college students use alcohol, but alcohol use among athletes is estimated to be $6 \%$ higher than that of non-athletes (Hildebrand et al., 2001; Huang et al., 2006; Leichliter et al., 1998). Increased alcohol use among college 
athletes has been positively correlated with risky behaviors that are associated with sexual assault (Gruenewald, Johnson, \& Treno, 2002).

Research Question Four: Does athletic status and victimization status relate to the participants' drinking rates? In order to address Research Question 4, the statistical analyses performed on the data gathered from the Alcohol Use Items revealed that the respondents' athletic status had no significant effect on their alcohol consumption except on Saturdays. Contrastingly, the respondent's victimization status had a significant effect on their alcohol consumption. The participants were asked if they ever had an alcoholic drink, the number of days in a typical week that they drink, the number of drinks on a typical drinking occasion, the highest number of drinks on one occasion in the last 30 days, and the number of drinks consumed on average for each day of the week. Participants were provided with the definition of the standard drink to facilitate their responses. The participant responses were examined to determine group differences in participant drinking rates across athletic status and sexual victimization.

The respondents' athletic status had no significant effect on their alcohol consumption, with one exception. On Saturdays, athletes reportedly consumed more alcohol than non-athletes in this study. Based on the previous research, it was hypothesized that female college athletes would consistently consume more alcohol than the non-college athletes everyday of the week. This finding contradicts the previous research that has consistently demonstrated greater alcohol consumption by athletes (Brenner \& Swanik, 2007; Grossbard, Lee, Neighbors, Hendershot, \& Larimer, 2007; Gutgesell et al., 2003; Hummer et al., 2009; Leichliter et al., 1998; Martens, Dams-O’Connor, \& Beck, 2006; Nelson \& Wechsler, 2001; Zamboanga \& Ham, 2008). It is unclear, why the alcohol consumption of the female athletes in this study did not differ from the non-athletes on Sunday-Friday. 
A possible explanation for the difference may be that several of the prior research studies on alcohol use and athletic status utilized different methodology and did not specifically test for differences between female college students and female college athletes (Brenner \& Swanik, 2007; Grossbard, Lee, Neighbors, Hendershot, \& Larimer, 2007; Gutgesell et al., 2003; Hummer et al., 2009; Leichliter et al., 1998; Martens, Dams-O’Connor, \& Beck, 2006; Nelson \& Wechsler, 2001; Zamboanga \& Ham, 2008). For instance, several samples consisted of male and female athletes (Brenner \& Swanik, 2007; Grossbard et al., 2007; Hummer et al., 2009; Leichliter et al., 1998; Martens, Dams-O’Connor, \& Beck, 2006; Nelson \& Wechsler, 2001). The studies that included male and female athletes may be limited due to an interaction that occurs between the genders and has an effect that alters the results. Male and female athletes may modify their responses and reactions due to the responses and reactions of the other gender. None of the reviewed studies controlled for the interaction between male and female athletes in their sample. Thus, by not including male athletes in this study may have caused us to get different results than previous studies.

Another explanation for the differences may be that this study's sample was too homogenous and needed to be more diverse in ethnicity and socio-economic status. For example, both the athlete and non-athlete samples of the current study were overwhelmingly Caucasian. Other studies involving female college athletes were more diverse (i.e., ethnicity, race, age, sexual orientation) than the current study (Hummer et al., 2009; Leichliter et al., 1998). In addition, the results were only representative of students from Eastern and Midwestern colleges and universities. The lack of diversity in the sample may have contributed to the lack of difference between athletes and non-athletes on alcohol consumption. 
Recent research may explain the finding that female college athletes drank significantly more on Saturdays. Zamboanga, Rodriguez and Horton (2008) examined social connectedness among female college athletes and its effect on hazardous alcohol use. Their research study found high episodic drinking associated with team social events. Their findings revealed that team social events primarily happen on the weekends and involve elevated alcohol use and an increased likelihood of drinking game participation. The female athletes sampled in the previous study also reported that these hazardous drinking events have been associated with team cohesion. Future studies should examine the influence of high episodic drinking and social connectedness on female college athletes.

Finally, these findings denote a clear main effect for sexual victimization on alcohol consumption. In other words, victims of sexual assault drank overwhelmingly more than individual who had not experienced sexual victimization. This is consistent with the belief that the negative impact of sexual assault is severe and far-reaching. The previous research has indicated that those who experience sexual assault are likely to experience high levels of psychological distress, including the development of posttraumatic stress disorder (PTSD), depression, substance abuse, and anxiety (Boudreaux, Kilpatrick, Resnick, Best, \& Saunders, 1998; Breslau et al., 1998; Kilpatrick et al., 2003). The findings of this study revealed statistically significant differences in the frequency of alcohol consumption on sexual victimization for female athletes and non-athletes. These results indicate that the severity of the sexual victimization is influenced by the number of days spent drinking alcohol. Specifically, rape victims reported drinking on more days and consumed more alcohol on the days they drank than any of the other victimization categories. The results also indicated that sexual victimization yielded higher scores with regard to the days per week spent drinking. Therefore, 
this implies that "rape", "attempted rape", "coercion", and "unwanted sexual contract" were more likely to drink more than none victims every day except on Sundays.

These findings are of concern because most sexual assault survivors suffer one or more negative consequences of their assault and the majority of survivors do not seek treatment from mental health professionals, crisis centers, or physicians (Kimmerling \& Calhoun, 1994; New \& Berliner, 2000; Ullman, 2011). Nearly half of survivors do not seek counseling until their symptoms have become too prolonged or intense to manage (Campbell, Ahrens, Sefl, Wasco, \& Barnes, 2001; Ullman, 2011). Given the vulnerability of the survivors and the failure to receive adequate support, professionals need to be better equipped to provide educational and prevention services to these populations. The results of this study indicate that treatment providers should ask victims of sexual assault about frequency of alcohol consumption. The results of the study also point to asking substance abusers about sexual assault histories. Thus, it is essential for researchers in the field of counseling psychology to work to identify individuals who have been sexual assaulted and provide them with appropriate treatment.

\section{Limitations of the Study}

Prior to the interpretation of data, consideration should be given to the limitations of the current study in the areas of sampling, measures, underreporting, and the sampled athlete

population. A potential limitation was the convenience sample used to generalize the results to the population it was intending to represent, female college athletes and non-athletes. The representativeness of the sample may have been affected by the use of only psychology students. Also, the findings should be viewed with caution and are applicable only to the athletes and nonathletes sampled from the fifteen institutions in the Midwest and North Eastern United States. A larger sample would have been beneficial to increase the generalizability of the study. Also, the 
racial diversity of the sample was limited. The sample was overwhelmingly made up of Caucasian students. A more diverse sample would have beneficial to understand the influence of demographic characteristics on both athletes and non-athletes. Additionally, participants were also self-selected so it is possible that the effects found in the present study are underestimated (Campbell \& Stanley, 1966). Those for whom the experience of sexual assault was difficult to discuss may have chosen not to participate in the study.

The measures used in the present study also posed some possible limitations. With regard to using questionnaires and self-report as the method of data collection, subject responses could be open to question, given concerns about social desirability of responses (Dunning, Heath, \& Suls, 2004; Rosenthal \& Rosnow, 2008). The use of questionnaires to ascertain prevalence of sexual victimization has not been supported consistently in previous research. McMahon (2007) found low acknowledgement of sexual victimization utilizing questionnaires solely. Although the reliability and validity of self-reports regarding alcohol use have been supported by the literature, the scores were still considered subject to response distortion and missing answers (Wechsler et al., 2002). Another limitation was the lack of standardization of the Alcohol Use Items that was developed specifically for this study; although, it was based on several items used in the Center on Addiction and Substance Abuse (2007) report, considered a valid and reliable measure of alcohol use.

In terms of potential limitations associated with underreporting, sexual assault history and alcohol consumption are sensitive and personal areas for many college students which may have led to socially desirable responses. In other words, sexual assault prevalence and alcohol consumption may have been underreported. It has also been documented that individuals fail to disclose sexual assault experiences which compound the limitations of this study. Despite 
research efforts to ascertain the scope of rape, a large number of victims do not report their sexual victimization to police or authorities (Tjaden \& Thoennes, 2000). In 2007, the National Crime Victimization Survey (NCVS) results revealed that only $41 \%$ of rapes/sexual assaults were reported to the police (Bureau of Justice Statistics, 2008). Nondisclosure, either by purposive non-reporting (e.g., withholding relevant experience) or unintentional non-reporting (e.g., lack of recall), has been a serious obstacle to understanding the prevalence of sexual assault (Koss, 1993; Littleton et al., 2007; Skogan, 1981). According to Fasting et al. (2008) student athletes are significantly less likely to report sexual victimization during there late high school and early college years than their nonathletic counterparts.

As stated earlier, gaining access to collegiate athletes for research on sexual violence has been extremely difficult and, in part, explained the complete dearth of relevant published data. Since the number of prevalence studies of sexual victimization in athletics is so small and each study has utilized different methodologies, definitions and samples, it is very difficult to make comparisons. This study asked only about generic college sports team participation, no crosssport analysis or in-season versus out-of-season analysis was conducted. Notwithstanding these limitations, this archival dataset offers unique access to research on the prevalence, differential impact of, and risk factors for sexual assault in an understudied population of female college athletes.

\section{Implications}

This investigation provided little support for the research hypotheses and some suggestive results for future research. The archival data did not yield a greater prevalence of self-reported sexual victimization or problem drinking behaviors among female collegiate athletes as compared with a control population. Additionally, the data did not support that 
athletes consumed more alcohol, there was no interaction effect between athletic status and sexual victimization, such that athletes who had been sexually assaulted did not drink more than athletes who had not reported having been sexually assaulted. The link between sexual victimization and athletic status was not arbitrated by alcohol consumption. This means that the alcohol intake of the female college student does not tone down the connection that involves their athletic status and sexual victimization.

The findings of the study provided insights on the perceptions of female college athletes and non-athletes on rape myth acceptance, the definition of sexual consent, sexual assault histories and the relationship of participants' drinking rates with their athletic status and victimization status. None of the factors that are linked to an increased risk for experiencing sexual victimization were found among the athletes in this study. Acceptance of rape myths, definitions of sexual consent, and alcohol consumption did not vary significantly across athletic status. In fact I seem to have found the opposite of my hypotheses. The data suggests some kind of protection processes associated with or mediated through athletic participation. In fact, there may be one or more factors that protect female college athletes from exposure to sexual victimization. These findings both point to the need for further research and also suggest the need for theoretical revision.

For future research, the methodology used to examine the research questions for this study could be modified to expand our knowledge of female college athletes. For instance, a longitudinal study could be developed in which female college athletes are assessed each year on factors that place females at risk for experiencing sexual victimization. This approach would allow any trends or inconsistencies in the data to be revealed. Additionally, examining the 
prevalence of self-reported sexual victimization of female college athletes that are in-season versus out-of-season as well as replicating the same study in different geographical areas.

Other methodological changes involve gathering larger, more diverse datasets to explore these hypotheses. Although the current sample was sufficient to produce statistically valid results, it is important to increase the sample size to make sure that findings are justifiable. By expanding the sample size future studies would be able to ensure that a good representation of the population is explored. Future studies could also be more diverse and expanded to involve perceptions of male athletes and non-athletes in terms of the variables examined. It would be appropriate to explore a more diverse population that differed on factors, such as race, ethnicity, and socioeconomic status. Therefore, replication of the study with a larger heterogeneous sample is recommended to corroborate the results and strengthen the generalizability of the findings.

Theoretically, the data can also be viewed in the context of athletic participation can protect female athletes from sexual victimization through a variety of social-psychological mechanisms. These findings may reflect the presence of a supportive environment for the female athletes and/or an increased knowledge of sexual assault risk factors. To this extent, and within the context of research and theory on sexual victimization, sport might be said to protect females from some forms of sexual victimization. Some of the more recent studies have suggested that sport participation may result in fewer high-risk health behaviors, such as binge drinking, tobacco and marijuana use, sexual activity and physical inactivity (Armstrong \& Oomen-Early, 2009; Fasting et al., 2008). Armstrong and Oomen-Early (2009) found that females who play sports have higher self-worth and engage in more positive social networks than non-athletes. Fasting et al. (2008) also suggested that sport offers some protection to female 
athletes because it develops their strength, self-confidence and sense of physical adeptness, characteristics which have previously been associated with resistance and rape avoidance. These accounts suggest that sport is a source of empowerment in many girls' lives, helping them to develop a positive body image and identity and to make confident choices about relationships and sexuality. The findings of this study point to the need for further theoretical revision in future studies focusing on the protective processes associate with or mediated through athletic participation.

This study helps to illuminate the perceptions and behaviors associated with sexual victimization in an under-researched population of female athletes. So, the results from this study of college athletic participation and risk of experiencing sexual victimization point to a contradiction. We know that women athletes experience sexual victimization (McMahon, 2007) yet we also suspect that, for some women, developing an athletic identity and/or living in the social psychological context of sport may reduce their risk for sexual victimization (Fastings et al. 2008). This apparent contradiction not only opens up further empirical enquiries, but may also assist in theoretical development of ideas about some kind of protection processes associated with athletic participation. Further, understanding how sports participation mediates protective processes and sexual victimization risk reduction, it can also help to develop policy and/or harm reduction measures. Only through further research, and with a strong evidence base, will such initiatives impact successfully on female athlete safety and health. 


\section{References}

Abbey, A. (2002). Alcohol related sexual assault: A common problem among college students. Journal of Studies on Alcohol, 14, 118-128.

Abbey, A., McAuslan, P., \& Ross, L. T. (1998). Sexual assault perpetration by college men: The role of alcohol, misconception of sexual intent and sexual beliefs and experiences. Journal of Social and Clinical Psychology, 17(2), 167-195.

Abbey, A., McAuslan, P., Zawacki, T., Clinton, A. M., \& Buck, P. O. (2001). Attitudinal experiential, and situational predictors of sexual assault perpetration. Journal of Interpersonal Violence, 16(8), 784-807.

Abbey, A., Zawacki, T., Buck, P. O., Clinton, A. M., \& McAuslan, P. (2004). Sexual assault and alcohol consumption: What do we know about their relationship and what types of research are still needed? Aggression and Violent Behavior, 9, 271-303.

Ahern, N. R. (2006). Adolescent resilience: An evolutionary concept analysis. Journal of Pediatric Nursing, 21, 175-185.

Aizenman, M., \& Kelley, G. (1988). The incidence and violence of acquaintance rape in dating relationships among college men and women. Journal of College Student Development, 29(4), 305-311.

Anderson, I. (2007). What is a typical rape? Effects of victim and participant gender in female and male rape perception. British Journal of Social Psychology, 46, 225-245.

Armstrong, S. \& Oomen-Early, J. (2009). Social connectedness, self-esteem and depression symptomatology among collegiate athletes vs. non athletes. Journal of American College Health, 57(5), 521-526. 
Arnett, J. J. (2000). Emerging adulthood: A theory of development from late teens through the twenties. American Psychologist, 55, 469-480.

Arnett, J. J. (2004). Adolescence in the $21^{\text {st }}$ century: A worldwide survey. In U. P. Gielen Roopnarine (Ed.), Childhood and adolescence in cross-cultural perspective (pp. 277294). New York: Guilford.

Arnett, J. J. (2006). Emerging adulthood: Understanding the new way of coming of age. In J. J. Arnett \& J. L. Tanner (Eds.), Emerging adults in America: Coming of age in the $21^{\text {st }}$ century, (pp. 3-20). Washington, DC: American Psychological Association Press.

Arnett, J. J. (2007). Adolescence and emerging adulthood: A cultural approach ( $\left.3^{\text {rd }} \mathrm{ed}.\right)$. New Jersey: Prentice Hall.

Avegno, J., Mills, T. J., \& Mills, L. D. (2009). Sexual assault victims in the emergency department: analysis by demographic and event characteristics. Journal of Emergency Medicine, 37(3), 328-334.

Bachman, R. (1998). The factors related to rape reporting behavior and arrest: New evidence from the national crime survey. Criminal Justice and Behavior, 25, 8-29.

Bartlett, M. S. (1954). "A note on multiplying factors for various $\chi^{2}$ approximations". Journal of Royal Statistics, 16, 296-298.

Basow, S. A, Cahill, K. F., Phelan, J. E., Longshore, K., \& McGillicuddy-DeLisi, A. (2007). Perceptions of relational and physical aggression among college students: Effects of gender of perpetrator, target, and perceiver. Psychology of Women Quarterly, 31, 85-95.

Berkowitz, A. D. (1992). College men as perpetrators of acquaintance rape and sexual assault: A review of recent research. Journal of American College Health, 40(4), 175-181. 
Berkowitz, A. D., \& Perkins, H. W. (1987). Recent research on gender differences in collegiate alcohol use. Journal of American College Health, 36, 123-129.

Blum, R. W., McNeely, C., \& Nonnemaker, J. (2002). Vulnerability, risk, and protection. Journal of Adolescent Health, 31, 28-39.

Boeringer, S. B. (1999). Associations of rape-supportive attitudes with fraternal and athletic participation. Violence Against Women, 5, 81-90.

Borges, A. M., Banyard, V. L., \& Moynihan, M. M. (2008). Clarifying consent: Primary prevention of sexual assault on a college campus. Journal of Prevention \& Intervention in the Community, 36, 75-88.

Boudreaux, E., Kilpatrick, D. G., Resnick, H. S., Best, C. L., \& Saunders, B. E. (1998). Criminal victimization, posttraumatic stress disorder and comorbid psychopathology among a community sample of women. Journal of Traumatic Stress, 11, 665-678.

Brecklin, L. R., \& Ullman, S. E. (2002). The roles of victim and offender alcohol use in sexual assaults: Results from the National Violence Against Women Survey. Journal of Studies on Alcohol, 63, 57-63.

Brener, N. D., McMahon, P. M., Warren, C. W., \& Douglas, K. A. (1999). Forced sexual intercourse and associated health-risk behaviors among female college students in the United States. Journal of Consulting and Clinical Psychology, 67, 252-259.

Brennan, A. F., Walfish, S., \& AuBuchon, P. (1986). Alcohol use and abuse in college students: A review of individual and personality correlates. International Journal of the Addictions, 21, 449-474.

Brenner, J., \& Swanik, K. (2007). High-risk drinking characteristics in collegiate athletes. Journal of American College Health, 56(3), 267-272. 
Breslau, N., Kessler, R. C., Chilcoat, H. D., Schultz, L. R., Davis, G. C., \& Andreski, P. (1998). Trauma and posttraumatic stress disorder in the community: The 1996 Detroit Area Survey of Trauma. Archives of General Psychiatry, 55, 626-632.

Bureau of Justice Statistics (2008). Criminal Victimization in the United States, 2007. National Crime Victimization Survey (NCVS), NCJ 224390. Washington, DC: U.S. Department of Justice.

Burt, M. R. (1980). Cultural myths and supports for rape. Journal of Personality and Social Psychology, 38(2), 217-230.

Burt, M. R. (1991). Rape myths and acquaintance rape. In A. Parrot \& L. Bechhofer (Eds.), Acquaintance rape: The hidden crime (pp. 26-40). New York: John Wiley \& Sons, Inc.

Byers, S. E. \& Heinlein, L. (1989). Predicting initiations and refusals of sexual activities in married and cohabiting heterosexual couples. Journal of Sex Research, 26, 210-231.

Campbell, R., Ahrens, C. E., Sefl, T., Wasco, S. M., \& Barnes, H. E. (2001). Social reactions to rape victims: Healing and hurtful effects on psychological and physical health outcomes. Violence \& Victims, 16, 287-302.

Campbell, D. T. \& Stanley, J. C. (1966). Experimental and quasi-experimental designs for research. Chicago: Rand McNally.

Cass, A. I. (2007). Routine activities and sexual assault: An analysis of individual and school level factors. Violence and Victims, 22(3), 350-366.

Cicchetti, D. V. (1994). Guidelines, criteria, and rules of thumb for evaluating normed and standardized assessment instruments in psychology. Psychological Assessment, 6(4), 284-290. 
Cohen, J. (1988). Statistical power analysis for the behavioral sciences (2nd ed.). Hillsdale, NJ: Erlbaum.

Cooper, M. L. (2002). Alcohol use and risky sexual behavior among college students and youth: Evaluating the evidence. Journal of Studies on Alcohol Supplement, 14, 101-117.

Davis, J. L., Combs-Lane, A. M., \& Jackson, T. L. (2002). Risky behaviors associated with interpersonal victimization: comparisons based on type, number, and characteristics of assault incidents. Journal of Interpersonal Violence, 17, 611- 629.

Desrichard, O., \& Denarie, V. (2005). Sensation seeking and negative affectivity as predictors of risky behaviors: A distinction between occasional and frequent risk-taking. Addictive Behaviors, 30(7), 1449-1453.

Donovan, C., \& McEwan, R. (1995). A review of the literature examining the relationship between alcohol use and HIV-related sexual risk-taking in young people. Addiction, 90, 319-328.

Douglas, K. A., Collins, J. L., \& Warren C. (1997). Results from the 1995 National College Health Risk Behavior Survey. Journal of American College Health, 46(5), 55-66.

Duangpatra, K., Bradley, G. L., \& Glendon, A. I. (2009). Variables affecting emerging adults' self-reported risk and reckless behaviors. Journal of Applied Developmental Psychology, 30, 298-309.

Dunning, D., Heath, C., \& Suls, J. M. (2004). Flawed self-assessment: Implications for health, education and the workplace. Psychological Science in the Public Interest, 5 (3), 69-106.

Edmonds, E. M., \& Cahoon, D. D. (1986). Attitudes concerning crimes related to clothing worn by the female victims. Bulletin of the Psychometric Society, 24(6), 444-446. 
Fallon, M. A., \& Jome, L. M. (2007). An exploration of gender-role expectations and conflict among women rugby players. Psychology of Women Quarterly, 31, 311-321.

Fasting, K., Brackenridge, C. H., Miller, K. E. \& Sabo, D. (2008) „Participation in college sports and protection from sexual victimization', International Journal of Sport and Exercise Psychology, Special Issue: Abuse and Harassment in Sport Implications for the Sport Psychology Profession (Edited by T. Leahy), 16(4), 1-33.

Faurie, C., Pontier, D., \& Raymond, M. (2004). Student athletes claim to have more sexual partners than other students. Evolution and Human Behavior, 25, 1-8.

Fisher, B. S., Cullen, F. T., \& Turner, M. G. (2000). The Sexual Victimization of College Women (NCJ 182369). United States Department of Justice. Washington, DC: U.S. Government Printing Office.

Flack, W. F., Daubman, K. A., Caron, M. L., Asadorian, J. A., D’Aureli, N. R., Gigliotti, S. N., Hall, A. T., Kisner, S., \& Stine, E. R. (2007). Risk factors and consequences of unwanted sex among university students: Hooking up, alcohol, and stress response. Journal of Interpersonal Violence, 22, 139-157.

Frazier, P., \& Borgida, E. (1988). Jurors common understanding and the admissibility of rape trauma syndrome evidence in court. Law and Human Behavior, 12, 101-122.

Gage, E. A. (2009). Gender attitudes and sexual behaviors. Violence Against Women, 14(9). 1014-1032.

Gartner, R., \& Macmillan, R. (1995). The effect of victim-offender relationship on reporting crimes of violence against women. Canadian Journal of Criminology, 37, 393-429. 
George, L. K., Winfield, I., \& Blazer, D. G. (1992). Sociocultural factors in sexual assault: Comparison of two representative samples of women. Journal of Social Issues, 48, 105125.

Gidycz, C. A., Orchowski, L. M., King, C. R., \& Rich, C. L. (2008). Sexual victimization and health-risk behaviors: A prospective analysis of college women. Journal of Interpersonal Violence, 23, 744-763.

Grossbard, J. R., Lee, C. M., Neighbors, C., Hendershot, C. S., \& Larimer, M. E. (2007). Alcohol and risky sex in athletes and non-athletes: What roles do sex motives play? Journal of Studies on Alcohol and Drugs, 68(4), 566-574.

Gutgesell, M., Moreau, K. L., \& Thompson, D. L. (2003). Weight concerns, problem eating behaviors, and problem drinking behaviors in female collegiate athletes. Journal of Athletic Training, 38, 62-66.

Hall, D. S. (1995). Consent for sexual behavior in a college student population. Unpublished doctoral dissertation, The Institute for Advanced Study of Human Sexuality, San Francisco, CA.

Hamilton, S. F., \& Hamilton, M. A. (2009). The transition to adulthood. In R. M. Lerner \& L. Steinberg (Eds.), Handbook of adolescent psychology ( $3^{\text {rd }}$ ed., pp. 492- 526). Hoboken, NJ: John Wiley \& Sons.

Hickman, S. E., \& Muehlenhard, C. L. (1997). College women's fears and precautionary behaviors relating to acquaintance rape and stranger rape. Psychology of Women Quarterly, 21, 527-547. 
Hildebrand, K. M., Johnson, D. J., \& Bogle, K. (2001). Comparison of patterns of tobacco use between high school and college athletes and non-athletes. American Journal of Health Education, 32, 75-80.

Hingson, R., Heeren, T., Winter, M., \& Wechsler, H. (2005). Magnitude of alcohol-related mortality and morbidity among U.S. college students ages 18-24: Changes from 1998 to 2001. Annual Review of Public Health, 26, 259-279.

Hindmarch, I., ElSohly, M., Gambles, J., \& Salamone, S. (2001). Forensic urinalysis of drug use in cases of alleged sexual assault. Journal of Clinical Forensic Medicine, 8(4), 197-205.

Hinogosa, R. (2010). Doing hegemony: Military, men, and constructing a hegemonic masculinity. The Journal of Men's Studies, 18(2), 179-194.

Howard, D. E., Griffen, M. A., \& Boekeloo, B. O. (2008). Prevalence and psychosocial correlates of alcohol-related sexual assault among university students. Adolescence, 43(172), 733-750.

Huang, J. H., DeJong, W., Schneider, S. K., \& Towvim, L. G. (2006). Measuring college student drinking: Illustrating the feasibility of a composite drinking scale. Substance Abuse, 27, 33-45.

Huang, J. H., Jacobs, D. F., \& Derevensky, J. L. (2010). Sexual risk-taking behaviors, gambling, and heavy drinking among U.S. college athletes. Archives of Sexual Behavior, 39(3), 706-713.

Hummer, J. F., LaBrie, J. W., \& Lac, A. (2009). The prognostic power of normative influence among NCAA student-athletes. Addictive Behaviors, 34, 573-580.

Humphreys, T. P. (2007). Perceptions of sexual consent: The impact of relationship, history and gender. Journal of Sex Research, 44(4), 307-315. 
Humphreys, T. P. (2004). Understanding sexual consent: An empirical investigation of the normative script for young heterosexual adults. In M. Cowling \& P. Reynolds (Eds.), Making sense of sexual consent. Aldershot, UK: Ashgate.

Jessor, R. (1991). Risk behavior in adolescence: A psychosocial framework for understanding and action. Journal of Adolescent Health, 12, 597-605.

Jones, C. (2010). Archival data: Advantages and disadvantages for research in psychology. Social and Personality Psychology Compass, 4(11), 1008-1017.

Kahn, A. S., Jackson, J., Kully, C., Badger, K., \& Halvorsen, J. (2003). Calling it rape: Differences in experiences of women who do or do not label their sexual assault as rape. Psychology of Women Quarterly, 18, 53-66.

Kalichman, S. C., \& Cain, D. (2004). A prospective study of sensation seeking and alcohol use as predictors of sexual risk behaviors among men and women receiving sexually transmitted infection clinic services. Psychology of Addictive Behavior, 18, 367-373.

Kilpatrick, D.G., Edmunds, C., \& Seymour, A. (1992). Rape in America: A report to the nation. Charleston, SC: National Victim Center \& the Crime Victims Research and Treatment Center, Medical University of South Carolina.

Kilpatrick, D. G., Ruggiero, K. J., Acierno, R. E., Saunders, B. E., Resnick, H. S., \& Best, C. L. (2003). Violence and risk of PTSD, major depression, substance abuse/dependence, and comorbidity: Results from the National Survey of Adolescents. Journal of Consulting and Clinical Psychology, 71, 692-700.

Kilpatrick, D. G., Saunders, B. E., Veronen, L. J., Best, C. L., \& Von, J. M. (1987). Criminal victimization: Lifetime prevalence, reporting to police, and psychological impact. Crime and Delinquency, 33, 479-489. 
Kilpatrick, D. G., Veronen, L. J., \& Best, C. L. (1984). Factors predicting psychological distress in rape victims. In C. Figley (Ed), Trauma and its wake. New York: Brunner/Mazel.

Kimble, M., Neacsiu, A. D., Flack, W. F., \& Horner, J. (2008). Risk of unwanted sex for college women: Evidence for a red zone. Journal of American College Health, 57(3), 331-337.

Kimmerling, R., \& Calhoun, K. S. (1994). Somatic symptoms, social support, and treatment seeking among sexual assault victims. Journal of Consulting and Clinical Psychology, $62,333-340$.

Koss, M. P. (1992). The underdetection of rape: A critical assessment of incidence data. Journal of Social Issues, 48, 61-76.

Koss, M. P. (1993). Detecting the scope of rape: A review of prevalence research methods. Journal of Interpersonal Violence, 8, 198-222.

Koss, M. P., \& Dinero, T. E. (1989). Discriminant analysis of risk factors for sexual victimization among a national sample of college women. Journal of Consulting and Clinical Psychology, 57, 242-250.

Koss, M. P., \& Gidycz, C. A. (1985). Sexual experiences survey: Reliability and validity. Journal of Consulting and Clinical Psychology, 53, 422-423.

Koss, M. P., Gidycz, C. J., \& Wisniewski, N. (1987). The scope of rape: Incidence and prevalence of sexual aggression and victimization in a national sample of higher education student. Journal of Consulting and Clinical Psychology, 55, 162-170.

Koss, M. P., Gidycz, C. A., \& Wisniewski, N. (1989). The scope of rape: Incidence and prevalence of sexual aggression and victimization among a national sample of college women. Journal of Consulting \& Clinical Psychology, 57, 242-250. 
Koss, M. P., Leonard, K. E., Beezley, D. A., Oros, C. J. (1985). Non-stranger sexual aggression: A discriminant analysis of the psychological characteristics of undetected offenders. Sex Roles, 12, 981-992.

Koss, M. P., \& Oros, C. J. (1982). Sexual experiences survey: A research instrument investigating sexual aggression and victimization. Journal of Consulting and Clinical Psychology, 50, 455-457.

Koss, M. P., Woodruff, W. J., \& Koss, P. G. (1991). Deleterious effects of criminal victimization on women's health and medical utilization. Archives of Internal Medicine, 151, 342-347.

LaPlante, M. N., McCormick, N., \& Brannigan, G. G. (1980). Living the sexual script: College students' views of influence in sexual encounters. Journal of Sex Research, 16, 338-355.

Lefkowitz, E. S., \& Gillen, M. M. (2006). "Sex is just a normal part of life": Sexuality in emerging adulthood. In J. J. Arnett \& J. L. Tanner (Eds.), Emerging adults in America: Coming of age in the $21^{\text {st }}$ century, (pp. 235-256). Washington, DC: American Psychological Association Press.

Lim, G. Y. \& Roloff, M. E. (1999). Attributing sexual consent. Journal of Applied Communication Research, 27, 1-23.

Letendre, J. (2007). "Sugar and spice but not always nice": Gender socialization and its impact on development and maintenance of aggression in adolescent girls. Child and Adolescent Social Work Journal, 24(4), 353-368.

Littleton, H. L., \& Radecki Breitkoph, C. (2006). Coping with the experience of rape. Psychology of Women Quarterly, 30, 106-116. 
Littleton, H., Radecki Breitkopf, C., \& Berenson, A. (2007). Sexual and physical abuse history and adult sexual risk behaviors: Relationships among women and potential mediators. Child Abuse \& Neglect, 31, 757-768.

Leichliter, J. S., Meilman, P. W., Presley, C. A., \& Cashin, J. R. (1998). Alcohol use and related consequences among college students with varying levels of involvement in college athletics. Journal of American College Health, 46(1), 257-262.

Lonsway, K. A., \& Fitzgerald, L. F. (1994). Rape myths: In review. Psychology of Women Quarterly, 18, 133-164.

Martens, M. P., Dams-O'Connor, K., \& Beck, N. C. (2006). A systematic review of college student-athlete drinking: Prevalence rates, sport-related factors, and interventions. Journal of Substance Abuse Treatment, 31(3), 305-316.

Martens, M. P., Dams-O’Connor, K., \& Kilmer, J. (2007). Alcohol and drug abuse among athletes: Prevalence, etiology, and interventions. In G. Tenenbaum \& R. C. Eklund (Eds.), Handbook of Sport and Exercise Psychology ( $3^{\text {rd }}$ Edition), (pp. 859-878). Hoboken, NJ: John Wiley \& Sons.

Martin, M. (1998). The use of alcohol among NCAA Division I female college basketball, softball and volleyball athletes. Journal of Athletic Training, 33(2), 163-167.

Mays, D., Thompson, N., Kushner, H. I., Mays, D. F., Farmer, D., \& Windle, M. (2010). Sportspecific factors, perceived peer drinking, and alcohol related behaviors among adolescents participating in school-based sports in Southwest Georgia. Addictive Behaviors, 35(3), 235-241.

McMahon, S. (2007). Understanding community specific rape myths: Exploring student athlete culture. Journal of Women and Social Work, 22(4), 357-370. 
Meadows, E. A., Jaycox L. H., Webb S., \& Foa E. B. (1996). Proceedings from the Use of Narrative Methodologies to Explore Cognitive and Emotional Dimensions Among Women with Posttraumatic Stress Disorder Symposium: The 30th Annual Meeting of the Association for Advancement of Behavior Therapy. New York.

Michaud, P. (2006). Adolescents and risks: Why not change our paradigm? Journal of Adolescent Health, 38, 481-483.

Miller, K. E., Melnick, M. J., Barnes, G. M., Sabo, D., \& Farrell, M. P. (2007). Athletic involvement and adolescent delinquency. Journal of Youth Adolescence, 36, 711-723.

Mohler-Kou, M., Dowdall, G. W., Koss, M. P., \& Wechsler, H. (2004). Correlates of rape while intoxicated in a national sample of college women. Journal of Studies of Alcohol, 65(1), $37-45$.

Muehlenhard, C.L., \& Linton, M.A. (1987). Date rape and sexual aggression in dating situations: Incidence of risk factors. Journal of Counseling Psychology, 34, 186-196.

Muehlenhard, C. L., Powch, I. G., Phelps, J. L., \& Giusti, L. M. (1992). Definitions of rape: Scientific and political implications. Journal of Social Issues, 48, 23-44.

Nattiv, A., \& Puffer, J. C. (1991). Lifestyles and health risks of college athletes. Journal of Family Practice, 33, 585-590.

Nattiv, A., Puffer, J., \& Green, G. S. (1997). Lifestyles and health risks of collegiate athletes: A multi-center study. Clinical Journal of Sports Medicine, 7, 262-272.

Negrusz, A., \& Gaensslen, R. (2003). Analytical developments in toxicological investigation of drug facilitated sexual assault. Analytical and Bianalytical Chemistry, 376(8), 11921197. 
Nelson, T. F., \& Wechsler, H. (2001). Alcohol and college athletes. Medicine and Science in Sport and Exercise, 33(1), 43-47.

New, M., \& Berliner, L. (2000). Mental health service utilization by victims of crime. Journal of Traumatic Stress, 13, 693-708.

NIH/National Institute on Alcohol Abuse and Alcoholism (NIAAA). (2007, December 6). Gene that influences alcohol consumption identified. Science Daily. Retrieved February 12, 2010, from http://www.sciencedaily.com/releases/2007/12/071205153142.htm.

Nolen-Hoeksema, S. (2004). Gender differences in risk factors and consequences for alcohol use and problems. Clinical Psychology Review, 24, 981-1010.

Norris, J., Nurius, P. S., \& Graham, T. L. (1999). When a date changes from too dangerous: Factors affecting women's ability to distinguish. Violence Against Women, 5(3), 230250.

Nunnally, J. C. (1978). Psychometric theory. New York: McGraw-Hill.

Nurius, P. S. (2000). Risk perception for acquaintance sexual aggression: A social-cognitive perspective. Aggression and Violent Behaviors, 5(1), 63-78.

O’Byrne, R., Hansen, S., \& Rapley, M. (2008). “If a girl doesn’t say „no’...”: Young men, rape and claims of ,insufficient knowledge'. Journal of Community \& Applied Social Psychology, 18, 168-193.

Parrot, A., Cummings, N., Marchell, T. C., \& Hofher, J. (1994). A rape awareness and prevention model for athletes. College Health, 42, 179-184.

Parrot, D. J., \& Gallagher, K. E. (2008). What accounts for heterosexual women's negative emotional responses to lesbians? Examination of traditional gender role beliefs and sexual prejudice. Sex Roles, 59, 229-239. 
Payne, D. L., Lonsway, K. A., \& Fitzgerald, L. F. (1999). Rape myth acceptance: Exploration of its structure and its measurement using the Illinois Rape Myth Acceptance Scale. Journal of Research in Personality, 33, 27-68.

Payne-James, J., \& Rogers, D. (2002). Drug-facilitated sexual assault, ,ladettes' and alcohol. Journal of the Royal Society of Medicine, 95, 326-327.

Petrak, J., \& Hedge, B. (2002). The trauma of sexual assault: Treatment, prevention, and practice. New York: John Wiley \& Sons.

Pope, E., \& Shouldice, M. (2001). Drugs and sexual assault: A review. Trauma, Violence, \& Abuse, 2(1), 51-55.

Pritchard, M. E., Milligan, B., Elgin, J., Rush, P., \& Shea, M. (2007). Comparisons of risky health behaviors between male and female college athletes and non-athletes. Athletic Insight, 9(1), 67-78.

Prochaska, J. O., Velicer, W. F., Rossi, J. S., Goldstein, M. G., Marcus, B., Rakowski, W., Fiore, C., Harlow, L. L., Redding, C. A., Rosenbloom, D., \& Rossi, S. R. (1994). Stages of change and decisional balance for 12 problem behaviors. Health Psychology, 13, 39-46.

Reidy, D. E., Shirk, S. D., Sloan, C. A., \& Zeichner, A. (2009). Men who aggress against women: Effects of feminine gender role violation on physical aggression in hypermasculine men. Psychology of Men \& Masculinity, 10, 1-12.

Reifman, A., Arnett, J. J., \& Colwell, M. J. (2007). Emerging adulthood: Theory, assessment, and application, Journal of Youth Development, 2(1), 45-52.

Reilly, M. E., Lott, B., Caldwell, D., \& Deluca, L. (1992). Tolerance for sexual harassment related to self-reported sexual victimization. Gender and Society, 6, 122-138. 
Rennison, C. M. (1999). Criminal victimization 1998: Changes 1997-98 with trends 1993-98 (NCJ 176353). Washington, D. C.: Government Printing Office.

Rew, L., \& Horner, S. D. (2003). Youth resilience framework for reducing health-risk behaviors in adolescents. Journal of Nursing Scholarship, 33, 33-40.

Rich, C. L., Combs-Lane, A. M., Resnick, H., \& Kilpatrick, D. G. (2004). Child sexual abuse and adult sexual revictimization. In L. J. Koenig, L. S. Doll, A. O’Leary, \& W. Pequegnat (Eds.), From child sexual abuse to adult sexual risk trauma, revictimization, and intervention (pp. 269-295). Washington, DC: American Psychological Association.

Richardson, D. S., \& Hammock, G. S. (2007). Social context of human aggression: are we paying too much attention to gender? Aggression and Violent Behavior, 12, 417-426.

Rosenthal, R., \& Rosnow, R. L. (2008). Essentials of Behavioral Research ( ${ }^{\text {rd }}$ Edition). Boston, MA: Mc-Graw Hill.

Saltz, R., \& Elandt, D. (1986). College student drinking studies 1976-1985. Contemporary Drug Problems, 13, 117-159.

Sampson, R. (2006). Acquaintance rape of college students. (Problem oriented guides for police, no 17). Washington, DC: U.S. Department of Justice, Office of Community Oriented Policing Services. Retrieved July 30, 2009, from http:// www.cops.usdoj.gov/html/cd\%5from/inactionl/pubs/AcquaintanceRapeCollegeStudents. pdf

Sawyer, R. G., Pinciaro, P. J., \& Jessell, J. K. (1998). Effects of coercion and verbal consent on university students' perceptions of date rape. American Journal of Health Behavior, $22(1), 46-53$ 
Sawyer, R. G., Thompson, E., \& Chicorelli, A. M. (2002). Rape myth acceptance among intercollegiate student athletes: A preliminary examination. American Journal of Health Studies, 18(1), 19-25.

Schulenberg, J., \& Zarrett, N. R. (2006). Mental health during emerging adulthood: Continuity and discontinuity in courses, causes, and functions. In J. J. Arnett \& J. L. Tanner (Eds.), Emerging adults in America: Coming of age in the $21^{\text {st }}$ century, (pp. 85-116). Washington, DC: American Psychological Association Press.

Schwartz, M. D., \& Leggett, M. S. (1999). Bad dates or emotional trauma? The aftermath of campus sexual assault. Violence Against Women, 5, 251-271.

Schwartz, R., Milteer, R., \& LeBeau, M. (2000). Drug-facilitated sexual assault (,date rape'). Southern Medical Journal, 93(6), 558-561.

Sher, K. J., \& Rutledge, P. C. (2007). Heavy drinking across the transition to college: Predicting first-semester heavy drinking from precollege variables. Addictive Behaviors, 32, 819835.

Simons J. S., Maisto, S. A., \& Wray, T. B. (2010). Sexual risk taking among young adult dual alcohol and marijuana users. Addictive Behaviors, 35(5), 5-33-536.

Skogan, W. (1981). Issues in the Measurement of Victimization (U. S. Department of Justice). Washington, D. C.: U. S. Government Printing Office.

Sloan, J. J., Fisher, B. S., \& Cullen, F. T. (1997). Assessing the student right-to-know and Campus Security Act of 1990: An analysis of the victim reporting practices of college and university students. Crime and Delinquency, 43, 148-168.

Sochting, I., Fairbrother, N., \& Koch, W. (2004). Sexual assault of women: Prevention efforts and risk factors. Violence Against Women, 10, 73-93. 
Sorenson, S. B., \& Siegel J. M. (1992), Gender, ethnicity, and sexual assault: findings from a Los Angeles study. Journal of Social Issues, 48(1), 93-104.

Stalker, K. (2003). Managing risk and uncertainty in social work: A literature review. Journal of Social Work, 3, 211-233.

Steptoe, A., \& Wardle, J. (2001). Health behavior, risk awareness, and emotional well-being in students from Europe and Western Europe. Social Science and Medicine, 53, 1621-1630.

Straus, R., \& Bacon, S. D. (1953). Drinking in college. New Haven, CT: Yale University Press. Syzmanski, L. A., Devlin, A. S., Chisler, J. C., \& Vyse, S. A. (1993). Gender role and attitudes toward rape in male and female college students. Sex Roles, 29, 37-57.

Tanner, J. L. (2006). Recentering during emerging adulthood: A critical turning point in life span human development. In J. J. Arnett \& J. L. Tanner (Eds.), Emerging adults in America: Coming of age in the $21^{\text {st }}$ century, (pp. 21-56). Washington, DC: American Psychological Association Press.

Testa, M. (2002). The impact of men's alcohol consumption on perpetration of sexual aggression. Clinical Psychology Review, 22, 1239-1263.

Testa, M., \& Parks, K. A. (1996). The role of women's alcohol consumption in sexual victimization. Aggression and Violent Behavior, 1, 217-234.

The National Center on Addiction and Substance Abuse (CASA) at Columbia University. (2007). CASA analysis of data obtained from the Campus Security Data Analysis Cutting Tool website provided by the U.S. Department of Education, Office of Postsecondary Education. Retrieved from: http://ope.ed.gov/security/. 
Tjaden, P., \& Thoennes, N. (2000). Full report of the prevalence, incidence, and consequences of violence against women: findings from the national violence against women survey. Washington, DC: National Institute of Justice.

Turchik, J. A., Probst, D. R., Irvin, C. R., Chau, M., \& Gidycz, C. A. (2009). Prediction of sexual assault experiences in college women based on rape scripts: A prospective analysis. Journal of Consulting and Clinical Psychology, 77(2), 361-366.

Ullman, S. E., (2003). A critical review of field studies on the link of alcohol and adult sexual assault in women. Aggression and Violent Behavior, 8, 471-486.

Ullman, S. E., (2011). Longitudinal tracking methods in a study of adult women sexual assault survivors. Violence Against Women, 17(2), 189-200.

US CODE: TITLE 18, CHAPTER 109A SEXUAL ABUSE § 2243 (1994).

Wechler, H., Davenport, A. E., Dowdall, G. W., Grossman, S. J., \& Zanakos, M. (1997). Binge drinking, tobacco, and illicit drug use and involvement in college athletics: A survey of students at 140 American colleges. Journal of American College Health, 45(5), 195-200.

Wechsler, H. \& Lee, J. E., Kou, M., \& Lee, H. (2000). College binge drinking in the 1990's: A continuing problem. Journal of American College Health, 48, 199.

Wechsler, H., Lee, J. E., Nelson, T. F., \& Kou, M. (2002). Underage college students’ drinking behavior, access to alcohol, and the influence of deterrence policies: Findings from the Harvard School of Public Health College Alcohol Study. Journal of American College Health, 50(5), 223-236.

Weinhardt, L. S., \& Carey, M. P. (2000). Does alcohol lead to sexual risk behavior? Findings from event-level research. Annual Reserve of Sex Research, 11, 125-157. 
Wetherill, R. R., \& Fromme, K. (2007). Alcohol use, sexual activity, and perceived risk in high school athletes and non-athletes. Journal of Adolescent Health, 41(3), 294-301.

Winfield, I., George, L. K., Swartz, M., \& Blazer, D. G. (1990). Sexual assault and psychiatric disorders among a community sample of women. American Journal of Psychiatry 147, $335-341$.

Yusko, D. Y., Buckman, J. F., White, H. R., \& Pandina, R. J. (2008). Alcohol, tobacco, illicit drug and performance enhancers: A comparison of use by college student athletes and non-athletes. Journal of American College Health, 57, 281-290.

Zamboanga, B. L., \& Ham, L. S. (2008). Alcohol expectancies and context-specific drinking behaviors among female college athletes. Behavior Therapy, 39, 162-170.

Zamboanga B. L., Rodriguez, L., \& Horton, N. J. (2008). Athletic involvement and its relevance to hazardous alcohol use and drinking game participation in female college athletes: A preliminary investigation. Journal of American College Health, 56(6), 651-656. 


\section{APPENDIX A: IRB PROTOCOL APPROVAL FOR DR. WARD'S DATA COLLECTION}

\section{-1P MIAMI EI UNIVERSITY}

Date: December 7, 2007

To: Dr. Rose Marie Ward, Kinesiology \& Health

From: Dr, Leonard S. Mark, Chai _ Institutional Review Board for Human Subjects Research

Re: Human Subjects Project: Sexual Assault and Alpha Persona
THE GRADUATE SCHOOL ARD THE GRADUATE SCHO OF RESEARCH AND SCHOLARSHIP

ROUDEUSU HAR. ROOM 102 OXFORD, OHIO $45056-3653$

(513) $520-4125$

(513) $529-3734$

(513) $529-3762$ FAX

Your proposed revisions / modifications to the above-referenced protocol was reviewed and approved by the Institutional Review Board for Human Subjects Research.

Your proposal approval number is: $07-128$

Approval of this project is in effect until: November 1, 2008

Should you decide to change your procedures relating to the use of human subjects in the above project, you must obtain approval from the Committee prior to instituting any changes.

Miami University policy requires periodic review of human subjects research for all ongoing projects. If your project will continue beyond the approval date mentioned above, you will need to submit an Application for Continuing Review so that the committee may review your application in a timely fashion.

Please submit your next application for continuing review by: Oetober 1, 2008

On behalf of the committee and the University, I thank you for your efforts to conduct your research in compliance with the federal regulation that have been established for the protection of human subjects. Thank you for your attention to this matter, and best wishes for the success of your project. 


\section{APPENDIX B: WEST VIRGINIA UNIVERISTY (IRB) PROTOCOL APPROVAL}

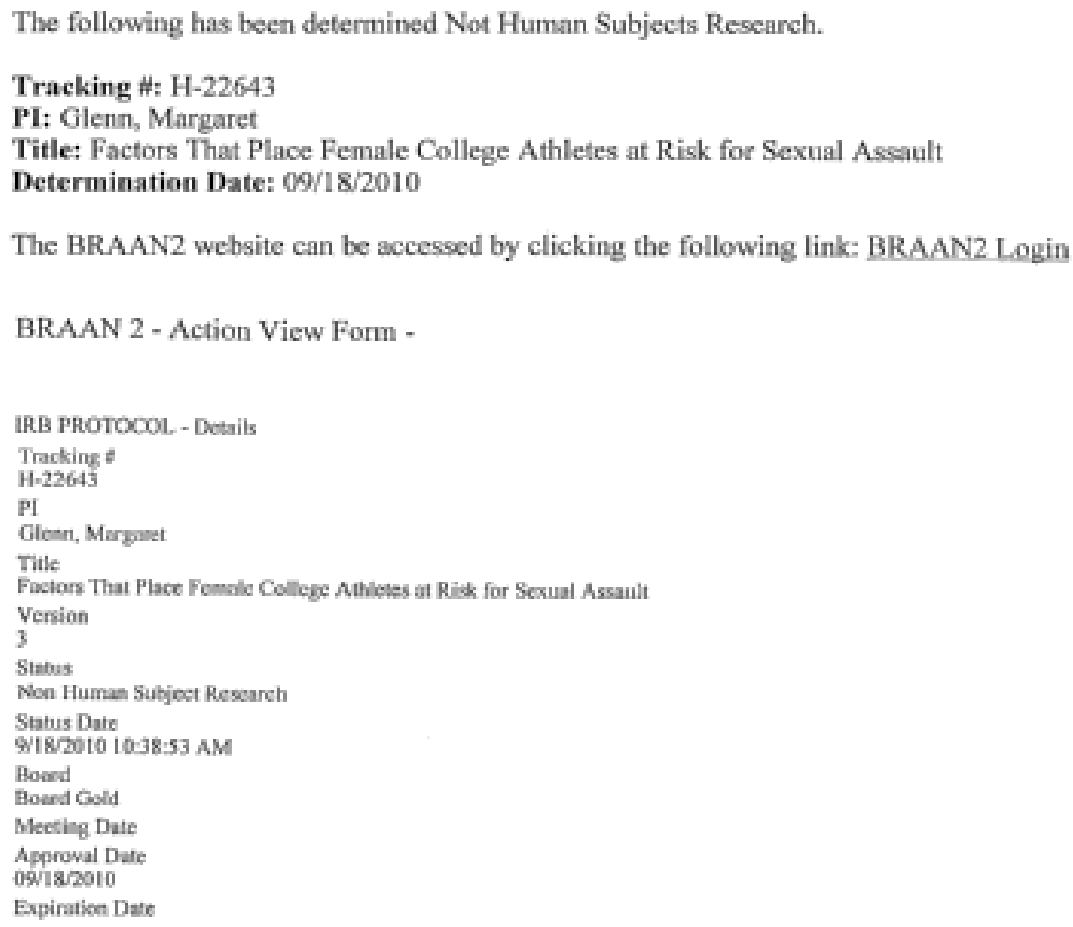




\section{APPENDIX C: INFORMED CONSENT FOR ARCHIVAL DATA}

\section{Dear Participant:}

You have been asked to take part in the research project described below. If you have any questions, please feel free to call Dr. Rose Marie Ward, the person mainly responsible for the study. The purpose of the study is to gather information from students about issues of alcohol and sexual assault. Although every effort will be done to ensure confidentiality of your responses, all Internet-based communication is subject to the remote likelihood of tampering from an outside source. IP addresses will not be investigated and data will be removed from the server.

1. YOU MUST BE AT LEAST 18 YEARS OLD to be in this research project.

2. If you decide to take part in this study, your participation will involve filling out a survey pertaining to attitudes towards different aspects of dating. The survey will ask you questions about your attitudes and knowledge concerning sexual assault. Some questions will ask about your behaviors, specifically your sexual and alcohol use history. The survey will take approximately 45-60 minutes to complete.

3. The possible risks or discomforts of the study are minimal, although you may feel some embarrassment answering some of the questions about private matters. Participants might find that some of the questions that are sexual in nature might make them feel uncomfortable. If you or someone you know has had a sexual assault experience, you may experience some psychological discomfort. In addition, some of the questions ask you to admit to potentially incriminating behavior. Resources are provided at the conclusion of this consent form. Previous participants have reported learning a lot about their relationships from reading these questions.

4. Although there are no direct benefits of the study, your answers may increase your awareness of issues that arise in the dating situation. Your answers will serve as a basis for understanding the college student sexual assault in the literature.

5. Alternative Treatments. There are no alternative treatments for the current study.

6. Your part in the study is confidential. That means your answers to all questions are private. No one else can find out what your answers are. Scientific reports will be based on group data and will not identify you or any individual as being in this project.

7. The decision to participate in this research is up to you. You do not have to participate and you can refuse to answer any question.

8. Participation in this study is not expected to be harmful or injurious to you. However, if this study causes you any injury, you should write or call Dr. Rose Marie Ward at (513) 529-9355.

If you have questions about the study, you can contact the investigator, Dr. Rose Marie Ward, 513-529-9355 or wardrm1@muohio.edu.

If you have any questions or concerns about your rights as a subject, you may contact Miami University's Office for the Advancement of Research and Scholarship, (513) 529-3600 or humansubjects@muohio.edu.

You are at least 18 years old. You have read the consent form and your questions have been answered to your satisfaction. Your filling out the survey implies your consent to participate in this study.

If these questions are upsetting and you want to talk, please use the phone numbers below:

RESOURCES WERE TAILORED TO EACH SCHOOL

Miami University Student Counseling Service 529-4634 
Psychology Clinic Psychology Building 529-2423

Community Counseling and Crisis Center 523-4146

Thank you, Rose Marie Ward, Ph.D. Principal Investigator 


\section{APPENDIX D: ILLINOIS RAPE MYTH ACCEPTANCE SCALE}

Payne, D. L., Lonsway, K. A., \& Fitzgerald, L. F. (1999). Rape myth acceptance: Exploration of its structure and its measurement using the Illinois Rape Myth Acceptance Scale. Journal of Research in Psychology, 33, 27-68.

The scale is comprised of 45 items rated on a seven-point Likert scale ranging from (1) not at all agree to (7) very much agree. High scores indicate that the respondent is expressing attitudes that are supportive of sexual assault. Good item test-retest reliability was found, $\mathrm{r}(495)=.90, \mathrm{p}<.01$. Internal consistency was reported as .93 for the full measure and .87 for the short form. Subscale levels of internal consistency ranged from .74 to .84 . Items are presented below.

1. If a woman is raped while she is drunk, she is at least somewhat responsible for letting things get out of control.

2. Although most women wouldn't admit it, they generally find being physically forced into sex a real "turn on."

3. When men rape, it is because of their strong desire for sex.

4. If a woman is willing to "make out" with a guy, then it's no big deal if he goes a little further and has sex.

5. Women who are caught having an illicit affair sometimes claim that it was rape.

6. Newspapers should not release the name of a rape victim to the public.

7. Many so-called rape victims are actually women who had sex and "changed their minds" afterwards.

8. Many women secretly desire to be raped.

9. Rape mainly occurs on the "bad" side of town.

10. Usually, it is only women who do things like hang out in bars and sleep around who are raped.

11. Most rapists are not caught by the police.

12. If a woman doesn't physically fight back, you can't really say that it was rape.

13. Men from nice middle-class homes almost never rape.

14. Rape isn't as big a problem as some feminists would like people to think.

15. When women go around wearing low-cut tops or short-skirts, they're just asking for trouble.

16. Rape accusations are often used as a way of getting back at men.

17. A rape probably didn't happen if the woman has no bruises or marks.

18. Many women find being forced to have sex very arousing.

19. If a woman goes home with a man she doesn't know, it is her own fault if she is raped.

20. Rapists are usually sexually frustrated individuals.

21. All women should have access to self-defense classes.

22. It is usually only women who dress suggestively that are raped.

23. Some women prefer to have sex forced on them so they don't have to feel guilty about it.

24. If the rapist doesn't have a weapon, you really can't call it rape.

25. When a woman is a sexual tease, eventually she is going to get into trouble.

26. Being raped isn't as bad as being mugged and beaten.

27. Rape is unlikely to happen in the woman's own familiar neighborhood.

28. In reality, women are almost never raped by their boyfriends.

29. Women tend to exaggerate how much rape affects them.

30. When a man is very sexually aroused, he may not even realize that the woman is resisting.

31. A lot of women lead a man on and then cry rape.

32. It is preferable that a female police officer conduct the questioning when a woman reports a rape.

33. A lot of times, women who claim they were raped just have emotional problems.

34. If a woman doesn't physically resist sex - even when protesting verbally - it really can't be considered rape.

35. Rape almost never happens in a woman's own home.

36. A woman who "teases" men deserves anything that might happen.

37. When women are raped, it's often because the way they said "no" was ambiguous.

38. If a woman isn't a virgin, then it shouldn't be a big deal if her date forces her to have sex.

39. Men don't usually intend to force sex on a woman, but sometimes they get too sexually carried away.

40. This society should devote more effort to preventing rape.

41. A woman who dresses in skimpy clothes should not be surprised if a man tries to force her to have sex.

42. Rape happens when a man's sex drive gets out of control. 
43. A woman who goes to the home or apartment of a man on the first date is implying that she wants to have sex. 44. Many women actually enjoy sex after the guy uses a little force.

45. If a woman claims to have been raped but has no bruises or scrapes, she probably shouldn't be taken too seriously. 


\section{APPENDIX E: SEXUAL ASSAULT QUESTIONNAIRE}

Frazier, P. \& Borgida, E. (1988). Juror common understanding and the admissibility of rape trauma syndrome evidence in court. Law and Human Behavior, 12,101-122.

The scale is comprised of eighteen items using true, false, don't know response options. Most of the questions are false $(56 \%)$. Participants are instructed to respond to the items to the best of their ability.

1. "Stranger" rape is much more common than "acquaintance" rape. FALSE

2. The percentage of false rape reports is about equal to that of the false reports of other crimes. TRUE

3. Women between the ages of 15 and 24 are most likely to be raped. TRUE

4. Women of all races and socioeconomic levels are equally likely to be raped. FALSE

5. Victims of attempted rapes are generally much less traumatized than victims of completed rapes. FALSE

6. Anger is the most common initial reaction to being raped. FALSE

7. Most victims have recovered from their initial symptoms by about one month after a rape. FALSE

8. The existence of prior stress and psychological problems can interfere with the ability of a rape victim to cope with an assault. TRUE

9. The severity of an assault is probably the most important factor in predicting how traumatized a rape victim will be. FALSE

10. A young couple is out on their first date. After going to dinner, they return to her apartment. They kiss for a while and he begins to insist that they have intercourse. She says that she does not want to, and he replies that he knows she does and proceeds to have intercourse with her against her will. Given the circumstances, would this be legally defined as rape? YES

11. Most rapes are planned in advance rather than occurring spontaneously. TRUE

12. If a rape victim blames herself for the assault, it often means she played some role in precipitating it. FALSE

13. It is not rare for a rape victim to have experienced more than one sexual assault during her lifetime. TRUE

14. Most victims report rapes to the police and want to see their assailant punished. FALSE

15. There is little consensus as to whether it is better to submit to rape attempt or try to resist and risk further harm. TRUE

16. It is not uncommon for a victim to delay reporting a sexual assault. TRUE

17. Because of the trauma of the rape experience, victims seek stability and tend not to make any sudden life changes, such as moving or changing jobs. FALSE

18. When victims delay in reporting rape, there is reason to suspect the rape did not really occur. FALSE 


\section{APPENDIX F: SEXUAL EXPERIENCE QUESTIONNAIRE}

1. What year are you in school?

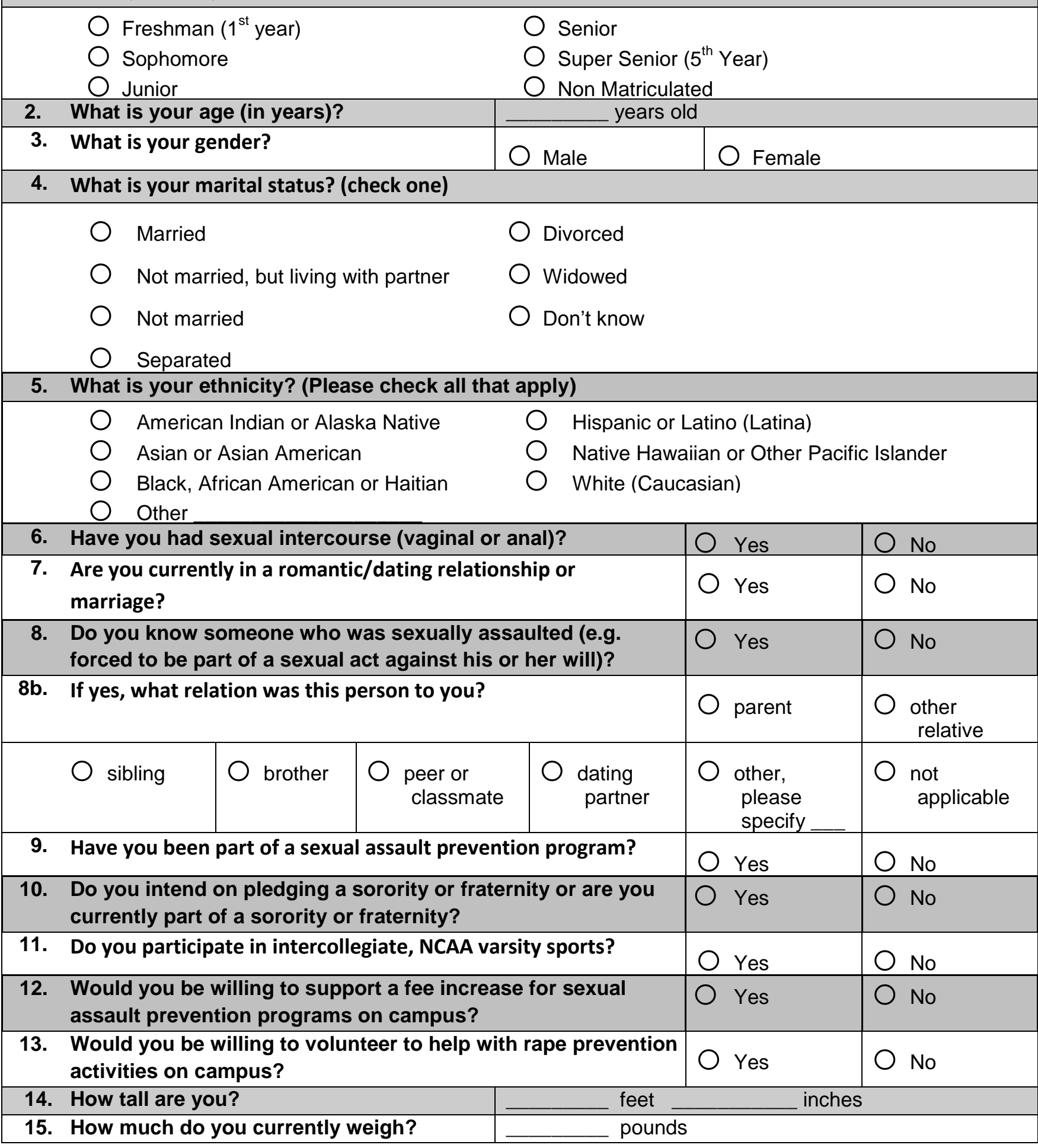




\begin{tabular}{|c|c|c|c|c|c|c|}
\hline 16. & \multicolumn{4}{|c|}{$\begin{array}{l}\text { How old were you when you first had sexual intercourse (vaginal or } \\
\text { anal sex)? (put N/A if you have not had sexual intercourse) }\end{array}$} & \multicolumn{2}{|c|}{ age } \\
\hline 17. & \multicolumn{4}{|c|}{$\begin{array}{l}\text { How many sexual partners have you had? (partners that you have had } \\
\text { sexual intercourse with, put } 0 \text { if you have not had sexual intercourse) }\end{array}$} & & \\
\hline 18. & \multicolumn{6}{|c|}{ What is your sexual orientation? } \\
\hline & $\begin{array}{l}\text { Completely } \\
\text { Heterosexual }\end{array}$ & $\begin{array}{l}\text { Mostly } \\
\text { Heterosexual }\end{array}$ & $\begin{array}{l}\text { Equally Heterosexual } \\
\text { and Homosexual }\end{array}$ & \multicolumn{2}{|c|}{$\begin{array}{l}\text { Mostly } \\
\text { Homosexual }\end{array}$} & $\begin{array}{l}\text { Completely } \\
\text { Homosexual }\end{array}$ \\
\hline
\end{tabular}




\title{
APPENDIX G: MODIFIED SEXUAL EXPERIENCES SURVEY -- FEMALE
}

\author{
Koss, M. P., \& Gidycz, C. A. (1985). Sexual experiences survey: Reliability and validity. Journal of \\ Consulting and Clinical Psychology, 53, 422-423.
}

This scale contains 13 items with the thirteenth specifically for females. Responses are either ,yes' or „no'. The aim of this measure is to assess sexual aggression (males) and sexual victimization (females) experiences.

Have you ever:

1. Had sexual intercourse with a man when you both wanted to?

2. Had a man misinterpret the level of sexual intimacy you desired?

3. Been in a situation where a man became so sexually aroused that you felt it was useless to stop him even though you did not want to have sexual intercourse?

4. Had sexual intercourse with a man even though you didn't really want to because he threatened to end your relationship otherwise?

5. Had sexual intercourse with a man when you didn't really want to because you felt pressured by his continual arguments?

6. Found out that a man had obtained sexual intercourse with you by saying things he didn't really mean?

7. Been in a situation where a man used some degree of physical force (twisting your arm, holding you down, etc.) to try to make you engage in kissing or petting when you didn't want to?

8. Been in a situation where a man tried to get sexual intercourse with you when you didn't want to by threatening to use physical force (twisting your arm, holding you down, etc.) if you didn't cooperate, but for various reasons sexual intercourse did not occur?

9. Been in a situation where a man used some degree of physical force (twisting your arm, holding you down, etc.) to try to get you to have sexual intercourse with him when you didn't want to, but for various reasons sexual intercourse did not occur?

10. Had sexual intercourse with a man when you didn't want to because he threatened to use physical force (twisting your arm, holding you down, etc.) if you didn't cooperate?

11. Had sexual intercourse with a man when you didn't want to because he used some degree of physical force (twisting your arm, holding you down, etc.)?

12. Been in a situation where a man obtained sexual acts with you such as anal or oral intercourse when you didn't want to by using threats or physical force (twisting your arm, holding you down, etc.)?

13. Have you ever been raped? 


\section{APPENDIX H: ALCOHOL USE ITEMS}

\section{Alcohol Use Items}

\section{Have you ever had an alcoholic beverage to drink?}
No
$\bigcirc$ Yes

2. In a typical week, on how many days did you have at least one drink containing alcohol?

3. How many drinks do you have on a typical day when you are drinking?

4. During the last $\mathbf{3 0}$ days, what is the highest number of drinks that you drank on any one occasion?

5. Please indicate how many drinks you have on average for each day of the week.

\begin{tabular}{|c|c|c|c|c|c|c|} 
Monday & \multicolumn{1}{c}{ Tuesday } & Wednesday & Thursday & Friday & \multicolumn{2}{c|}{ Saturday } \\
& & & & & & \\
\hline
\end{tabular}

6. In the last month have you had $\mathbf{5}$ or more (for males) or $\mathbf{4}$ or more (for females) drinks in a row?

Yes, and I do not intend to stop drinking 5 or more (4 or more) drinks in a row.

Yes, but I intend to stop drinking 5 or more (4 or more) drinks in a row during the next 6 months.

Yes, but I intend to stop drinking 5 or more (4 or more) drinks in a row during in the next 30 days.

No, but I have had 5 or more (4 or more) drinks in a row in the past 6 months.

No, and I have not had 5 or more (4 or more) drinks in a row in the past 6 months.

No, I have never had 5 or more (4 or more) drinks in a row.

7. Think back over the last month. How many times have you consumed 5 or more drinks in one day?

$\bigcirc$ Never

Once

2 to 3 times

4 to 6 times 
8. Have you ever drank until you got drunk or intoxicated?

Yes, and I plan to again.

$\bigcirc$ Yes, but I don't plan on ever getting drunk again.

No, but I think that I might try in the next 6 months.

No, and I don't plan to.

9. Did you drink until you got drunk or intoxicated at least once in the last month?

No, I have not been drunk in the last 6 months.

No, I have not been drunk in the last month, but I have been drunk in the last 6 months.

Yes, but I intend to stop getting drunk in the next 30 days.

Yes, but I intend to stop getting drunk in the next 6 months.

Yes, and I do not intend to stop getting drunk 


\section{APPENDIX I: ALCOHOL AND SEXUAL CONSENT SCALE}

\section{Alcohol and Sexual Consent Scale}

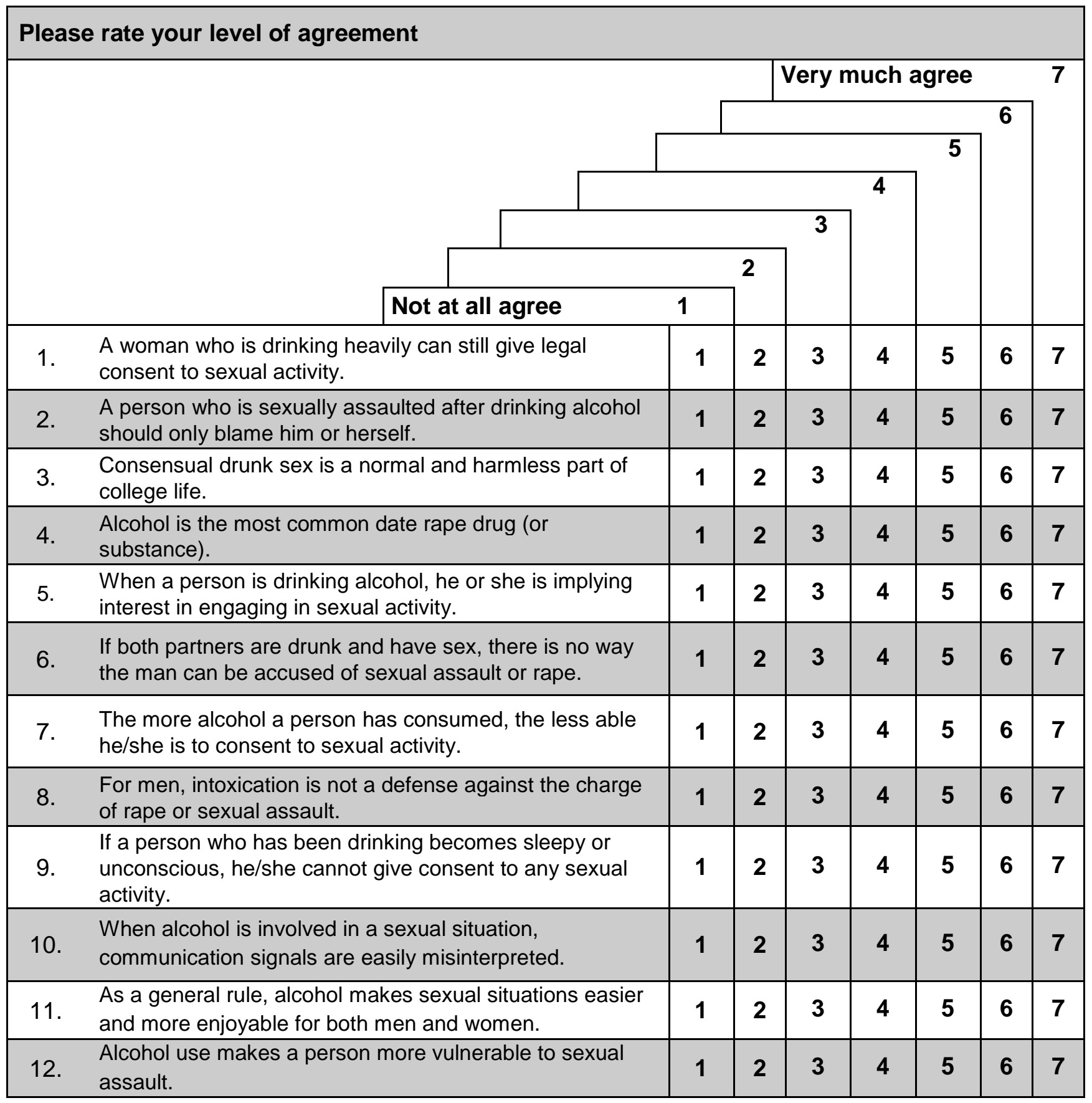


APPENDIX J: TABLE OF RESEARCH QUESTIONS AND ANALYSES

\begin{tabular}{|c|c|c|c|c|}
\hline Research Question & IV & DV & Analysis & Comment \\
\hline $\begin{array}{c}\text { Research Question } 1 \\
\text { IRMAS }\end{array}$ & Athletic Status & $\begin{array}{l}\text { Seven Scales } \\
\text { of the IRMA }\end{array}$ & $\begin{array}{c}\text { Oneway } \\
\text { MANOVA }\end{array}$ & $\begin{array}{c}\text { Tukey HSD if } \\
\text { significant }\end{array}$ \\
\hline $\begin{array}{c}\text { Research Question } 2 \\
\text { ASCS }\end{array}$ & Athletic Status & $\begin{array}{c}\text { Total Score of } \\
\text { ASCS }\end{array}$ & $\begin{array}{c}\text { Independent t- } \\
\text { test }\end{array}$ & \\
\hline $\begin{array}{c}\text { Research Question } 3 \\
\text { SES }\end{array}$ & Athletic Status & $\begin{array}{c}\text { Sexual } \\
\text { Victimization } \\
\text { Category }\end{array}$ & $\begin{array}{l}\text { Chi-Square test } \\
\text { of } \\
\text { Independence }\end{array}$ & $\begin{array}{c}5 \text { levels of } \\
\text { victimization } \\
\text { status }\end{array}$ \\
\hline \multirow[t]{3}{*}{$\begin{array}{c}\text { Research Question } 4 \\
\text { Alcohol and } \\
\text { SES }\end{array}$} & $\begin{array}{l}\text { 1. Athletic } \\
\text { Status (i.e., } \\
\text { athlete, non- } \\
\text { athlete) } \\
\text { 2. Victimization } \\
\text { Category } \\
\text { (i.e., non- } \\
\text { victim, } \\
\text { unwanted } \\
\text { sexual } \\
\text { contact, } \\
\text { coercion, } \\
\text { attempted } \\
\text { rape, rape) }\end{array}$ & $\begin{array}{c}\text { Typical } \\
\text { number of } \\
\text { drinks }\end{array}$ & 2 X 5 ANOVA & $\begin{array}{l}\text { Tukey HSD if } \\
\text { significant }\end{array}$ \\
\hline & $\begin{array}{l}\text { 1. Athletic } \\
\text { Status (i.e., } \\
\text { athlete, non- } \\
\text { athlete) } \\
\text { 2. Victimization } \\
\text { Category } \\
\text { (i.e., non- } \\
\text { victim, } \\
\text { unwanted } \\
\text { sexual } \\
\text { contact, } \\
\text { coercion, } \\
\text { attempted } \\
\text { rape, rape) }\end{array}$ & $\begin{array}{c}\text { Typical } \\
\text { number of days } \\
\text { drinking }\end{array}$ & 2 X 5 ANOVA & $\begin{array}{l}\text { Tukey HSD if } \\
\text { significant }\end{array}$ \\
\hline & $\begin{array}{l}\text { 1. Athletic } \\
\text { Status (i.e., } \\
\text { athlete, non- } \\
\text { athlete) } \\
\text { 2. Victimization }\end{array}$ & $\begin{array}{l}\text { Highest } \\
\text { drinking } \\
\text { occasion }\end{array}$ & 2 X 5 ANOVA & $\begin{array}{c}\text { Tukey HSD if } \\
\text { significant }\end{array}$ \\
\hline
\end{tabular}




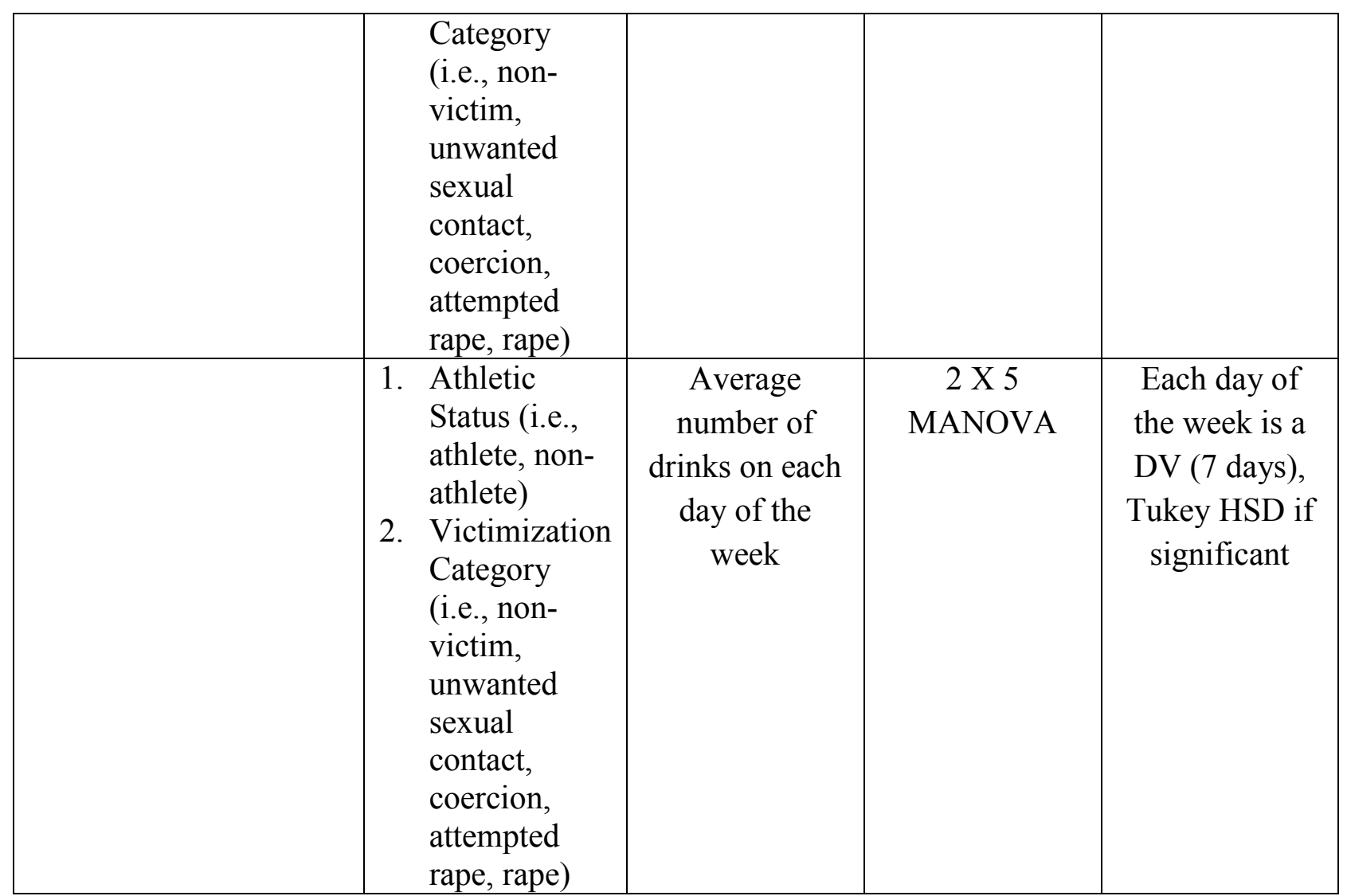

